UNIVERSIDADE DE BRASÍLIA

FACULDADE DE CIÊNCIAS DA SAÚDE

DEPARTAMENTO DE ENFERMAGEM

PROGRAMA DE PÓS-GRADUAÇÃO EM ENFERMAGEM

MARIA DA GRAÇA CAMARGO NEVES

OBJEÇÃO DA CONSCIÊNCIA E ABORTO PREVISTO EM LEI:

VIVÊNCIAS EM UM SERVIÇO PÚBLICO DE SAÚDE

BRASÍLIA-DF

2015 


\author{
UNIVERSIDADE DE BRASÍLIA \\ FACULDADE DE CIÊNCIAS DA SAÚDE \\ DEPARTAMENTO DE ENFERMAGEM \\ PROGRAMA DE PÓS-GRADUAÇÃO EM ENFERMAGEM
}

MARIA DA GRAÇA CAMARGO NEVES

OBJEÇÃO DA CONSCIÊNCIA E ABORTO PREVISTO EM LEI: VIVÊNCIAS EM UM SERVIÇO PÚBLICO DE SAÚDE

Tese apresentada como requisito parcial para a obtenção do Título de Doutora em Enfermagem pelo Programa de Pós-Graduação em Enfermagem da Universidade de Brasília.

Área de Concentração: Políticas, Práticas e Cuidado em Saúde e Enfermagem.

Linha de Pesquisa: Gestão da Atenção à Saúde e Organização dos Serviços em Saúde.

Orientadora: Profa. Dra. Dirce Guilhem

Brasília-DF 
MARIA DA GRAÇA CAMARGO NEVES

\section{OBJEÇÃO DA CONSCIÊNCIA E ABORTO PREVISTO EM LEI: VIVÊNCIAS EM UM SERVIÇO PÚBLICO DE SAÚDE}

Tese apresentada como requisito parcial para a obtenção do título de Doutora em Enfermagem pelo Programa de Pós-Graduação em Enfermagem da Universidade de Brasília.

Aprovado em:

1

\section{BANCA EXAMINADORA}

\begin{tabular}{c} 
Profa. Dra. Dirce Guilhem \\
Universidade de Brasília (UnB) \\
Presidente \\
Profa. Dra. Leila Bernarda Donato Gottems \\
Escola Superior em Ciências da Saúde/FEPECS/SES-DF \\
Membro Efetivo - Externo à UnB \\
Prof. Dr. Marcelo Medeiros \\
Universidade Federal de Goiás (UFG) \\
Membro Efetivo - Externo à UnB \\
\hline Profa. Dra. Maria Rita Carvalho Garbi Novaes \\
Membro Efetivo - Externo à UnB \\
\hline
\end{tabular}

Profa. Dra. Leides Barroso Azevedo Moura

Instituição: Universidade de Brasília (UnB)

Membro Efetivo - Externo ao PPGEnf/UnB

Profa. Dra. Muna Muhammad Odeh

Instituição: Universidade de Brasília (UnB)

Membro Suplente - Externo ao PPGEnf/UnB 
Dedico este trabalho ao ETERNO, Senhor do Exército de Anjos. Obrigada, Pai!

Ao Beto, Diego, Victor e Pedro Ubatan, presentes d'Ele. 


\section{AGRADECIMENTOS}

À minha família, presente de Deus para mim.

À professora Dr. ${ }^{a}$ Dirce Guilhem, que sabe saber ser, saber fazer e saber acolher. Muitíssimo obrigada!

Às minhas colegas e amigas Akiko, Diane e Rejane, pelas horas desgastantes, mas felizes.

Sou grata aos professores, por aceitarem participar da banca do meu estudo e contribuir com o mesmo. Em ordem alfabética, agradeço: à Professora Dr. ${ }^{a}$ Leides Barroso

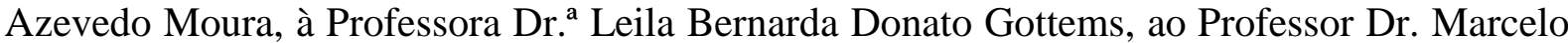
Ribeiro, à Professora Dr. ${ }^{\mathrm{a}}$ Maria Rita Carvalho Garbi Novaes.

Às vítimas de violência sexual, com quem aprendi a ver a vida de outra forma e que muitas carregam anos buscando a ressignificação.

À Esmeralda, por interceder por mim. 
NEVES, Camargo Maria da Graça. Objeção da consciência e aborto previsto em lei: vivências em um serviço público de saúde. 2015. 95 p. Tese (Doutorado) - Departamento de Enfermagem, Faculdade de Ciências da Saúde, Universidade de Brasília, Brasília, DF, 2015.

\section{RESUMO}

INTRODUÇÃO: A objeção de consciência emergiu e se consolidou em função das exigências decorrentes do exercício da cidadania no Estado Democrático de Direito. Pode ser declarada sempre que uma pessoa ou grupo de pessoas são confrontados com questões conflituosas, que vão de encontro às suas crenças pessoais em situações como o serviço militar obrigatório, o enfrentamento de situações-limite como a eutanásia, atenção pré-natal ou o aborto, objeto deste trabalho. A maioria dessas tensões aflora nos serviços de saúde, confrontando posicionamentos opostos, o que ocasiona conflitos de difícil mediação moral. A bioética oferece ferramentas para intermediar embates ideológicos, morais, religiosos e filosóficos, favorecendo a defesa de direitos e contribuindo para a concretização do estado laico e da objeção de consciência. O profissional de saúde vivencia situações desafiadoras, porém, a objeção de consciência não deve colocar em risco o processo de atenção à saúde, direito garantido por lei para todas as pessoas. Geralmente, o objetor de consciência declara sua posição em situações como a prática do aborto previsto em lei, que é um direto da mulher brasileira, em caso de gravidez decorrente de violência sexual, risco de morte para a mulher e anencefalia. OBJETIVO: Conhecer e compreender a existência da objeção de consciência na prática do aborto previsto em lei em um hospital público. MÉTODO: Pesquisa exploratória, descritiva, desenvolvida por meio de investigação multidimensional em uma concepção pragmática, tendo como base a utilização de métodos mistos. RESULTADOS: Os resultados da revisão integrativa (artigo 1) revelaram que é incipiente a apropriação do conceito Objeção de Consciência por profissionais da saúde. Enfermeiros ancoram seu significado baseando-se no Código de Ética dos Profissionais de Enfermagem. O artigo 2 apresentou o perfil das mulheres que realizaram a interrupção da gestação no período de 2007 a 2013 . A gestação foi, na maioria das vezes, consequência de violência sexual extrafamiliar, interrompida até 12 semanas de gestacão, sendo que 7,4\% das interrupções gestacionais divergiram do protocolo na forma utilizada para esvaziamento uterino. A maioria das mulheres se autodeterminou de religião evangélica e de cor parda, com idade entre 26 anos e 35 anos de idade, não registraram boletim de ocorrência. A pesquisa qualitativa revelou que a equipe que acolhia essas mulheres no momento da interrupção sofria com a dificuldade de enfrentamento nesse momento delicado da vida das mulheres. CONCLUSÃO: Enfermeiros apresentaram maior dificuldade para compreender o direito à Objeção de Consciência pela pouca apropriação do conceito à prática cotidiana e possuem conhecimento limitado do Código de Ética que incorpora a ideia no caso do aborto. O cumprimento do protocolo para o momento do esvaziamento uterino, segundo a norma técnica, ainda é pouco sólido. Faz-se necessária a realização de debates intra e extrainstitucionais sobre o tema da objeção de consciência e sua relação com o aborto previsto em lei, como forma de garantir o direito aos preceitos bioéticos das mulheres e adolescentes que procuram o serviço.

DESCRITORES: Objeção de Consciência (não controlado); Aborto legal; Pessoal de saúde; Equipe de enfermagem; Conhecimentos, atitudes e prática em saúde; Bioética. 


\begin{abstract}
INTRODUCTION: Conscientious objection has emerged and consolidated according to the requirements arising from the exercise of citizenship in a Democratic Constitutional State. It can be declared whenever a person or a group of people are faced with conflicting issues that go against their personal beliefs in situations such as compulsory military service, coping with extreme situations such as euthanasia, prenatal care or abortion, object of this work. Most of these tensions arises in health care, confronting opposing positions, which causes conflicts of difficult moral mediation. Bioethics offers tools to intermediate ideological, moral, religious and philosophical conflicts, promoting advocacy and contributing to the achievement of the secular state and conscientious objection. The health professional experiences challenging situations, however, conscientious objection should not put at risk the health care process, right guaranteed by law for all people. Generally, the conscientious objector declares its position in situations such as abortion provided by law, which is a right of Brazilian woman, in case of pregnancy resulting from sexual violence, risk of death for women and anencephaly. OBJECTIVE: To know and understand the existence of conscientious objection on abortion provided by law in a public hospital. METHODS: exploratory, descriptive research, developed through multidimensional research on a pragmatic conception, based on the use of mixed methods. RESULTS: The results of the integrative review (article 1) revealed that the appropriation of Objection of Conscience concept by health professionals is incipient. Nurses anchor its meaning based on the Code of Ethics of Nursing Professionals. The article 2 presented the profile of the women who underwent the termination of pregnancy from 2007 to 2013. The pregnancy was, for the most part, a result of extra-familial sexual violence, stopped up to 12 weeks of pregnancy, and 7.4\% of pregnancy interruptions deviated from the protocol used for uterine evacuation. Most women said they were of evangelical religion and mulatto, aged between 26 and 35 years old, did not record police report. The qualitative research revealed that the team that welcomed these women by the time of abandonment suffered from the difficulty of coping in this delicate moment of women's lives. CONCLUSION: Nurses presented more difficulty to understand the right to the objection of conscience by little ownership to everyday practice and have limited knowledge of the Code of Ethics that incorporates the idea in the case of abortion. Compliance with the protocol for the time of uterine evacuation, according to the technical standard, is still not solid. Intra and extra-institutional discussions about the subject of conscientious objection and its relationship to abortion provided by law are necessary, in order to guarantee the right to bioethical principles of women and girls who seek the service.
\end{abstract}

DESCRIPTORS: Conscientious Objection (uncontrolled); Legal abortion; Health personnel; Nursing staff; Knowledge, attitudes and health practice; Bioethics. 


\section{RESUMEN}

INTRODUCCIÓN: La objeción de conciencia surgió y se consolidó de acuerdo con las exigencias derivadas del ejercicio de la ciudadanía en un Estado Democrático de Derecho. Puede ser declarada siempre que una persona o grupo de personas se enfrentan a cuestiones conflictivas que van en contra de sus creencias personales en situaciones tales como el servicio militar obligatorio, para hacer frente a situaciones extremas como la eutanasia, la atención prenatal y el aborto, el objeto de este trabajo. La mayor parte de estas tensiones surge en el cuidado de la salud, confrontando posiciones opuestas, lo que provoca conflictos de mediación moral difícil. La bioética ofrece herramientas para mediar los conflictos ideológicos, morales, religiosos y filosóficos, favoreciendo la defensa de derechos y contribuyendo a la consecución del estado laico y de la objeción de conciencia. El profesional de la salud vive situaciones difíciles, sin embargo, la objeción de conciencia no debe poner en riesgo el proceso de atención de la salud, derecho garantizado por la ley para todas las personas. Generalmente, el objetor de conciencia declara su posición en situaciones como el aborto previsto por la ley, que es un derecho de la mujer brasileña, en caso de embarazo resultante de la violencia sexual, el riesgo de muerte en mujeres y la anencefalia. OBJETIVO: Conocer y comprender la existencia de la objeción de conciencia al aborto previsto por la ley en un hospital público. MÉTODO: Estudio exploratorio, descriptivo, desarrollado a través de método multidimensional en una concepción pragmática, basada en el uso de métodos mixtos. RESULTADOS: Los resultados de la revisión integradora (artículo 1) revelaron que la apropiación del concepto de la Objeción de Conciencia por profesionales de la salud es incipiente. Enfermeras anclan su significado basado en el Código de Ética de los Profesionales de Enfermería. El artículo 2 presenta el perfil de las mujeres que se sometieron a la interrupción del embarazo, de 2007 a 2013. El embarazo fue, en su mayor parte, a consecuencia de la violencia sexual extra familiar, se suspendió hasta 12 semanas de embarazo, y el 7,4\% de interrupciones del embarazo divergieron del protocolo que se utiliza para la evacuación uterina. La mayoría de las mujeres dijo que eran de la religión evangélica y mulata, con edades comprendidas entre 26 y 35 años de edad, no registraron informe policial. La investigación cualitativa reveló que el equipo dio la bienvenida a estas mujeres el momento del abandono sufrido por la dificultad de hacer frente en este delicado momento de la vida de las mujeres. CONCLUSIÓN: Las enfermeras fueron más difíciles de entender el derecho a la objeción de conciencia debido a poca apropiación del concepto a la práctica cotidiana y por tener conocimiento limitado del Código de Ética que incorpora la idea en el caso del aborto. El cumplimiento del protocolo para el momento de la evacuación uterina, de acuerdo con la norma técnica, todavía no es sólido. La realización de debates intra y extrainstitucionales sobre el tema de la objeción de conciencia y su relación con el aborto en acuerdo con la ley es necesaria, a fin de garantizar el derecho de los principios bioéticos de las mujeres y adolescentes que buscan el servicio.

DESCRIPTORES: Objeción de Conciencia (no controlado); Aborto legal; El personal de salud; El personal de enfermería; Conocimientos, actitudes y práctica de la salud; Bioética. 


\section{SUMÁRIO}

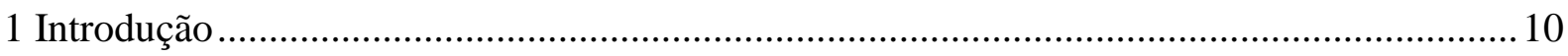

1.1 Breve evolução histórica da Objeção de Consciência no mundo .................................... 10

1.2 A Objeção de Consciência e os serviços de saúde ........................................................... 13

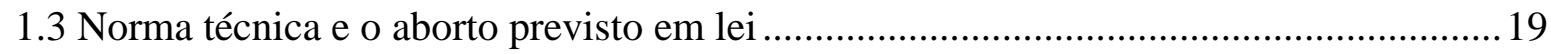

1.3.1 Procedimentos de justificação e autorização para interrupção de gestação prevista

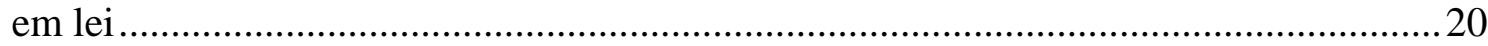

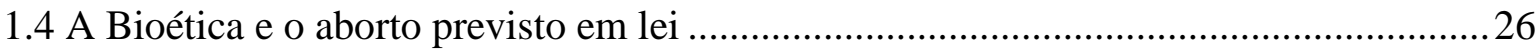

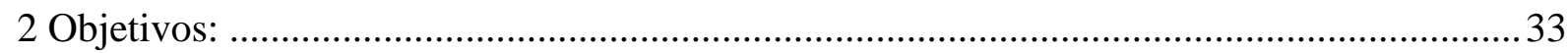

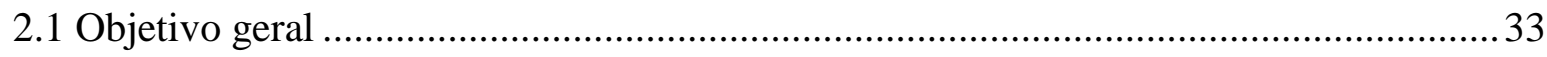

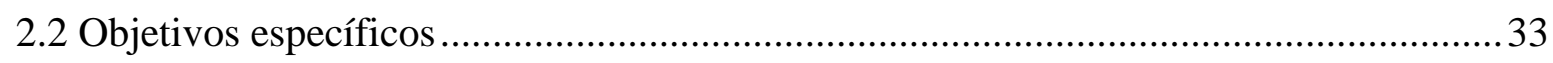

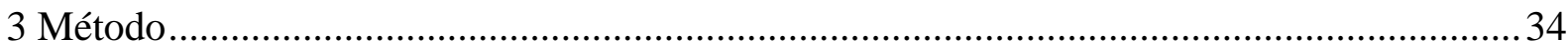

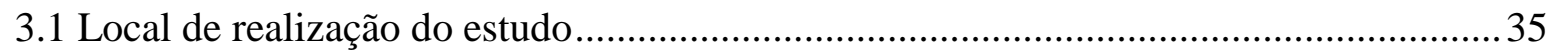

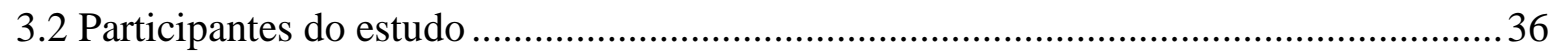

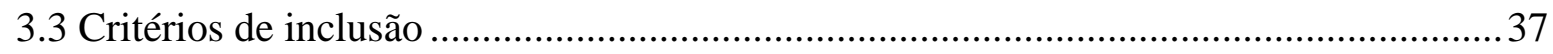

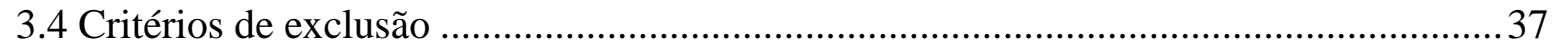

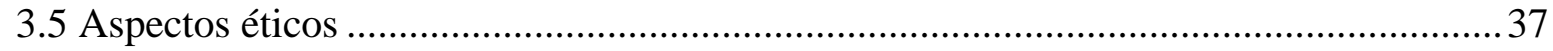

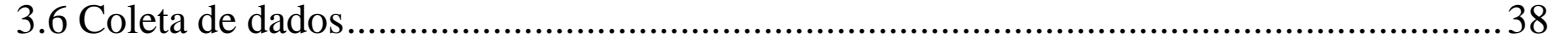

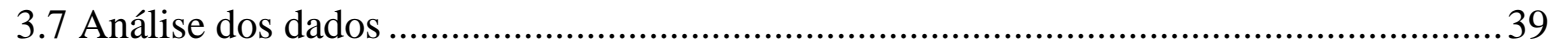

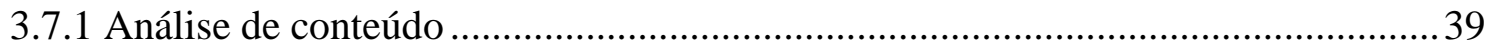

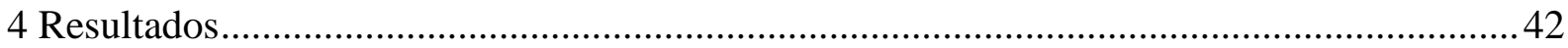

4.1 Artigo 1: Objeção de consciência e aborto legal sob a perspectiva da saúde: revisão

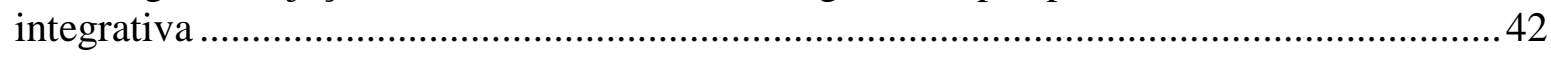

4.2 Artigo 2: Perfil de mulheres submetidas ao aborto previsto em lei: estudo descritivo

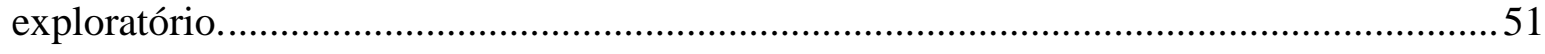

4.3 Artigo 3: Concepções que os profissionais de saúde que atuam no aborto previsto em lei possuem sobre o conceito de Objeção de Consciência.........................................................6 60

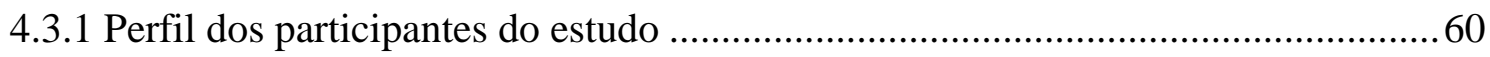

4.3.2 Categorias-síntese que emergiram a partir das verbalizações dos entrevistados ...63

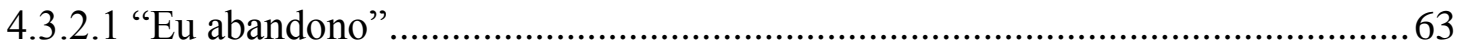

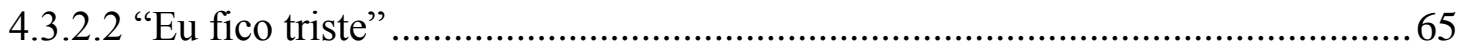

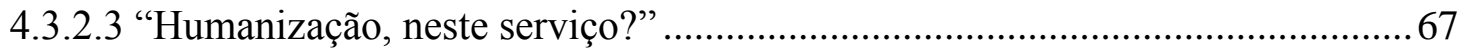


5 Considerações finais e recomendações.

Referências

Apêndice A - Termo de Consentimento Livre e Esclarecido (TCLE) para a participação na pesquisa que tem como título: aborto previsto em lei e suas repercussões: vivências em um serviço público

Apêndice B - Pesquisa: Aborto Previsto em Lei e suas repercussões: vivências em um serviço oferecido por hospital público

Apêndice $\mathrm{C}$ - Roteiro para a entrevista aberta com profissionais da equipe multidiscilplinar que atuaM No aborto previsto em lei

Apêndice D - Matriz: ações, verbalizações, temas, frequência, categoria e definição das categorias

Anexo 1 - Carta de aprovação do Comitê de Ética em Pesquisa da Secretaria de Estado de Saúde do Distrito Federal 


\section{INTRODUÇÃO}

\subsection{BREVE EVOLUÇÃO HISTÓRICA DA OBJEÇÃO DE CONSCIÊNCIA NO MUNDO}

As sociedades pluralistas e laicas, como a brasileira, pressupõem uma gama de diversidades morais, o que tem como possíveis consequências conflitos de várias origens. Nesse âmbito, a bioética promove seus princípios de autonomia, justiça, não maleficência e beneficência e encontra seu lugar ao promover justiça social. Atua, assim, como mediadora de embates ideológicos, morais, religiosos e filosóficos, contribuindo para garantir a separação entre estado laico e igreja, e assegurando, como um de seus avanços, a Objeção de Consciência (HOTTOIS; MISSA, 2001; PELLEGRINO; THOMASMA, 1988).

A Objeção de Consciência teve seu início na história, provavelmente, com o Cristianismo. Nessa ocasião ocorreram as primeiras situações que podem ter permitido o surgimento do direito à Objeção de Consciência, que se manifesta como o direito de expressar e se posicionar quanto à liberdade de pensamento, consciência ou religião.

Com o nascimento do primeiro direito, aflorou a distinção entre a obediência a Deus e a obediência às leis terrenas (CABRAL TAVARES, 1989). A primeira manifestação da Objeção de Consciência teria acontecido em relação a ordens antirreligiosas, especificamente com os mártires cristãos do Império Romano, quando esses foram alvo da fúria imperial por terem se negado a apostatar a sua fé (DALMAU LLISO, 1996).

Essa história desvela a intromissão do Estado nas convicções dos indivíduos, pois aquele estava a exigir destes, algo que lhes é sagrado e que não podiam, de forma alguma, abdicar, sob pena de ficarem privados do sentido pelo qual orientam a sua vida. A Objeção de Consciência surgiu, assim, como um desenvolvimento necessário da própria liberdade de consciência, funcionando como a única forma de não infringir normas de cunho religioso (DAMASCENO CORREIA, 1993).

A Constituição da Pensilvânia, datada de 16 de agosto de 1776, no artigo $8^{\circ}$, relatou a consagração do direito à Objeção de Consciência nos Estados Unidos da América, municiando essa possibilidade para várias situações, de forma generalizada (GOMES CANOTILHO, 1991). Entre as situações, surge o direito à Objeção de Consciência acolhida na Constituição do Vermont, de 8 de junho de 1777 (artigo 9º ), tendo sido adaptado, a respeito do serviço militar, no Delaware (seção 10) e no New Hampshire (art. 13º), 
respectivamente em 11 de setembro de 1776 e a 2 de junho de 1774. Essa constituição daria ao indivíduo o direito de não prestar o serviço militar, desde que apresentasse respaldo religioso.

Embora houvesse alguns Estados federados debatendo a interposição da Objeção de Consciência, a Constituição Federal norte-americana, de 17 de setembro de 1787, não incluiu nenhuma disposição em que se consagre explicitamente o direito à Objeção de Consciência (GOMES CANOTILHO, 1991). Em 1789, James Madison, um dos founding fathers da democracia americana, propôs, sem sucesso, a inclusão de um aditamento à Constituição Federal, no qual se acolhesse expressamente o direito à Objeção de Consciência ao serviço militar (GOMES CANOTILHO, 1996-1997).

A proteção legal norte-americana do direito à Objeção de Consciência atual encontra-se fundamentada em nível infraconstitucional no Selective Service Act, de 18 de maio de 1917, que prevê, no seu artigo 59, a isenção de serviço militar para "todas as pessoas que, em virtude de uma convicção religiosa, solicitem ser isentas do serviço militar, se for estabelecida essa atitude de consciência” (MARTINEZ-TORRON, 1985).

$\mathrm{Na}$ Itália, há pouco da interferência constitucional sobre a Objeção de Consciência, sendo de suma importância a deliberação de debates regulares para evolução de possíveis proposições de mudanças, pois o Tribunal Constitucional Italiano reconheceu este direito a partir da Decisão n. ${ }^{o}$ 164/1985. Desse modo, inferiu o direito à Objeção de Consciência a partir dos artigos $2^{\circ}$ e 19 da respectiva Constituição, os quais consagram, respectivamente, uma cláusula aberta para recepção de direitos fundamentais (aqueles que garantem o mínimo de qualidade de vida para sobrevivência) e a liberdade religiosa (GOMES CANOTILHO; MOREIRA, 1993).

Já na Alemanha, há referência à Objeção de Consciência na constituição liberal de Frankfurt, em 1849. No artigo 144 se estabelece a completa liberdade de crença e de consciência, tendo esse princípio sido retomado mais tarde na Constituição de Weimar, datada de 1919, no seu artigo 135. Contudo, a liberdade de mudança de religião e algumas situações de consciência eram timidamente tratadas (LAMEGO, 1985).

Em 1949, na constituição alemã, foi reconhecido o direito de manifestação exterior da liberdade de consciência fora da esfera da prática religiosa, por meio da consagração do direito à Objeção de Consciência, o qual permite recusar o cumprimento de uma obrigação legal em nome da consciência individual. Com efeito, o seu artigo $4 .^{\circ}$, n. $^{\circ} 3$, prevê expressamente a Objeção de Consciência ao serviço militar como direito fundamental, 
estando também prevista a obrigatoriedade do serviço não militar (ou cívico) como sucedâneo do serviço militar (cf. artigo 12-A, n. ${ }^{\text {2) }}$ (MARTINEZ-TORRON, 1985).

A França, em sua Constituição, não aborda o direito à Objeção de Consciência, visto este estar apenas regulado em leis ordinárias (MENESES CORDEIRO, 2003). Já na Espanha, o mesmo vem referido no artigo 30, n. $^{\circ} 2$, da sua Constituição, no qual se prevê a Objeção de Consciência perante o serviço militar obrigatório (MIRANDA, 1992).

A Inglaterra não faz referência ao assunto em Constituição, pois desde muito cedo há a consagração do direito à Objeção de Consciência em leis ordinárias. Na verdade, desde 1916 que o Reino Unido reconheceu um estatuto legal aos objetores de consciência, regulamentados em 1946 no National Service Act.

Há também relatos sobre a Objeção de Consciência em países escandinavos. $\mathrm{Na}$ Dinamarca, uma lei datada de 13 de dezembro de 1917 institui "o emprego dos refratários ao serviço militar em trabalhos cívicos”.

Nas constituiçõos dos estados de língua portuguesa, além da Constituição portuguesa, encontramos igualmente várias alusões ao direito à Objeção de Consciência, designadamente na Constituição do Brasil de 1988, no seu artigo 143, n. ${ }^{\circ}$ 1. Nela se prevê a Objeção de Consciência perante o serviço militar. Na Constituição de Cabo Verde, de 1992, o artigo 48, n. ${ }^{\circ}$, garante o direito à Objeção de Consciência, a se concretizar em normas infraconstitucionais. A Constituição da República Democrática de Timor-Leste, de 2002, garante a Objeção de Consciência, a se estabelecer em normas legais no seu artigo 45, n. ${ }^{\circ} 3$ (MIRANDA, 2000).

No Brasil, a Constituição Federal trata da questão da consciência em dois momentos: o primeiro no artigo $5^{\circ}$, quando descreve práticas de cultos religiosos e liturgias, garantindo a liberdade de consciência de crença; e no artigo 143, inciso I, quando referencia que

\footnotetext{
às Forças Armadas compete, na forma da lei, atribuir serviço alternativo aos que, em tempo de paz, após alistados, alegarem imperativo de consciência, entendendo-se como tal o decorrente de crença religiosa e de convicção filosófica ou política, para se eximirem de atividades de caráter essencialmente militar (BRASIL, 2012).
}

A consagração desse direito se traduz em uma evolução centrada no princípio da tolerância, com a qual se procurou proteger os aspectos mais invioláveis do ser humano, nomeadamente os que dizem respeito às decisões de consciência. Ratifica-se, assim, a democracia e o embate a regimes autoritários que perpassam pelos continentes durante os 
séculos XX e XXI, quando a liberdade de consciência legitima a liberdade de opinião e de decisões conscientes.

A atual perspectiva da Objeção de Consciência evoluiu devido a exigências decorrentes de uma cidadania inerente a um Estado de Direito Democrático e que surgem sempre que nos vemos confrontados com questões conflituosas para cada um de nós, como, por exemplo, a clonagem, o serviço militar obrigatório, a eutanásia e o aborto (GOMES CANOTILHO, 1991). A maioria desses embates se mostra nos serviços de saúde.

\subsection{A OBJEÇÃO DE CONSCIÊNCIA E OS SERVIÇOS DE SAÚDE}

O direito à Objeção de Consciência deve ser encontrado na dignidade da consciência de cada um, inclusive nos casos em que esta seja errônea (SORIANO, 1987). Com efeito, o direito à Objeção de Consciência está ancorado em uma premissa que se traduz na circunstância de cada pessoa ser capaz de se autodeterminar segundo o seu próprio critério de decisão (VENDITTI, 1989).

A Objeção de Consciência torna-se, assim, o mais forte obstáculo ao progresso de qualquer forma de tirania, a defesa mais segura da dignidade inalienável da liberdade e da dignidade intrínseca e essencial ao ser humano. No trabalho diário honesto, deixar de exercer esse direito, a qualquer preço, é tornar-se, muitas vezes, cúmplice de crimes monstruosos (VELÁSQUEZ-CÓRDOBA; CÓRDOBA-PALACIO, 2010).

Ao se explorarem as formas em que a Objeção de Consciência se revela nos atendimentos ao aborto previsto em lei na África do Sul, despontaram diferentes atitudes nos distintos níveis de profissionais de saúde em relação à prática do aborto. Surgiram questões contraditórias em relação a quando, como e por que o fato de se lançar mão da Objeção de Consciência.

Para discernir o que é resistência e o que é Objeção de Consciência, fazem-se necessárias orientações claras sobre a causa de ser objetor de consciência, a fim de facilitar planos de contingência para o trabalho na interrupção da gestação (HARRIES; COOPER; STREBEL; COLVIN, 2014).

A Objeção de Consciência na Noruega é um fator de poucos debates externos ao ambiente de trabalho, em contraposição a internos (NORDBERG; SKIRBEKK; MAGELSSEN, 2014). Muitos clínicos se recusam ao encaminhamento de mulheres que 
optam pelo aborto, embora essa seja uma prática legal, até 12 semanas de gestação, enquanto a eutanásia é ilegal, independente da argumentação ou fato.

O Tribunal Europeu de Direitos Humanos argumenta que uma abordagem de equilíbrio deve ser aplicada em casos de Objeção de Consciência no contexto dos cuidados de saúde sexual e reprodutiva (GOFFIN, 2010; LAMACKOVÁ, 2008). A ideia de cumprimento ao equilíbrio já é esboçada também nos EUA.

Na Itália, há diferentes perspectivas. Uma delas - expressa por associações profissionais, como a Liga dos Ginecologistas Não Oponentes, chamada LAIGA, e a comissão de especialistas em bioética, como o Comitê Nacional de Bioética, no documento de 30 de julho de 2012, intitulado Objeção de Consciência e Bioética - declarou ser favorável à objeção de consciência (BALZANO, 2013).

Outro embate importante na Itália se dá em relação ao direito do profissional de prescrever, para acesso gratuito, a contracepção de emergência, visto que aborto, inseminação artificial e experimentos com animais são permitidos.

No Uruguai, a Objeção de Consciência articula a não dissociação com outras vertentes como desobediência civil. A responsabilidade pessoal privada e a responsabilidade público-social devem ser unidas no serviço comum, herdado dos antepassados na pátria e fortalecidos no dia a dia das práticas em saúde (CASANOVA-RÍSPOLI, 2010).

No Brasil, muitas questões permeiam entre o crédito dado pelo médico em torno das informações fornecidas pela mulher violentada que engravidou, assim como a repeticão da história para fins confirmatórios da verdade ou não (DINIZ; DIOS; MASTRELLA; MADEIRO, 2014). Cinquenta, de um total de 1.650 entrevistados, alegaram lançar mão da Objeção de Consciência quando a história não os persuadia. Outro fato é a exigência do boletim de ocorrência, evento não previsto na norma técnica do Ministério da Saúde (BRAIL, 2012). Há a recomendação que a FEBRASGO e o Ministério da Saúde trabalhem em conjunto, a fim de orientar os médicos para que o simples relato da mulher garanta a ela a interrupção legal da gestação, assim como o ambiente moral do aborto ilegal altera o propósito de ouvir uma paciente - de prestação de cuidados a um julgamento sobre ela, evitando o acesso das mulheres ao aborto legal devido a essas barreiras, mesmo existindo a lei.

Outras formas de manifestação da objeção de consciência podem acontecer na atuação da equipe de saúde. A forma passiva da eutanásia é legalizada em quase todos os países civilizados. Sua forma ativa não é uma instituição legal geralmente aceita (TUDOMÁNYEGYETEM; SZENTHÁROMSÁG, 2014). Na Europa, a eutanásia ativa é 
legalizada apenas na Holanda, Bélgica, Luxemburgo e Suíça. Na Austrália, a Lei sobre os Direitos dos Doentes Terminais legalizou, em 1995, a instituição do suicídio assistido, que não é idêntica à eutanásia ativa. A diferença reside no fato de que legalizar a eutanásia ativa significa que o autor de um "assassinato" não é punível (sob certas circunstâncias), enquanto que no suicídio assistido, o autor é o próprio paciente, e isso não é um assassinato.

No primeiro caso, o paciente é morto a seu pedido por outra pessoa. No segundo caso, o paciente executa o autoextermínio, com a ajuda de um profissional de saúde. $\mathrm{Na}$ Austrália, a instituição do suicídio assistido foi revogada em 1997.

O suicídio assistido é legal em quatro Estados-Membros dos EUA: em Vermont, Washington, Montana e Oregon. No Uruguai, a forma ativa da eutanásia é legal desde 1932 (CASANOVA-RÍSPOLI, 2010).

Centenas de artigos descrevem questões sobre eutanásia no mundo, relacionandoas a vários aspectos, porém são poucos os recentes que os relacionam a aspectos morais da equipe.

No estágio final da vida (SMITH, 2011), um componente indissociável da ética do cuidado ajustado exige o reconhecimento de um direito fundamental para evitar o sofrimento cruel e incomum de uma doença terminal, utilizando a sedação até a morte como um tratamento paliativo eficaz e como um procedimento médico razoável, a fim de salvaguardar o "direito" a uma morte digna.

Uma vez que o Estado estabelece um direito humano para evitar a dor refratária de qualquer natureza na fase final da doença, a responsabilidade deve ser assumida por prestadores de cuidados de saúde, a fim de indicar procedimentos consistentes, visando à preservação dos melhores interesses da qualidade da vida de um paciente para aliviar o sofrimento.

Um esforço para avaliar se as decisões da fase final dos prestadores de cuidados de saúde são lícitas ou ilícitas, um teste relativamente simples de proporcionalidade do custobeneficio é oferecido. Embutida, necessariamente, nessa equação é a virtude humana de compaixão, caridade, misericórdia ou ágape. Afirmações de interesse do Estado em proteger a moralidade pública restringem as liberdades de associação íntima para acelerar a morte em uma doença terminal. Nenhum sofrimento de um indivíduo doente terminal a partir de qualquer somática intratável ou dor não somática, ou ambos, deve forçá-lo a continuar vivendo.

A falta de consenso entre os enfermeiros sobre a eutanásia, em geral, e sobre o envolvimento deles em particular, chama a atenção para a necessidade do debate em 
enfermagem (QUAGHEBEUR; CASTERLE; GASTMANS, 2009). A atenção foca-se em quatro áreas:

1) A melhor análise da essência do cuidado em geral, e dos cuidados paliativos em particular, tem que refinar a relação entre o cuidado e a eutanásia. A esse respeito, enfermeiras(os) podem oferecer uma contribuição original e específica, afirmando, explicitamente, re-pensar e tornar pública a exploração de suas próprias experiências e percepções em cuidar de pessoas que solicitam a eutanásia. Aspectos ocultos ou desconhecidos do processo de cuidar devem emergir e fomentar o debate ético.

2) Estudos sobre a eutanásia também são necessários. Métodos de investigação complementares levam a uma melhor visão sobre o fenômeno estudado.

3) Os documentos de posição das organizações de profissionais de enfermagem e códigos profissionais de ética devem ser estudados, a fim de mapear o ponto de vista éticoprofissional em enfermagem, cuidados e eutanásia.

Questões devem ser debatidas entre a equipe de enfermagem sobre como o envolvimento dos enfermeiros em cuidar de um paciente que solicita a eutanásia corresponde aos valores e às normas éticas profissionais.

4) Devido à especificidade dos conhecimentos de enfermagem e experiências nos cuidados de fim de vida, enfermeiros têm de ser inspirados a participar mais no debate público sobre ética e eutanásia por meio de pesquisa e publicação de seus próprios pontos de vista.

A Objeção de Consciência revela-se em toda a atuação do profissional de saúde, porém, em algumas situações, como aborto e eutanásia, ela aflora com maior avidez ao despontar-se como uma das formas de tornar a assistência à saúde, o ambiente hospitalar e os profissionais embasados pela consideração e pelo respeito à diversidade de culturas, crenças, valores e convicções individuais característicos de uma sociedade pluralista e tolerante.

Essa ferramenta é utilizada por profissionais de saúde quando suas crenças pessoais vão de encontro aos procedimentos adotados na atenção à saúde das populações. São respaldados pelos seus respectivos Códigos de Ética, desde que não se contraponham ao direito de pacientes atendidas nos serviços, fato que pode afetar questões relacionadas ao direito reprodutivo feminino (HOTTOIS; MISSA, 2001; PELLEGRINO; THOMASMA, 1988; MOLLER, 2008; PORTO, 2008).

Relatos sobre a Objeção de Consciência caminham a passos lentos na sociedade brasileira de pesquisadores, o que já acontece, há algumas décadas, em países da Europa, América do Norte e Oceania, onde se debate esse tema e suas influências em vários âmbitos. 
Segundo revista de enfermagem internacional, a Objeção de Consciência e o aborto foram legalizados na Inglaterra, Gales e Escócia desde 1967, quando a lei do aborto foi introduzida (JOURNAL OF NURSING MANAGEMENT, 2009). O acesso de mulheres britânicas aos serviços que realizam o aborto é relativamente simples, embora exista uma perspectiva de redução dessa oferta devido à desistência de alguns médicos em atuarem nessa área.

A argumentação (KANE, 2009) defende uma sociedade britânica laica (NATIONAL SECULAR SOCIETY, 2007) e corrobora com a universidade britânica de enfermeiros (COLLEGE OF REGISTERED NURSES OF BRITISH COLUMBIA - CRNBC, 2007) quando afirma que enfermeiros podem "lançar mão" da Objeção de Consciência e usufruí-la, de preferência quando a equipe de plantão está completa. Caso contrário, ela poderá gerar uma experiência hostil entre o profissional e o cliente, relegando a segurança, os direitos e os cuidados ao cliente como algo secundário e trazendo dificuldades de gerenciamento da equipe (KANE, 2009).

Nessa mesma linha de pensamento, um artigo publicado em uma revista britânica de enfermagem (McHALE, 2009) concorda em muitos aspectos já descritos anteriormente. Refere-se à Objeção de Consciência como "opt out"1 e receia que, com o avanço tecnológico eminente, haja aumento de sua utilização em relação a outros procedimentos, levando-se a questionamentos sobre a Objeção de Consciência ser um direito ou privilégio, a depender do momento.

Ser um objetor de consciência como profissional da saúde, pode estar relacionado à prática do aborto previsto em lei. Norma Técnica (BRASIL, 2012) revela que, em caso de gravidez decorrente de violência sexual, é direito das mulheres e adolescentes, bem como de seus representantes legais, serem informadas(os) da possibilidade de interrupção da gravidez, conforme o Código Penal (BRASIL, 1940). Há também o direito de mantê-la até seu término, optando pela doação ou não do recém-nascido, garantindo-lhe os cuidados pré-natais.

A violência sexual apresenta-se de forma constante na sociedade brasileira, tendo origem nas relações desiguais de poder. Algumas vezes, essa violência resulta em uma gravidez indesejada, inesperada, que se destaca pela complexidade de reações psicológicas, sociais e biológicas e é encarada como uma segunda violência, intolerável para muitas mulheres (BRASIL, 2010).

Na América Latina e Central, países como Chile, El Salvador, Nicarágua e República Dominicana não concordam com a interrupção gestacional sob qualquer hipótese.

\footnotetext{
${ }^{1}$ Expressão inglesa que significa "optar por fora", "afastar-se".
} 
Já a Argentina, Venezuela, Costa Rica, Peru e Paraguai admitem o aborto em casos de risco de morte materna, enquanto na Venezuela é admitido, também, para proteção da honra da mulher ou homem. Uruguai, Colômbia, Equador, Bolívia, México, Panamá e Guatemala permitem o aborto nos casos de violação ou incesto, mas o Uruguai também o admite no caso de "angústia econômica". Ainda a Colômbia, o México e o Panamá também o admitem quando há malformação fetal (TORRES, 2012).

No Brasil, há permissão legal para a realização da interrupção legal da gestação nos casos de risco de morte materna, anencefalia, desde abril de 2012, e gravidez fruto de violência sexual, sendo que esta não se condiciona à decisão judicial, bastando a apresentação de boletim de ocorrência policial ou mesmo o laudo do exame de corpo de delito. Hoje há 557 serviços de saúde que acolhem mulheres vitimas de violência sexual; desses, 63 realizam a interrupção legal da gestação e 30 recebem capacitação para tal.

Por ser um direito da mulher, não há sustentação legal para que os serviços de saúde neguem o procedimento, embora alguns profissionais possam se recusar a realizá-lo, sendo respaldados, como já dito, pelos seus respectivos Códigos de Ética, como o de Enfermagem e Medicina, no que se refere à Objeção de Consciência (COFEN, 2007; CFM, 2015).

A objeção de consciência é um mecanismo capaz de manter a integridade profissional e contribuir para a humanização da área da saúde, pois fornece uma base para os profissionais, por meio de relações marcadas por respeito pelas culturas, diversidade, crenças, valores e convicções pessoais, que são característicos de uma sociedade pluralista e tolerante. A objeção de consciência também tem sido exercida por profissionais de saúde quando suas crenças possuem conflitos com os procedimentos a serem dispensados.

Durante o processo de cuidado na saúde, por exemplo, em situações associadas a obstinação terapêutica e futilidade em unidades de terapia intensiva neonatal ou com o fim de cuidar da vida, bem como a situação recorrente, referente ao aborto legal ou eletivo, a medicina e a enfermagem brasileiras possuem códigos de ética profissional que oferecem apoio às posições decorrentes da objeção de consciência.

No Código de Ética dos Profissionais de Enfermagem, o artigo 28, parágrafo único, indica: "nos casos previstos em lei, o profissional deverá decidir, de acordo com a sua consciência, sobre a sua participação ou não no ato abortivo" (COFEn, 2007). Da mesma forma, o Código de Ética Médica, em seu Capítulo I, Princípios Fundamentais, inciso VII, prescreve que "o médico exercerá sua profissão com autonomia, não sendo obrigado a prestar serviços que contrariem os ditames de sua consciência". 
A OMS não compartilha dessa ideia para as situações de ausência de outro médico, em caso de urgência ou emergência, ou quando sua recusa poderia trazer danos à saúde do paciente, o que é previsto no Capítulo II, Direitos dos Médicos, inciso IX, que diz: "recusar-se a realizar atos médicos que, embora permitidos por lei, sejam contrários aos ditames de sua consciência" (CFM, 2010).

Hottois e Missa (2001), Moller (2008) e Porto (2008) concordam que, embora os códigos não prejudiquem os direitos dos doentes tratados nos serviços, quanto aos problemas com direitos sexuais e reprodutivos, é importante destacar a obrigação moral de profissionais de saúde de fornecer à equipe sua posição, quando a situação é caracterizada pela urgência ou emergência (COFEn 2007; CRM 2010). Esse argumento, reforçado nos códigos de ética, permite às enfermeiras fazerem uso da objeção de consciência e exercê-la, de preferência quando a equipe está completa (KANE, 2009; COLLEGE OF REGISTERED NURSES OF BRITISH COLUMBIA, 2012).

Kane (2009) alega que a objeção de consciência pode gerar uma experiência hostil entre o profissional e o paciente, que pode ser entendida como desrespeito aos direitos de segurança e aos cuidados que devem ser fornecidos ao paciente. Essa situação também pode provocar dificuldades na gestão de equipe. Entretanto, estar inserido na equipe do aborto previsto em lei é um forte indicativo de que não há conflitos ideológicos ou de qualquer natureza para atuar nesses casos, estando sujeitos a cumprir a norma técnica do aborto previsto em lei.

\subsection{NORMA TÉCNICA E O ABORTO PREVISTO EM LEI}

O Ministério da Saúde, atento à primazia dos direitos humanos e sensível às reivindicações dos movimentos feministas e de mulheres que não arrefecem na luta histórica por tais direitos, adotou, nos últimos anos, visível e inexorável fôlego no compromisso com a garantia dos direitos reprodutivos e sexuais das mulheres. Vem pautando o direcionamento de suas ações no seguimento de acordos internacionais dos quais o Brasil é signatário e pela legislação nacional vigente, com destaque para a consolidação de garantias constitucionais. A elaboração e a implementação da Lei Maria da Penha transformaram-se em um marco político essencial para o enfrentamento dos diferentes tipos de violências praticadas contra as mulheres nas esferas doméstica e pública (BRASIL, 2006). A violência sexual configura-se 
como atentado à integridade das mulheres e não raro provoca traumas indeléveis na vida de mulheres, adolescentes e crianças. Pode ocasionar gestações indesejadas, doenças sexualmente transmissíveis e disfunções sexuais e reprodutivas (BRASIL, 2012).

Considerando-se esses aspectos e em conformidade com o Código Penal Brasileiro (BRASIL, 1940), o Ministério da Saúde elaborou a Norma Técnica de Atenção Humanizada ao Abortamento (BRASIL, 2012). Essa norma fornece aos profissionais de saúde diretrizes para o processo de condução do aborto previsto em lei, que requer o oferecimento de cuidados imediatos e qualificados para as mulheres em situação de abortamento, oferecidos sob a perspectiva da integralidade da atenção à saúde, fornecimento de alternativas contraceptivas e medicamentos para prevenção de DST. Para mulheres com abortamentos espontâneos e que desejem nova gestação deve ser garantido atendimento adequado às suas necessidades. Além disso, a Norma prevê o encaminhamento das mulheres e adolescentes para Centros de Atendimento Psicossocial para acompanhamento psicológico (BRASIL, 2012).

\subsubsection{Procedimentos de justificação e autorização para interrupção de gestação prevista em lei}

No Brasil, o abortamento é crime tipificado pelo Código Penal, com exceção das situações previstas nos incisos I e II do artigo 128, que estabelece, desde 1940, o direito ao abortamento em casos de gravidez decorrente de estupro (abortamento sentimental), ou quando há risco de morte para a gestante (abortamento necessário) (BRASIL, 1940).

A Portaria MS/GM n ${ }^{\circ} 1.508$, do Ministério da Saúde, de $1^{\circ}$ de setembro de 2005, estabelece os Procedimentos de Justificação e Autorização da Interrupção da Gravidez nos casos previstos em lei, no âmbito do Sistema Único de Saúde (BRASIL, 2005). Esses procedimentos devem ser adotados pelos serviços de saúde para a realização do abortamento em situações de violência sexual, e incluem cinco diferentes termos: o Termo de Consentimento Livre e Esclarecido, o Termo de Responsabilidade, o Termo de Relato Circunstanciado, o Parecer Técnico assinado por médico e o Termo de Aprovação de Procedimento de Interrupção de Gravidez.

O Termo de Consentimento Livre e Esclarecido é documento imprescindível para a realização do abortamento. Deve incluir a declaração da mulher e/ou de seu representante 
legal pela escolha da interrupção da gestação, ciente da possibilidade de manter a gestação até o seu término e das alternativas existentes nesse caso. Inclui a declaração de conhecimento sobre os procedimentos médicos que serão adotados, bem como dos desconfortos e riscos possíveis para a saúde, formas de assistência e acompanhamentos posteriores. Deve constar que a mulher e/ou seu representante legal solicitam a interrupção da gestação e autorizam os profissionais de saúde a realizar os procedimentos necessários.

O Termo de Responsabilidade é assinado pela mulher e/ou seu representante legal, no qual se declara que as informações prestadas para a equipe de saúde correspondem à legítima expressão da verdade. Deve constar que os(as) declarantes estão cientes das consequências dos crimes de Falsidade Ideológica e de Aborto previstos nos artigos 299 e 214 do Código Penal, respectivamente, assumindo a responsabilidade caso as informações prestadas não correspondam à verdade (BRASIL,1940 e BRASIL, 2005).

No terceiro documento, o Termo de Relato Circunstanciado, a mulher e/ou seu representante legal devem descrever as circunstâncias da violência sexual sofrida que resultaram na gravidez. No que se refere à violência sexual, deve constar a data, o horário aproximado, o local, e a descrição detalhada do ocorrido. Quanto ao autor ou autores da violência, deve ser especificado o número de envolvidos. Se forem conhecidos, incluir a idade aparente, a raça, a cor dos cabelos, os trajes, sinais particulares, eventual grau de parentesco e se apresentavam sinais de uso de álcool ou de drogas ilícitas. Deve acrescentar se o crime sexual foi ocasionalmente testemunhado por alguma pessoa.

Acrescenta-se um Parecer Técnico assinado por médico, atestando a compatibilidade da idade gestacional com a data da violência sexual alegada, afastando-se a hipótese de gravidez decorrente de outra circunstância distinta da violência sexual.

Cumpridas as etapas anteriores, a documentação é completada pelo Termo de Aprovação de Procedimento de Interrupção de Gravidez, firmado pela equipe multiprofissional que compõe o aborto previsto em lei e pelo diretor ou responsável pela instituição. Todos os termos, devidamente assinados, devem ser anexados ao prontuário hospitalar. Uma cópia de cada um desses formulários deve ser entregue à mulher e/ou a seu representante legal.

Para os casos em que a solicitação não receba aprovação, os motivos e justificativas devem ser cuidadosamente registrados no prontuário da paciente.

A realização do abortamento não se condiciona a decisão judicial que sentencie e decida se ocorreu estupro ou violência sexual. A Lei Penal Brasileira também não exige alvará ou autorização judicial para a realização do abortamento em casos de gravidez 
decorrente de violência sexual. Esse posicionamento também se aplica ao Boletim de Ocorrência Policial e ao laudo do Exame de Corpo de Delito e Conjunção Carnal, do Instituto Médico Legal (BRASIL, 1940).

Embora esses documentos possam ser desejáveis em algumas circunstâncias, a realização do abortamento não está condicionada à sua apresentação. Não há sustentação legal para que os serviços de saúde neguem a realização do procedimento, caso a mulher não possa apresentá-los.

Segundo o Código Penal, é imprescindível o consentimento por escrito da mulher, que deve ser anexado ao prontuário da paciente, para a realização do abortamento em caso de violência sexual. O Código Civil estabelece que, a partir dos 18 anos, a mulher é considerada capaz de consentir sozinha para a realização do abortamento.

No caso de adolescentes, a existência de limitações etárias para o exercício de seus direitos em diversas normas legais como o Código Civil, o Código Penal, dentre outros, suscita dúvidas e receios éticos e legais entre profissionais de saúde que atendem essa população.

O primeiro Marco Legal - Saúde, um Direito de Adolescentes, do Ministério da Saúde - recomenda que, na interpretação e aplicação das diversas normas de tutela, é necessário compreender, primeiramente, a concepção dos direitos que envolvem a assistência à saúde do adolescente (MINISTÉRIO DA SAÚDE, 2005). O direito à saúde, garantido pela Constituição Federal, constitui-se em um direito humano fundamental. É compreendido em uma perspectiva integradora e harmônica dos direitos individuais e sociais. O direito tutelar deve atuar no melhor benefício das adolescentes e exclui qualquer outra norma que se mostre prejudicial ao bem juridicamente garantido a esse grupo.

O Estatuto da Criança e do Adolescente (ECA), que data de 1990, no seu artigo $1^{\circ}$, dispõe sobre a proteção integral à criança e ao adolescente, determinando a natureza dos direitos ali elencados, que estarão acima de qualquer outro que possa prejudicá-los. O Art. $3^{\circ}$ aponta que a criança e o adolescente gozam de todos os direitos fundamentais inerentes à pessoa humana, sem prejuízo da proteção integral de que trata essa lei, assegurando-se-lhes, por lei ou por outros meios, todas as oportunidades e facilidades, a fim de lhes facultar o desenvolvimento físico, mental, moral, espiritual e social, em condições de liberdade e de dignidade (BRASIL, 1990).

O segundo Marco Legal define que qualquer exigência, como a obrigatoriedade da presença de um responsável para acompanhamento no serviço de saúde, que possa afastar ou impedir o exercício pleno do adolescente e seu direito fundamental à saúde e à liberdade, 
constitui lesão ao direito maior de uma vida saudável. Caso a equipe de saúde entenda que o usuário não possui condições de decidir sozinho sobre alguma intervenção em razão de sua complexidade, deve, primeiramente, realizar as intervenções urgentes que se façam necessárias, e, em seguida, abordar o adolescente de forma clara quanto à necessidade de que um responsável o assista e o auxilie no acompanhamento (BRASIL, 1990).

A ausência dos pais ou responsáveis legais não deve impedir o atendimento pela equipe de saúde em nenhuma consulta. Todos os esclarecimentos e informações quanto a riscos sobre aborto legal devem ser fornecidos à adolescente. É indispensável comunicar, esclarecer e acordar com a adolescente sobre o momento e os procedimentos que serão realizados. Quando houver indicação de um procedimento invasivo, como no caso do aborto, torna-se necessária a presença de um dos pais ou do responsável, excluindo-se as situações de urgência, quando há risco de vida iminente e em casos de violência sexual.

Tal procedimento deve estar rigorosamente dentro das normas técnicas do Ministério da Saúde para a realização do aborto legal. Havendo desejo de continuidade da gravidez pela adolescente e discordância de pais ou responsáveis que desejam o aborto, o serviço deve respeitar o direito de escolha da adolescente e não realizar nenhum encaminhamento ou procedimento que se oponha à sua vontade. Nesses casos, deve ser oferecido o acompanhamento psicossocial à família e à adolescente (BRASIL, 2010/2012).

Em casos nos quais haja posicionamentos conflitantes - a adolescente deseja a interrupção da gravidez e a família não; sem o seu envolvimento na violência sexual -, a resolução do problema deve ser buscada por via judicial, através do Conselho Tutelar ou da Promotoria de Justiça da Infância e da Juventude. A instauração do processo legal contribuirá para solucionar o impasse.

Cabe ao Promotor de Justiça da Infância e da Juventude postular em juízo os direitos da adolescente. Para o atendimento das solicitantes ao aborto legal, devem ser seguidas as orientações da Portaria $\mathrm{n}^{\circ} 1.508$, de 2005, de Procedimento ao Aborto Legal (BRASIL, 2015).

Menores de 18 anos grávidas com direito ao aborto legal devem ser acolhidas e esclarecidas sobre o seu direito à escolha da opção do abortamento, sendo necessária a autorização de responsáveis ou tutores para a solicitação do procedimento. Menores de 14 anos necessitam adicionalmente de uma comunicação ao Conselho Tutelar, que se encarregará de acompanhar o processo e solicitar sua agilização (BRASIL, 2010/2012).

Se a adolescente se recusa a fornecer informações sobre determinadas situações de sua vida à família, fica caracterizada desarmonia familiar, que deverá ser enfrentada pela 
equipe de saúde. Porém, é preciso preservar sempre o direito que a adolescente possui de exercer seu direito de atenção à saúde. Recomenda-se que em situações nas quais existe resistência evidente e receio que a comunicação ao responsável legal implique afastamento do programa ou dano à sua saúde, seja aceita a presença de pessoa maior e capaz indicada pela adolescente para acompanhá-la e auxiliar a equipe de saúde na condução do caso. Aplica-se, de forma análoga, o princípio do art. 142 do Estatuto da Criança e do Adolescente, que estatui que menores de dezesseis anos sejam representados; e que maiores de dezesseis e menores de vinte e um anos sejam assistidos por seus pais, tutores ou curadores, na forma da legislação civil ou processual (BRASIL, 1990).

O parágrafo único do Art, 142, reforça, ainda, que a autoridade judiciária indicará curador especial à criança ou ao adolescente, sempre que seus interesses colidirem com os de seus pais ou responsáveis, ou quando carecer de representação ou assistência legal, ainda que eventual (BRASIL, 1990).

Frente a casos de maior complexidade e que podem culminar em consequências legais, recomenda-se que o serviço de saúde busque desenvolver ação conjunta com o Conselho Tutelar da região e com a Promotoria da Infância e da Juventude na condução das questões excepcionais, de forma harmônica com os princípios éticos que regem esse atendimento.

O consentimento do(a) representante legal também é necessário se, por qualquer razão, a mulher não tiver condição de discernimento ou não puder expressar sua vontade, a exemplo das deficientes mentais. É desejável que conste no Termo de Consentimento que foi fornecida informação à mulher ou a seu representante legal sobre a possibilidade de responsabilização criminal caso as declarações prestadas forem falsas, conforme consta no artigo 299 do Código Penal brasileiro, sem prejuízo para a credibilidade da palavra da mulher (BRASIL, 1940). De qualquer forma, sempre que a mulher ou a adolescente tiver condições de discernimento e de expressão de sua vontade, deverá também consentir. Deverá ser respeitada sua vontade mesmo se a decisão estiver relacionada a não consentir com o abortamento. Desse modo, o procedimento não deverá ser realizado, ainda que seus representantes legais assim o desejem.

É fundamental reconhecer que a qualidade da atenção ofertada inclua aspectos relativos à humanização da assistência em saúde. Crenças e valores morais e religiosos não devem interferir no direito à realização do procedimento por parte das mulheres e adolescentes. $\mathrm{O}$ requisito ético fundamental busca preservar e garantir o respeito aos direitos humanos das mulheres. 
O propósito adotado pela Norma Técnica foi o da inclusão de um modelo humanizado de atenção às mulheres em situação de abortamento, com a intenção de oferecer às mulheres, aos serviços de saúde e à sociedade um novo paradigma que torne segura, sustentável e efetiva a atenção às mulheres que buscam o programa do aborto previsto em lei.

Para que esse processo seja colocado em prática, torna-se necessário o atendimento dos seguintes aspectos:

1. Existência de rede integrada com a comunidade e com os prestadores de serviço para a prevenção das gestações indesejadas e do abortamento inseguro, para a mobilização de recursos e para a garantia de que os serviços reflitam as necessidades da comunidade e satisfaçam suas expectativas;

2. Acolhimento e orientação para responder às necessidades de saúde mental e física das mulheres, além de outras preocupações que possam surgir;

3. Atenção clínica adequada ao abortamento e suas complicações, segundo referenciais éticos, legais e bioéticos;

4. Oferecimento de serviços de planejamento reprodutivo pós-abortamento às mulheres, inclusive orientações para aquelas que desejem nova gestação;

5. Integração com outros serviços de atenção integral à saúde e de inclusão social para as mulheres (BRASIL, 2011).

No que diz respeito à objeção de consciência, a liberdade de consciência descrita na Constituição da República Federativa do Brasil, a qual engloba diversos outros direitos, enfatiza a escusa de consciência, ou objeção de consciência, que significa a recusa a cumprimento de deveres incompatíveis com as convicções morais, políticas, filosóficas ou religiosas, possuindo interrelacionamento com a dignidade da pessoa humana ( $\operatorname{art} .1^{\circ}$, III), não tendo o Estado poder de ingerência em assuntos privativos da consciência individual e da privacidade da pessoa (BRASIL, 1988).

A norma técnica (2012) ressalta o direito à objeção de consciência do médico CRM (2010) e o direito de recusa em realizar o abortamento em casos de gravidez resultante de violência sexual. Porém indica que não é possível recorrer à objeção de consciência: “b) Em qualquer situação de abortamento juridicamente permitido, na ausência de outro(a) médico(a) que o faça e quando a mulher puder sofrer danos ou agravos à saúde em razão da omissão do(a) médico(a)".

As características de um bom acolhimento incluem: acolher sem julgar, realizar escuta qualificada, oferecer informações e orientações relacionadas ao serviço e procedimento, iniciar o acompanhamento que se faz necessário para cada situação e que 
deverá ser o sustentado pelos princípios do SUS. Em todo caso de abortamento, deve estar garantida de forma prioritária a atenção à saúde da mulher, por meio de atuação de equipe multiprofissional e, acima de tudo, o respeito à mulher no que se refere à sua liberdade, dignidade, autonomia e autoridade moral e ética para decidir, afastando-se preconceitos, estereótipos e discriminações de quaisquer naturezas que possam negar e desumanizar esse atendimento. A escolha do tipo de procedimento a ser utilizado para o esvaziamento uterino deve ser resultado de conciliação entre o profissional e a mulher (BRASIL, 2011).

\subsection{A BIOÉTICA E O ABORTO PREVISTO EM LEI}

A Bioética emergiu na contemporaneidade como ferramenta para auxiliar na mediação de conflitos de difícil mediação moral, tanto no campo da prática científica, como no cenário da atenção em saúde. Com o processo de medicalização e o rápido desenvolvimento científico e tecnológico, pacientes e sujeitos de pesquisa tornaram-se vulneráveis em suas relações com médicos e cientistas (ROTHMAN, 2003).

A preocupação com as questões que emergiam da prática clínica levaram Daniel Callahan e Willard Gayling a criar, no ano de 1969, o primeiro centro de pesquisa sobre aspectos éticos e sociais envolvidos nas ciências da vida, denominado Institute of Society, Ethics and the Life Sciences. Posteriormente, essa instituição passou a chamar-se Hastings Center, sendo reconhecida internacionalmente como um local de excelência para reflexão e resolução de temas que passaram a se mostrar relevantes para a sociedade em geral. A grande responsabilidade pública ficou evidente nesse novo cenário (JONSEN, 2003).

Porém, o marco simbólico ainda reconhecido como precursor da Bioética no Ocidente foi o neologismo divulgado por Van Rensselaer Potter a partir dos anos 1970. Potter questionou a possibilidade de sobrevivência da própria humanidade em sua interrelação com a reflexão produzida por ética interdisciplinar capaz de vincular as ciências biológicas e as humanidades. No livro publicado em 1971, intitulado Bioética: ponte para o futuro, foram lançadas as bases para a adoção dessa nova forma de pensar no campo da vida e da saúde de seres humanos e animais não humanos (POTTER, 1971, 1998; SCHRAMM, 2011).

A definição de Bioética, contida nas três edições da prestigiada Encyclopedia of Bioethics passou por algumas modificações, mas manteve a ideia inicial de vincular conduta humana, interdisciplinaridade, vida e saúde, e análise moral dos conflitos em pauta. A 
primeira definição apresentada - "o estudo sistemático da conduta humana na área das ciências da vida e cuidados de saúde, como tal comportamento é analisado à luz dos valores e princípios morais" (REICH, 1982) - foi modificada, na $2^{a}$ edição da obra, para "Estudo sistemático das dimensões morais - incluindo visão, decisão, conduta e normas morais - das ciências da vida e da saúde, utilizando uma variedade de metodologias éticas num contexto interdisciplinar" (REICH, 1995). Finalmente, foi apresentada como "Exame moral interdisciplinar e ético das dimensões da conduta humana nas áreas das ciências da vida e da saúde" (POST, 2003).

A primeira e mais conhecida teoria da Bioética foi expressa no livro publicado por Tom Beauchamp e James Chidress, no ano de 1979, intitulado Principles of Biomedical Ethics. Os autores, ambos vinculados ao Kennedy Institute, propuseram a utilização de quatro princípios - Autonomia, Beneficência, Não Maleficência e Justiça - para a abordagem dos conflitos provenientes da prática clínica (PESSINI; BARCHIFONTAINE, 2012).

Basearam-se no então recentemente divulgado Relatório Belmont, publicado em 1978, que indicou três princípios básicos - Respeito pelas Pessoas, Beneficência e Justiça que deveriam ser utilizados como referência ética para o desenvolvimento de pesquisas biomédicas e comportamentais (USA GOVERNMENT, 1978).

Devido a sua grande aceitação, o conjunto dos quatro princípios passou a ser chamado de Mantra do Instituto Kennedy de Ética. Foi denominado de Principlism ou Principialismo, como conhecemos na língua portuguesa, ou seja, a escola bioética baseada no uso dos quatro princípios como modelo explicativo e resolutivo para as tensões no campo da atenção à saúde e serviu como base para muitas diretrizes internacionais no campo da ética em pesquisa (BEAUCHAMP; CHILDRESS 1994, apud GOLDIN, 2013).

Beauchamp e Childress (2009) foram aprimorando a concepção inicial em sua obra e, na $7^{\mathrm{a}}$ edição do livro Principles of Biomedical Ethics, realizaram análise detalhada de cada um dos princípios prima facie centrais no debate bioético. Foram incluídas também as questões e/ou problemas éticos que cada um desses princípios envolve. Um exemplo da complexidade da resolução de conflitos morais emerge quando diferentes princípios devem ser utilizados para análise da situação. Embora os autores mencionem que não existe hierarquização entre eles, permanece a preponderância do princípio da autonomia. Em outros casos, mesmo que não fique evidente a hierarquização entre os princípios, em determinadas situações de conflito, um pode se sobrepor aos outros.

Beauchamp (2003) diferencia a ética normativa e ética não normativa, esclarecendo que o objeto da ação ética deve ficar claro para que se possa identificar qual é o 
melhor caminho para eleger os aspectos éticos aplicáveis às decisões clínicas. Essa análise requer conhecimento sobre o conjunto de princípios morais nucleares que deve ser utilizado, indicando-se um modelo que permita reduzir a complexidade da vida moral, sobretudo quando esta é confrontada com situações difíceis no processo de atenção à saúde, podendo emergir conflitos entre os próprios princípios.

Mais do que explicar o papel de cada um dos princípios morais, Beauchamp e Childress (2009), procuram explicar como operacionalizar sua aplicação de modo que possam ser compreendidos coletivamente como uma ferramenta adequada para a tomada de decisões no campo da Bioética. Diego Gracia (2001) defende que os princípios pretendem dar sustentação moral para declaração dos valores morais e da dignidade humana.

Ainda de acordo com a argumentação de Beauchamp e Childress (2009), embora os quatro princípios possuam características provenientes da ética tradicional, também incluem aspectos da moralidade que foram anteriormente negligenciados. Um exemplo desse movimento está relacionado ao respeito pela autonomia do paciente, isto é, o seu direito moral de decidir autonomamente, com base no consentimento livre e informado, mesmo que em sentido contrário ao da prescrição.

Há um princípio tradicional na ética médica hipocrática, o princípio de não maleficência, isto é, a obrigação de não causar, em termos gerais, qualquer mal ou dano. Do ponto de vista da saúde, a aplicação desse princípio reporta-se à obrigação de não causar danos físicos, incluindo dor ou sofrimento, invalidez e morte. (MARTINS, 2013).

No conceito de beneficência, Beauchamp e Childress (2009) distinguem a beneficência de benevolência, referindo-se ao primeiro como o ato concreto de ajudar os outros, ou seja, a “obrigação de agirmos em benefício de outrem”. Já no caso da benevolência, os autores referem-se à virtude de quem pratica as ações, ou seja, ao fato de agir por simples generosidade, sem que a ela estejamos obrigados.

Mesmo que não seja considerado o principal princípio, a beneficência impõe, tal como os outros princípios, uma obrigação prima facie, já que os atos de beneficência também não são considerados absolutamente obrigatórios. A necessidade de aprofundamento sobre a especificidade desse princípio parte da concepção de que é preciso saber o que ele nos traz de novo em relação a outros princípios como, por exemplo, o princípio da não maleficência (FERRER, 2003).

Beauchamp (2011) aponta que as normas morais baseadas no princípio da não maleficência estão associadas a obrigações negativas ou proibições, às quais se deverá obedecer imparcialmente sob pena de, em caso descumprimento, serem aplicadas sanções 
legais. Portanto, essas normas nos proíbem de praticar o mal universalmente. Em contrapartida, as normas morais baseadas no princípio da beneficência nos impõem obrigações positivas, às quais nem sempre é possível obedecer de forma imparcial, sendo-nos permitido favorecer aqueles com quem temos uma relação especial.

O conceito de beneficência positiva com algumas regras básicas, como a de prevenir possíveis danos, ajudar os incapacitados ou resgatar as pessoas em perigo, não clarificam em que circunstâncias essas ações devem ser praticiadas, isto é, em que circunstâncias seremos obrigados a agir de forma beneficente (MARTIS, 2013).

Beauchamp e Childress (2009) apontaram que o principio da beneficência está intrinsecamente ligado à qualidade de vida de cada ser humano. Se um tratamento possui potencial de melhorar a qualidade de vida, ele deve ser colocado em prática. Porém, os autores questionam se o conceito de qualidade de vida assume a mesma conotação para todas as pessoas. Por exemplo, aumentar a sobrevida, em termos de anos, implica que ações baseadas na beneficência se contrapõem ao significativo aumentos nos custos do cuidado em saúde. Segundo os autores, salvar mais vidas aparenta ser menos importante do que aumentar o número de anos de vida, o que levanta sérias questões morais sobre direitos das pessoas e deveres dos profissionais de saúde.

O quarto princípio bioético é o da justiça, que impõe o dever de dar a cada pessoa o que lhe é devido, ou lhe pertence, em termos de benefícios ou direitos, e de responsabilidades ou deveres. Assim, enquanto a justiça está associada a direitos e deveres, a injustiça está relacionada com o ato de negar determinados direitos às pessoas, por erro ou por omissão (GRACIA, 2004).

Beauchamp e Childress (2009) debatem o direito aos bens e serviços relacionados à saúde e consideram que no processo de tomada de decisões sobre quem receberá os escassos recursos médicos disponíveis (os quais não poderão ser fornecidos a todas as pessoas carentes) devem ser combinadas duas perspectivas: a utilitarista, com a sua estratégia de maximizar benefícios para os pacientes e a sociedade, e a igualitarista, que defende o igual valor das pessoas e as justas oportunidades.

Como critérios que determinam um conjunto qualificado de potenciais benefícios para os pacientes, apresentam: a constituição (que determina os limites sociais); os progressos da ciência (que determinam o uso de determinados recursos); e a probabilidade de sucesso (que determina a quem devem ser distribuídos os recursos). O problema da aplicabilidade do princípio da justiça reporta-se à equidade no campo da biomedicina (BEAUCHAMP, 2011). 
A reflexão sobre os princípios bioéticos que permeiam a prática do profissional de saúde no programa de aborto previsto em lei verifica que, de acordo com a norma técnica, o princípio da autonomia mantém sua relevância e importância, indicando que é de fundamental importância respeitar a autonomia, a individualidade e os direitos das pessoas em situação de violência sexual. Deve-se resguardar sua identidade e sua integridade moral e psicológica, tanto no espaço da instituição quanto no espaço público. Da mesma forma, deve-se respeitar a vontade expressa da vítima em não compartilhar sua história com familiares e/ou outras pessoas (BRASIL, 2012; BEAUCHAMP; CHILDRESS, 2009).

Para as situações de violência de qualquer tipo, como as sexuais contra crianças e adolescentes, a lei é clara. Segundo o ECA, em seu Art. 13º,

cabe ao profissional de saúde notificar o Conselho Tutelar casos suspeitos ou confirmados, esta atitude reflete a beneficência e não maleficência com a vida de crianças e adolescentes, promovendo justiça social quando o(a) autor(a) assume as responsabilidades sobre seus atos (BRASIL, 1990).

Na violência cometida por parceiros íntimos, a mulher pode estar assustada, traumatizada e emocionalmente ferida. Seus limites precisam ser respeitados. Torna-se necessário reconhecer que cada pessoa tem seu tempo próprio de amadurecimento para romper a situação de violência e que esse tempo deve ser respeitado. A pressa do(a) profissional que busca alcançar resultados imediatos pode intimidar a mulher ou até mesmo paralisá-la. O respeito aos princípios da autonomia e da justiça são apontados como requisitos primordiais no processo de atenção ao aborto previsto em lei (BRASIL, 2012).

A reflexão sobre o aborto exigida para os profissionais de saúde que atuam nos serviços pode se traduzir em angústia e sofrimento. Mas, seguramente, a maior sobrecarga de dor e angústia está reservada às mulheres que, depois de violadas, abrigam em seu útero o ser resultante dessa violência. Deparam-se com o conflito que emerge da possibilidade de interrupção de uma gravidez, ainda que indesejada (BRASIL, 2009).

Muitas são as motivações que levam ao conflito frente à realização do aborto: ter sido a mulher vítima de violência sexual; presença de doenças no corpo ou na mente da mulher; existência de diagnóstico de doenças no nascituro; situação socioeconômica desfavorável; medo de não ter condições de desempenhar a função materna; temor de não contar com a aceitação social; situação familiar, especialmente em decorrência do elevado número de filhos; entre tantas outras vivenciadas pelas mulheres que levam o assunto ao conhecimento dos profissionais da saúde (BRASIL, 2009). 
Infelizmente, parcela significativa da população toma a decisão de interromper a gestação sem buscar recursos disponíveis por meio dos setores da assistência social, da saúde, da psicologia, dos programas de orientação ao planejamento familiar. Tornam-se. uma vez mais, vítimas do sistema, ao recorrerem a métodos clandestinos de abortamento, com sérios, e por vezes irreversíveis, prejuízos à sua saúde física, reprodutiva e emocional (BRASIL, 2009)

Rocha e colaboradores (2015) no estudo sobre a Percepção de profissionais da saúde sobre abortamento legal revela que a Declaração Universal sobre Bioética e Direitos Humanos (DUBDH) vincula o princípio da não discriminação e não estigmatização ao princípio da dignidade da pessoa humana, aos direitos fundamentais e às liberdades individuais. Esse seria um motivo pelo qual ninguém deveria sofrer qualquer constrangimento ou ser diminuído em razão do que quer que faça ou escolha, sob pena de ter retirada sua dignidade.

Embora o estudo não quisesse equiparar, ou mesmo comparar, o sofrimento da mulher que aborta e do profissional que o executa, cabe destacar que todos aqueles envolvidos no abortamento, mesmo que legal, parecem estar vulneráveis a diferentes processos de estigmatização e discriminação (ROCHA et al., 2015).

Os autores concluem ainda que as verbalizações desses participantes - médicos, enfermeiros, assistentes sociais, técnicos, psicólogos - alinham-se com a bioética principialista, segundo a qual é preciso respeitar a autonomia da mulher no que se refere à sua vida e ao seu corpo. Também é imprescindível almejar seu bem integralmente, maximizandoo e minorando o dano (beneficência), e evitar qualquer prejuízo que lhe cause sofrimento (não maleficência (ROCHA et al. 2015).

Na mesma linha de argumentação, Faúndes e Barzelatto (2004) apontam que os princípios da não maleficência e da beneficência desencadeiam vários posicionamentos, entre os quais o repúdio a qualquer restrição de acesso aos serviços de abortamento e a atos burocráticos que o tornem inacessível à paciente.

Na Bioética, o aborto não é tema exclusivo de mulheres ou de militantes de movimentos sociais. A ideia da autonomia do indivíduo possui penetração imensa na Bioética laica e gira em torno do princípio do respeito à autonomia reprodutiva, aos quais os proponentes da questão do aborto se agregam (DINIZ; ALMEIDA, 2012).

No programa de aborto previsto em lei, os princípios da Bioética são a base para o estabelecimento da relação entre a equipe e a mulher. O princípio da justiça se efetiva a partir do momento em que a mulher desfruta do livre acesso, o livre acesso está associado com a equidade, para a realização do procedimento de acordo com sua necessidade. $\mathrm{O}$ respeito à 
autonomia da mulher deve acompanhá-la desde o momento de seu acolhimento, o processo de tomada de decisão, até a efetivação do esvaziamento uterino. A equipe deve introduzir no acompanhamento da mulher o enfoque dos princípios da não maleficência, da beneficência e do respeito às suas escolhas (BRASIL, 2012).

O procedimento apresentado pelo médico e pela equipe de saúde deve ir ao encontro das expectativas da mulher. No entanto, o momento de tomada de decisão deve ser uma prerrogativa da mulher, levando-se em conta o momento gestacional. O exercício da autonomia se reflete no processo de escolha, sendo que, ao optar pelo método mais confortável, a mulher estará se autoprotegendo. Após a interrupção gestacional e a alta hospitalar, a mulher deverá receber apoio psíquico até a ressignificação do momento da violência sexual e suas consequências, a fim de que seja garantida a não maleficência a essa mulher (BRASIL, 2012).

As equipes que trabalham com essas mulheres em situação de aborto legal devem ser isentas de objeção de consciência sobre esse tema, a fim de fundamentar o cuidado com benevolência, beneficência, não maleficência de forma justa, ao permitir que a autonomia da mulher se manifeste durante todo processo (BRASIL, 2012). 


\section{OBJETIVOS:}

\subsection{OBJETIVO GERAL}

- Conhecer e compreender a existência da objeção de consciência na prática do aborto previsto em lei em um hospital público.

\subsection{OBJETIVOS ESPECÍFICOS}

- Realizar revisão integrativa da literatura científica de autores brasileiros sobre o tema da Objeção de Consciência e sua interface com o aborto previsto em lei;

- Caracterizar o perfil de adolescentes e mulheres que buscam o Serviço de Aborto Previsto em Lei;

- Conhecer as concepções que profissionais de saúde que atuam no aborto previsto em lei possuem sobre o conceito de Objeção de Consciência e como se dá sua apropriação na prática cotidiana. 


\section{MÉTODO}

Estudo com delineamento exploratório-descritivo realizado por meio de investigação multidimensional em uma concepção pragmática, tendo como base a utilização dos métodos mistos.

Estudos descritivos buscam detalhar as características de determinado fenômeno mediante a mensuração ou coleta de informações, possibilitando previsões ou relações causais (SAMPIERE; COLLADO; LÚCIO, 2006, p. 100).

A abordagem de métodos mistos empregada neste estudo iniciou-se no campo da psicologia. Tem como objetivo fornecer maior vigor aos resultados das pesquisas em detrimento da utilização individualizada das metodologias qualitativa e quantitativa. Esse sinergismo possibilita a complementação de metodologias, favorecendo maior compreensão do problema estudado (CRESWELL; PLANO CLARK, 2007).

Creswell (2014, p. 4) define métodos mistos como a combinação de abordagens qualitativas e quantitativas que objetivam a compreensão mais completa de um problema de pesquisa do que qualquer abordagem isoladamente. Os métodos mistos refletem a constante evolução pela qual passa o campo da pesquisa, aliando-se ao fato de se constituir em uma abordagem que procura utilizar os pontos fortes de ambas as metodologias (quantitativa e qualitativa). Espera-se, com a utilização desta metodologia, encontrar respostas a problemas complexos, favorecendo as preferências de investigadores multidisciplinares (CRESWELL, 2011).

Os métodos mistos ou múltiplos promovem a concepção de novos insights e perspectivas de compreensão sobre os fenômenos na pesquisa de enfermagem. $\mathrm{O}$ uso de mais de um método oferece o potencial de entendimento mais profundo de complexos problemas da saúde frequentemente enfrentados, como é o caso neste estudo.

Os dados quantitativos foram utilizados de forma secundária, com o intuito de complementar a investigação, aumentando a gama de observações sobre o tema (DRIESSINACK; SOUSA; MENDES, 2007, p. 1049).

Associada ao método misto, realizou-se integração criteriosa de coleta de informações realizada por meio de pesquisa bibliográfica. Buscou-se, com essa estratégia, reunir conhecimentos sobre o tema em pauta, contribuindo para fundamentar, de forma significativa, o conhecimento no campo do estudo (WHITTEMORE; KNAFL, 2005). 
Creswell (2011) defende o diálogo entre os métodos, o que permite a combinação de fontes variadas de coleta de dados - questionário semiestruturado, entrevista, dados do prontuário dos participantes, observação -, bem como a utilização de métodos de análise distintos: análise descritiva e análise de conteúdo. Métodos associados diminuem as possibilidades de fragilidades existentes em abordagens individualizadas.

A utilização deste desenho favoreceu a aproximação do objeto de estudo a partir de diferentes abordagens, permitindo-se alcançar os objetivos propostos para a pesquisa.

Os resultados da pesquisa serão apresentados em duas modalidades: no formato de dois artigos e nos resultados da pesquisa qualitativa realizada com os profissionais de saúde. A metodologia proposta para cada fase do estudo está descrita detalhadamente nos artigos e nos resultados da pesquisa exploratória.

\subsection{LOCAL DE REALIZAÇÃO DO ESTUDO}

A instituição na qual foi realizado este estudo é um centro de referência para a realização do aborto previsto em lei na região Centro-Oeste do Brasil. Nesse serviço, o Programa do Aborto Previsto em Lei deveria ser constituído por uma equipe multiprofissional que tem como principal atributo acolher, proteger e fornecer cuidado biopsicossocial a mulheres e adolescentes que buscam o serviço nas seguintes situações: foram vítimas de violência sexual, se encontram em risco de morte materna, ou ainda receberam um diagnóstico de anencefalia fetal. Nesses casos, existe a prerrogativa para interrupção legal da gestação.

O serviço iniciou suas atividades no ano de 1996, tendo como base a Norma Técnica de Atenção humanizada ao abortamento, do Ministério da Saúde (BRASIL, 2011) que indicava uma equipe multiprofissional composta por assistente social, enfermeira, psicóloga e médico. Atualmente, a equipe é composta por apenas dois desses profissionais: médico e psicólogas. A norma técnica (2011) indica que os profissionais devem atender aos princípios da Bioética, como beneficência, não maleficência, justiça e autonomia.

Até o ano de 2014 havia uma equipe fixa, acima descrita, que atuava junto às mulheres e adolescentes, fornecendo os cuidados requeridos durante todo o processo, incluindo-se acolhimento e acompanhamento biopsicossocial antes e após a interrupção da gravidez. No período pós-interrupção, o acompanhamento é implementado apenas se a mulher 
ou adolescente concordar. A equipe fixa não efetuava acompanhamento constante das usuárias no momento da internação para o procedimento de interrupção da gestação.

Outra equipe de cuidado, existente até 2014, denominada aqui de equipe flutuante - composta por médicos(as), enfermeiras, técnicos(as) de enfermagem, psicóloga - atuava apenas no momento da interrupção gestacional, que coincidia com a escala de trabalho desses profissionais.

A partir de 2015, com a reestruturação interna, a equipe fixa efetivou o acompanhamento da mulher que busca o aborto previsto em lei, desde sua chegada ao serviço até a alta hospitalar, incluindo-se o momento do procedimento de interrupção da gravidez.

\subsection{PARTICIPANTES DO ESTUDO}

As equipes dos potenciais participantes deste estudo eram compostas por 125 profissionais, da qual faziam parte médicos, enfermeiras, técnicos de enfermagem, assistentes sociais e psicólogos.

O contato prévio realizado com 45 participantes ocorreu durante os plantões das equipes fixa e flutuante do programa de aborto previsto em lei, de acordo com a escala de trabalho de cada profissional. Após esse contato inicial, as entrevistas foram marcadas para um dos momentos de descanso dos voluntários que aceitaram participar deste estudo.

Problemas institucionais interferiram na participação da pesquisa. Aceitaram ser incluídos no estudo 10 profissionais que compunham a equipe flutuante e que atendiam aos critérios de inclusão descritos abaixo. Embora convidados, os membros da equipe fixa não aceitaram participar.

Alguns dos motivos alegados para a não participação na pesquisa foram os seguintes: "este é um assunto polêmico", "este tema ocasiona muito sofrimento", "não aceito a realização do procedimento de interrupção da gestação", além de vivências profissionais anteriores e que ocasionavam difíceis enfrentamentos pessoais e profissionais. 


\subsection{CRITÉRIOS DE INCLUSÃO}

Ser profissional de saúde lotado na instituição de referência para o aborto previsto em lei, ter atuado em algum momento do processo de abortamento legal, fazer parte da equipe fixa ou flutuante, aceitar participar da pesquisa por meio da assinatura do Termo de Consentimento Livre e Esclarecido.

\subsection{CRITÉRIOS DE EXCLUSÃO}

Não possuir vínculo empregatício com a instituição (no caso ser residente ou interno), não ter participado dos momentos relacionados ao processo do abortamento legal, não aceitar participar da pesquisa.

\subsection{ASPECTOS ÉTICOS}

A Resolução n. ${ }^{\circ}$ 466, de 12 de dezembro de 2012, do Conselho Nacional de Saúde, dispõe sobre pesquisas envolvendo seres humanos e aponta que é necessário prever procedimentos que assegurem a confidencialidade e a privacidade, a proteção da imagem e a não estigmatização (BRASIL, 2012).

O protocolo de pesquisa foi submetido para avaliação pelo Comitê de Ética em Pesquisa da Secretaria do Estado de Saúde do Distrito Federal (CEP/SES/DF). Foi considerado aprovado e recebeu o número 0475/2011. A coleta de dados teve início apenas após a sua aprovação. Houve uma emenda em 2013, a fim de estender o tempo de realização do estudo, para que houvesse o cumprimento dos objetivos específicos propostos no projeto (Anexo 1).

A pesquisadora principal ficou responsável por efetuar os contatos iniciais com as(os) participantes e realizar as entrevistas. Após o primeiro convite, foram fornecidas todas as informações relativas aos objetivos do estudo e aos procedimentos que seriam adotados para a coleta de dados e divulgação dos resultados. Foi efetuada a leitura do Termo de 
Consentimento Livre e Esclarecido (TCLE), esclarecendo-se aos profissionais de saúde todos os aspectos relativos às dúvidas que porventura surgiram nesse processo (Apêndice A).

Os documentos foram assinados em duas vias: uma ficou sob a posse dos(das) participantes e outra com a pesquisadora, para validar a realização de pesquisas e o tratamento de dados. Após a concordância e assinatura do TCLE, os documentos foram colocados em envelope lacrado e arquivados em local seguro.

As entrevistas foram realizadas em sala privativa, na qual estavam presentes apenas a pesquisadora e as(os) entrevistada(os). As entrevistas foram gravadas e transcritas pela própria pesquisadora como salvaguarda adicional de manutenção da confidencialidade. Por se tratar de tema delicado, o acesso às informações foi restrito para evitar o vazamento de dados, o que poderia expor os participantes.

\subsection{COLETA DE DADOS}

Para a coleta dos dados, utilizaram-se dois instrumentos. O primeiro foi composto por um roteiro que continha questões fechadas, relacionadas aos dados sociodemográficos dos entrevistados, e foi aplicado no início da entrevista (Apêndice B). O segundo instrumento denominado roteiro de entrevistas - era composto por questões abertas que tinham o objetivo de direcionar a realização da entrevista em profundidade, o que favoreceu a interlocução confidencial e íntima em algumas entrevistas (Apêndice C). Esse procedimento possibilitou que os entrevistados explicitassem ideias, situações e comportamentos, geralmente não relatados em entrevistas formais.

A escolha de roteiro de entrevistas composto por questões abertas evidencia a opção pelo método indutivo, aquele que busca os significados e não adota ideias, categorias, definições ou hipóteses pré-concebidas. Esse instrumento é especialmente apropriado para pesquisas qualitativas, por conferir descrição compreensiva em maior profundidade e leitura de significações, particularidades e complexidades (BARDIN, 2001; MINAYO, 2004).

As dificuldades com as quais o pesquisador poderia se deparar na condução das entrevistas puderam ser minimizadas com cuidado e técnicas adequadas à realização do procedimento (BAUER e GASKELL; 2002). O rapport, compreendido como a relação que se estabelece entre pesquisador e entrevistado, cria ambiente de confidencialidade e estabelece relação de confiança e de segurança. Realizar as perguntas com tranquilidade e utilizar-se de 
reforço e encorajamento favorecem o bem-estar do entrevistado e maior interação nesse momento.

\subsection{ANÁLISE DOS DADOS}

Os dados sociodemográficos foram analisados por meio de estatística descritiva sem, no entanto, serem efetuadas inferências e generalizações para um grupo populacional maior.

Nas observações conclusivas obteve-se a síntese da interpretação feita pela equipe de pesquisa das unidades textuais básicas. Em seguida, procedeu-se ao refinamento, com a classificação das temáticas que emergiram: categorias empíricas que, analisadas em relação à semelhança de significados, foram sistematizadas em categorias teóricas definidas conforme o delineamento apresentado pelos participantes e inferidas pela equipe de pesquisa. Essas categorias resultantes da análise de conteúdo foram validadas por três avaliadores distintos (juízes): a autora da pesquisa, uma pesquisadora enfermeira e uma psicóloga com expertise nesse tipo de abordagem, utilizando-se os mesmos recursos de avaliação.

O objetivo desse procedimento foi o de se obter informações e significados sobre a percepção individual de pessoas que vivenciam o aborto previsto em lei em suas práticas profissionais cotidianas.

\subsubsection{Análise de conteúdo}

A análise de conteúdo tem como definição a assertiva de que é representada por um conjunto de instrumentos utilizados para a compreensão e interpretação das diversas formas de comunicação, proposta metodológica de Laurence Bardin (2001). Essa metodologia é utilizada desde o século XX, inicialmente para análise jornalística e de propagandas relativas às primeira e segunda guerras mundiais e, posteriormente, introduzida nos campos das ciências políticas e da psicologia. Inicialmente, estava voltada para a análise de frequência das verbalizações, tendo sido aperfeiçoada ao longo do tempo, a partir da década de 1940.

Como método para análise de textos, a análise de conteúdo faz correlação entre os métodos quantitativos e qualitativos, uma vez que pode estar baseada na frequência com que 
emergem temas, palavras ou frases, dentro de uma categoria. Por outro lado, pode basear sua análise apenas nos núcleos de sentido presentes nas verbalizações (BAUER; GASKELL, 2002).

As características da análise de conteúdo permitem a codificação sistemática que autoriza a elaboração de "inferências a partir de um texto focal para o seu contexto social de maneira objetivada". O texto se transforma em informações prontas para a interpretação à luz dos materiais pesquisados e do objetivo do estudo (BAUER; GASKELL, 2002, p. 19).

Conhecer o processo que se desencadeia no momento de uma entrevista é importante para sua compreensão e interpretação. O discorrer da fala de quem é entrevistado traz à tona conflitos, incoerências, valores e atitudes nos quais os processos inconscientes mais profundos tomam forma durante as falas. É importante a desconfiança diante de descobertas, a vigilância científica e a utilização de técnicas que possam transpor as evidências e contribuir para a aproximação com o mundo real.

Bardin (2001), Bauer e Gaskell (2002), conceberam a comunicação como um processo e não apenas como dados a serem decodificados. Sua análise se baseia na interferência sobre os significados apresentados e que emergem na unidade de registro.

São várias as técnicas de análise de conteúdo e, dentre elas, a análise temática foi a escolhida para a obtenção de informações para esta investigação. Essa escolha ocorreu porque ser a técnica mais utilizada para acessar os dados resultantes da aplicação de entrevistas, na qual são analisados valores e crenças dos sujeitos. Foi, portanto, aquela mais relacionada com nosso objeto de estudo (BARDIN, 2001). Bardin enfatiza ainda que a análise do conteúdo em entrevista é muito complexa e, em alguns casos, determinados programas de computadores não podem tratá-las.

O tema é considerado uma unidade de significação presente em um texto e pode ser identificado a partir da teoria que serve de guia para o estudo. Bardin (2001) argumenta que sua validade não é de ordem linguística, mas psicológica. Pode constituir-se apenas a partir de uma afirmação, uma alusão ou proposições. Neste estudo, foi definido o tema como qualquer ideia ou pensamento expresso pela pessoa acerca de sua vida, sua condição atual, tanto individual como nos seus relacionamentos, nos quais se possam identificar núcleos de sentidos.

A etapa subsequente da análise é a mais comumente utilizada, denominada de “categorização dos temas identificados”, e pode ser realizada segundo vários critérios. Optouse pela organização das categorias a partir da sua estrutura semântica, isto é, das palavras e 
seus significados em determinado tema. Para realizar a categorização, é imprescindível a investigação sobre o que cada tema tem em comum com outros (BARDIN, 2001).

A definição das categorias é o processo central da análise de conteúdo, porém não é somente a partir delas que serão realizadas as interpretações das mensagens. O conteúdo do texto construído, assim como suas redes de significados e particularidades participam como um todo, no qual o que importa é o sentido do discurso (MENDES, 2002). A categoria deve ser aperfeiçoada até poder assumir status de indicador para a inferência, bem elaborada, qualificada e refinada.

Para atingir a melhor categorização neste estudo, observaram-se os critérios elaborados por Bardin (2001): exclusão mútua, que se refere ao fato de que cada tema só pode estar localizado em uma das categorias; homogeneidade em relação à identificação e à forma de análise em todas as categorias; pertinência ao material de análise e ao quadro teórico do estudo; objetividade e fidelidade dos juízes na identificação dos temas e das categorias; e, para finalizar, a produtividade em fornecer informações e inferências de hipóteses novas. 


\section{RESULTADOS}

Há grande quantidade de referenciais teóricos que abordam o aborto no Brasil, porém escassos são os que o fazem sobre o aborto previsto em lei e suas repercussões para a equipe de saúde, como o caso da Objeção de Consciência e conflitos internos entre os membros da equipe de saúde que atuam nessa área.

Os resultados aqui representados são frutos das reflexões, debates e análises sob diferentes perspectivas do tema abordado e serão apresentados em forma de artigos e de categorias temáticas.

\subsection{ARTIGO 1: OBJEÇÃO DE CONSCIÊNCIA E ABORTO LEGAL SOB A PERSPECTIVA DA SAÚDE: REVISÃO INTEGRATIVA}

Objeção de consciência e aborto legal sob a perspectiva da saúde: revisão integrativa: Neves MGC, Guilhem DB, Lago DMSK, Rodrigues SG. Rev Enferm UFPE on line. v. 8, n. 6, p. 1774-1981, 2014.

Este artigo responde ao seguinte objetivo específico desta tese: 1) Realizar revisão integrativa da literatura científica de autores brasileiros sobre Objeção de Consciência e sua interface com o aborto previsto em lei 


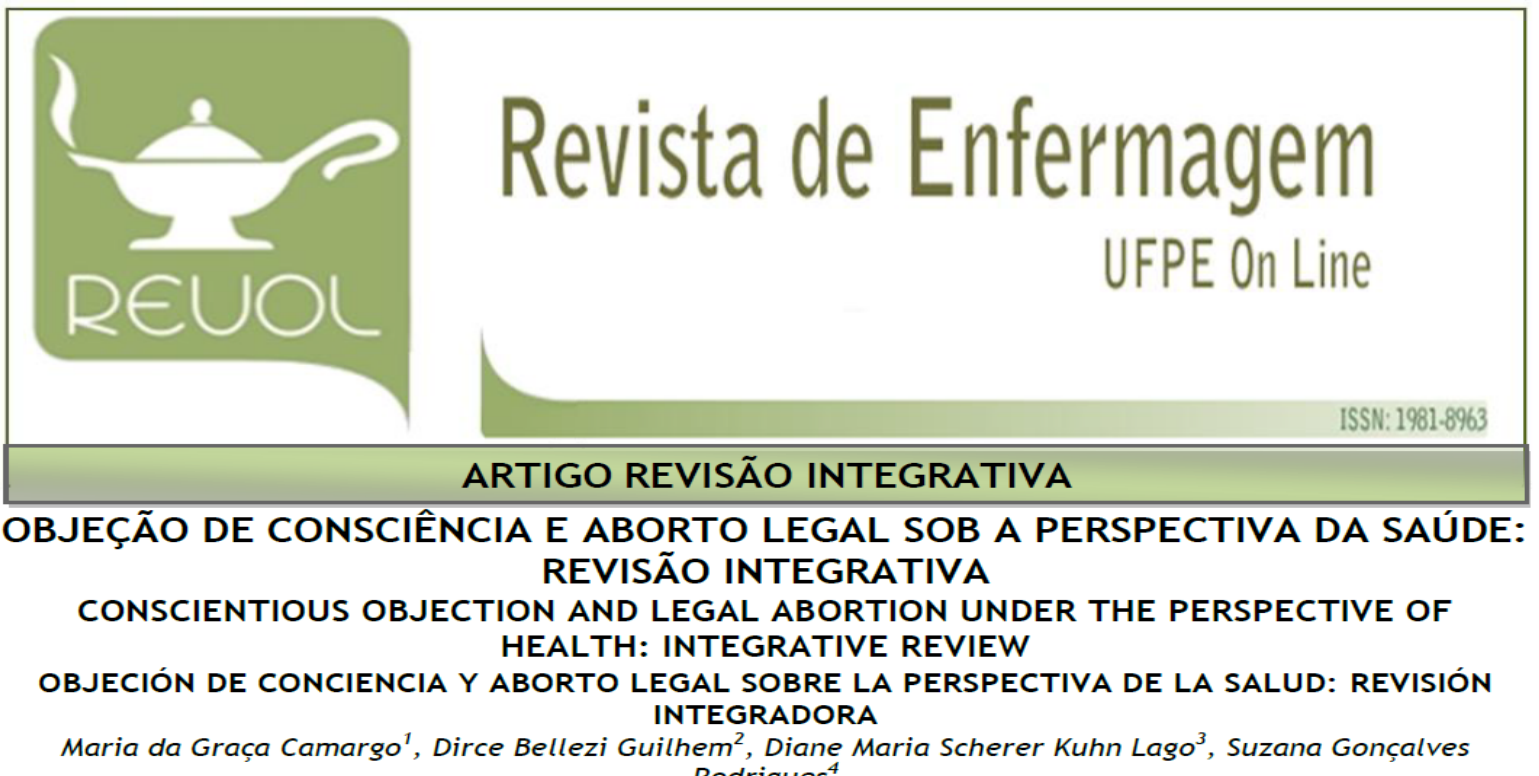

\section{RESUMO}

Rodrigues

Objetivo: analisar as produções científicas brasileiras sobre a utilização do conceito objeção de consciência no cenário do aborto legal. Método: revisão integrativa, que partiu da seguinte questão << Qual é o conhecimento científico produzido por autores brasileiros acerca da apropriação do conceito Objeção de Consciência por parte dos profissionais de saúde no contexto do aborto previsto em lei? >> Foi realizada uma busca nas bases de dados LILACS, MEDLINE, BDENF e bibliotecas virtuais Cochrane e SciELO. Identificaram-se cinco artigos que representam a amostra do estudo, segundo o nivel de evidência. Resultados: existe ainda apropriação incipiente do conceito Objeção de Consciência por profissionais da saúde, sendo que os enfermeiros ancoram seu significado baseando-se no Código de Ética dos Profissionais de Enfermagem. Conclusão: a avaliação estrutural crítica e detalhada dos artigos indicam que os enfermeiros apresentam maior dificuldade para compreender o direito à Objeção de Consciência pela pouca apropriação de seu conceito. Descritores: Aborto Legal; Pessoal de Saúde; Equipe de Enfermagem; Conhecimentos, Atitudes e Prática em Saúde; Bioética.

\section{ABSTRACT}

Objective: to analyze the Brazilian scientific papers on the use of the concept of conscientious objection on the set of legal abortion. Method: an integrative review, which left the following question << What is the scientific knowledge produced by Brazilians about the appropriation of the concept Conscientious Objection by health professionals in the context of abortion provided by law?>> A search in LILACS, MEDLINE, Cochrane BDENF and virtual libraries and SciELO databases was performed. We identified five articles that represent the study sample according to level of evidence. Results: there is an incipient appropriation of the concept Conscientious Objection by health professionals where the nurses anchor the meanings based on the Code of Ethics for Professional Nursing. Conclusion: a critical and detailed structural assessment of the reports indicate that nurses are more difficult to understand the right to Conscientious Objection by little appropriation of their concept. Descriptors: Legal Abortion; Health Personnel; Nursing Staff; Knowledge, Attitudes and Practice; Bioethics.

\section{RESUMEN}

Objetivo: analizar las producciones científicas brasileñas sobre la utilización del concepto objeción de conciencia en el ecenario del aborto legal. Método: revisión integradora, que surgió de la seguiente pregunta $<$ ¿Cuál es el conocimiento científico producido por autores brasileños acerca de la apropriación del concepto Objeción de Conciencia por parte de los profesionales de salud en el contexto del aborto previsto en la ley? >> Fue realizada una búsqueda em las bases de datos LILACS, MEDLINE, BDENF y bibliotecas virtuales Cochrane y SciELO. Se identificaron cinco artículos que representan la muestra del estudio, según el nivel de evidencia. Resultados: existe también la apropriación incipiente del concepto Objeción de Conciencia por profesionales de la salud, siendo que los enfermeros basan su significado en el Código de Ética de los Profesionales de Enfermería. Conclusión: la evaluación estructural crítica y detallada de los artículos indican que los enfermeros presentan mayor dificultad para comprender el derecho a la Objeción de Conciencia por la poca apropiación de su concepto. Descriptors: Aborto Legal; Personal de Salud; Equipo de Enfermería; Conocimientos, Actitudes y Práctica en Salud; Bioética.

${ }^{1}$ Enfermeira, Mestre em Ciências da Saúde, Doutoranda em Enfermagem, Universidade de Brasília/UnB. Brasília (DF), Brasil. E-mail: gracacamargo@uol.com.br; ${ }^{2}$ Enfermeira, Professora Titular, Pós-Doutora, Departamento de Enfermagem/Programa de Pós Graduação em Enfermagem, Universidade de Brasília/ UnB. Brasília (DF), Brasil. Email: guilhem@unb.br; ${ }^{3}$ Enfermeira, Professora, Curso de Graduação

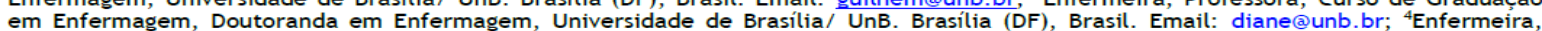
Escola Superior de Ciências da Saúde, Universidade de Brasília/ UnB. Brasília (DF), Brasil. Email: suzanarodriguesyeah@gmail.com 
Camargo MG, Guilhem DB, Lago DMSK et al.

INTRODUÇÃO

A contemporaneidade contribuiu para o surgimento de sociedades pluralistas e laicas em muitos países, postura que foi acompanhada pelo Brasil. 0 pluralismo pressupõe a convivência de diversidades morais, o que pode ocasionar conflitos de distintas origens.

Nesse cenário, a bioética emerge como uma possibilidade de mediação dos conflitos morais ao tomar como referência os princípios da autonomia, justiça, não maleficência e beneficência, entre outros que poderiam ser mencionados. Ao mesmo tempo em que busca promover a justiça social, assume papel de mediadora em embates ideológicos, morais, religiosos e filosóficos, contribuindo, assim, para garantir a separação entre o Estado Laico e a Igreja. ${ }^{1,2}$ Talvez, um dos principais avanços nesse contexto tenha sido o de assegurar o exercício à Objeção de Consciência, compreendida como o direito à liberdade de pensamento, consciência e religião, embora este último tenha critérios mais específicos quanto a sua utilização. Esse é um tema que se apresenta de múltiplas formas, começa a ser amplamente debatido e tem repercussões inequívocas no contexto da atenção à saúde. ${ }^{3}$

A Objeção de Consciência revela-se como mecanismo capaz de contribuir para a humanização no campo da saúde, pois embasa os profissionais no estabelecimento de relações marcadas pelo respeito à diversidade de culturas, crenças, valores e convicções individuais, tão característicos de uma sociedade pluralista e tolerante. Essa ferramenta tem sido utilizada, também, por profissionais de saúde quando suas crenças pessoais vão de encontro aos procedimentos que deverão ser dispensados no processo de atenção à saúde das populações. Os códigos de ética profissionais oferecem respaldo para as posturas decorrentes de Objeção de Consciência desde que não se contraponham ao direito dos pacientes atendidos nos serviços, especialmente às mulheres nas questões relacionadas aos direitos sexuais e reprodutivos. ${ }^{1,4,5}$

Há um argumento de que os enfermeiros podem "lançar mão" da Objeção de Consciência e usufrui-la, de preferência, quando a equipe de plantão está completa. ${ }^{6.9}$ Caso contrário, alegar Objeção de Consciência poderá gerar uma experiência hostil entre o profissional e $\circ$ paciente, 0 que poderá ser compreendido como desconsideração pela seguranç, direitos e cuidados que the devem ser dispensados. Uma situação como essa
Objeção de consciência e aborto legal sob...

pode ocasionar ainda dificuldade para o gerenciamento da equipe. ${ }^{6}$

Soma-se a esse pensamento, a ideia da Objeção de Consciência compreendida como "opt out" (expressão inglesa que significa "optar por fora", "afastar-se”), e na presença do crescente avanço tecnológico, poderá ocasionar dificuldades para proporcionar todos os cuidados de saúde que as pessoas necessitam. ${ }^{10}$ O aumento na sua utilização levanta questionamentos sobre como deve ser considerada: direito ou privilégio, a depender do momento em que é requerida pelos profissionais.

Debates mais recentes, procedentes da Universidade de Oslo, defendem cinco critérios que necessitam ser cumpridos para que uma pessoa possa ser considarada um objetor de consciência, ser aceita na sociedade e, ainda, manter-se moralmente aceitável. $^{11} 0$ potencial objetor de consciência se depara com duas situações importantes: por um lado, está a necessidade de manter a integridade profissional com o objetivo de proteger sua saúde moral, fundamento legítimo para sua saúde. Por outro, encontra-se o direito da sociedade de receber cuidados de saúde de forma humanizada e respeitosa.

Os critérios apontados abrangem as seguintes situações: 1) os cuidados dispensados aos pacientes podem prejudicar seriamente a saúde e a integridade moral e profissional do cuidador, que considera o procedimento uma violação grave; 2) o posicionamento de ser um objetor deve estar baseado em uma justificativa moral ou religiosa plausível; 3) o tratamento não é considerado emergencial para o usuário que está sob os cuidados do profissional da saúde que assume o papel de objetor; 4) a postura adotada não acarretará riscos à saúde do paciente; 5) a solicitação para que outros colegas realizem os procedimentos não acarreta encargos adicionais para os mesmos. ${ }^{11}$

Diferentemente do que ocorre em países europeus, norte-americanos e até mesmo na Oceania, onde o tema da Objeção de Consciência é discutido há algumas décadas, este assunto tem sido pouco debatido entre profissionais de saúde, pesquisadores e sociedade brasileira. É mais frequentemente associado a questões relacionadas ao início da vida, embora ainda suscite muitas controvérsias. $^{12}$

É justamente o que ocorre na prática do Aborto Previsto em Lei (Aborto Legal) quando - profissional de saúde pode posicionar-se como objetor de consciência e negar-se a 
Camargo MG, Guilhem DB, Lago DMSK et al.

participar do procedimento de interrupção da gravidez. 0 Ministério da Saúde indica que em caso de gravidez decorrente de violência sexual é direito das mulheres e adolescentes, bem como de seus representantes legais, serem informadas (os) tanto sobre a possibilidade de interrupção da gravidez, conforme previsto no Código Penal Brasileiro, como do direito de mantê-la até seu término, optando pela doação ou não do recémnascido. ${ }^{13}$ No entanto, independente da decisão da mulher ou adolescente, os cuidados para a realização do aborto ou os cuidados pré-natais thes serão garantidos.

A violência sexual mantém-se de forma crescente no Brasil, originando-se nas relações desiguais de poder. Com o passar dos tempos, essa violência tomou proporções maiores, afetando a sociedade como um todo, além de afetar 0 indivíduo isoladamente, gerando traumas de difícil reversão. ${ }^{14}$ Neste sentido, múltiplos esforços têm sido realizados no Brasil no que diz respeito à atuação em violência sexual sob forma de redes de atenção. ${ }^{15}$ Algumas vezes, a violência sexual resulta em uma gravidez indesejada, inesperada, que se destaca pela complexidade de reações psicológicas, sociais e biológicas e é encarada como uma segunda violência, intolerável para muitas mulheres. ${ }^{13}$

No Brasil, a interrupção legal da gestação em mulheres adultas não está condicionada à decisão judicial, apresentação de boletim de ocorrência policial ou mesmo ao laudo do exame de corpo de delito. Dessa forma, não há sustentação legal para que os serviços de saúde neguem a realização do procedimento, embora alguns profissionais se recusem a realizá-lo, alcançando respaldo nos códigos de ética profissionais da Enfermagem e Medicina. ${ }^{16,17}$

O Brasil possui 557 serviços de acolhimento a mulheres vítimas de violência sexual. Desses, 63 realizam o Aborto Previsto em Lei e outros 30 recebem hoje, capacitação para tal. Porém, até o momento, poucos são os relatos de pesquisas realizadas quanto à utilização da Objeção de Consciência por parte de equipe de saúde que dispensa cuidados às mulheres que buscam o Aborto Previsto em Lei quando vítimas de violência sexual. ${ }^{18}$ Considerando-se o acima exposto, o nosso objetivo principal é:

- Analisar produções científicas brasileiras sobre a utilização do conceito Objeção de Consciência no cenário do aborto legal.

MÉTODO

Trata-se de revisão integrativa com coleta de informações criteriosa realizada por meio
Objeção de consciência e aborto legal sob...

de pesquisa bibliográfica, considerada uma das melhores formas de se iniciar um estudo.

0 propósito geral de uma pesquisa que utiliza a revisão de literatura é o de reunir conhecimentos sobre determinado assunto, contribuindo para fundamentar de forma significativa o conhecimento no campo da Enfermagem, neste caso a vinculação entre Objeção de Consciência e Aborto Legal. ${ }^{19} \mathrm{~A}$ revisão integrativa é um dos instrumentos da Prática Baseada em Evidências, que é definida como o cuidado guiado pelos resultados de pesquisa, consenso de especialistas ou combinação de ambos. ${ }^{20}$

Essa pesquisa cumpriu cinco fases estabelecidas para elaboração da revisão integrativa ${ }^{21}$ a partir da seguinte pergunta: qual é o conhecimento científico produzido por autores brasileiros acerca da apropriação do conceito Objeção de Consciência por parte dos profissionais de saúde no contexto do aborto previsto em lei? Essa fase foi delineada para se obter uma clara identificação do problema e do propósito desta pesquisa com objetivo de delimitar o foco e o alcance para - processo da revisão integrativa.

Para coleta de dados utilizaram-se as seguintes bases de dados: Literatura LatinoAmericana e do Caribe em Ciências da Saúde (LILACS), Medical Literature Analysis and Retrieval System Online (Medline), Base de Dados de Enfermagem (BDENF), bibliotecas virtuais Scientific Electronic Library Online (SciELO) e Cochrane.

Os artigos foram selecionados nos meses de setembro e outubro de 2012, analisados criticamente após sua leitura na íntegra. Para sistematizar $\circ$ procedimento e garantir adequada análise qualitativa dos estudos, foi utilizado instrumento de coleta de dados específico para o tipo de método.

Para refinamento da pesquisa, a amostra foi definida a partir dos seguintes critérios de inclusão dos artigos: terem sido publicados a partir do ano 2000 e estarem disponíveis online em texto completo, possuírem em sua autoria pelo menos um autor brasileiro, abordarem o tema da Objeção de Consciência no Brasil, que contivessem como descritores controlados: "Aborto Legal" (Aborto Previsto em Lei) coexistindo com "Pessoal de Saúde" ou "Conhecimentos, Atitudes e Práticas em Saúde" ou "Bioética" ou "Equipe de Enfermagem" ou "Ética" ou "Violência Sexual" ou "Estupro", e como descritor não controlado: "Objeção de Consciência", os quais foram cruzados entre si. 0 aumento do quantitativo de descritores para coleta objetivou garantir uma busca aperfeiçoada dos artigos nas bases de dados. 
Camargo MG, Guithem DB, Lago DMSK et al.

Os critérios de exclusão ficaram assim definidos: artigos brasileiros e internacionais disponiveis online sem disponibilidade do texto completo ou artigos publicados antes do ano 2000 ou artigos nas seguintes modalidades: editorial, resumo de teses, dissertações ou monografias, ou aqueles que, após análise, apresentaram escore abaixo de quatro, segundo critérios pré-estabelecidos pelo CASP. Os requisitos apontados contribuíram para definir as estratégias de pesquisa, que bem definidas, foram fundamentais para manter o rigor do estudo.

Elaborou-se um instrumento para coleta e análise de dados que contemplava os seguintes aspectos: periódico, autor(es), formação acadêmica, estudo e ano de publicação, método do estudo, abordagem, o que permitiu o ordenamento, codificação, categorização e elaboração do resumo para que fosse efetivada uma interpretação completa e imparcial das informações coletadas. Os artigos selecionados foram analisados criticamente por juizes, utilizandose três instrumentos:

1) Programa de habilidades em leitura crítica (do inglês, Critical Appraisal Skills Programme-CASP), que integra a Unidade de Recursos em Saúde Pública (do inglês, Public Health Resource Unit-PHRU) do Reino Unido. 0 instrumento é composto por 10 itens, com escore de um ponto por item (máximo de 10 pontos), que abrangem os seguintes aspectos: 1) objetivo; 2) adequação metodológica; 3) apresentação dos procedimentos teóricos e metodológicos; 4) seleção da amostra; 5) procedimento para a coleta de dados; 6) relação entre pesquisador e pesquisados; 7) consideração sobre os aspectos éticos; 8) procedimento para a análise dos dados; 9) apresentação dos resultados; 10) importância da pesquisa. Segundo esses critérios, préestabelecidos pelo CASP, os estudos foram
Objeção de consciência e aborto legal sob...

classificados de acordo com suas pontuações: 06 a 10 pontos (boa qualidade metodológica e viés reduzido) e mínima de 5 pontos (qualidade metodológica satisfatória, porém com risco de viés aumentado). ${ }^{22}$

2) Classificação Hierárquica das Evidências para Avaliação dos Estudos. ${ }^{22,23}$ Essa proposta contempla os seguintes níveis: 1) revisão sistemática ou metanálise; 2) ensaios clínicos randomizados; 3) ensaio clínico sem randomização; 4) estudos de corte e de casocontrole; 5) revisão sistemática de estudos descritivos e qualitativos; 6) único estudo descritivo ou qualitativo; 7) opinião de autoridades e/ou relatório de comitês de especialidades.

3) Fator de Impacto: uma das maneiras de avaliar a qualidade de uma publicação consiste em verificar o nível de interesse dos outros pesquisadores pela pesquisa. 0 método para se obter essa medida se dá por meio da quantidade de citações do artigo nas referências de outros autores em seus trabalhos. O Fator de Impacto (FI) é um sistema que determina a quantidade de vezes que uma publicação é citada em certo período de tempo, dividida pela quantidade de artigos publicados nesse mesmo período. ${ }^{24}$

\begin{tabular}{|l|l|}
\hline \multicolumn{2}{ll}{ RESULTADOS E DISCUSSÃO } \\
\hline Inicialmente serão apresentados os
\end{tabular}
resultados da revisão no que se referem às fontes, características e seleção dos artigos elegidos (Figura 1). Após essa etapa, foi efetuada a análise crítica dos estudos incluídos com o objetivo de favorecer o estabelecimento dos links no que se relaciona aos conteúdos dos artigos.

\begin{tabular}{|ccccccccc|}
\hline Base de Dados & \multicolumn{2}{c|}{ Artigos encontrados } & \multicolumn{2}{c|}{ Artigos Pré- Selecionados } & \multicolumn{2}{c|}{ Excluídos } & \multicolumn{3}{c|}{ Incluídos } \\
\cline { 2 - 9 } & $\mathrm{n}$ & $\%$ & $\mathrm{n}$ & $\%$ & $\mathrm{n}$ & $\%$ & $\mathrm{n}$ & $\%$ \\
\hline SCIELO & 21 & 2,1 & 5 & 16,1 & 2 & 10,5 & 3 & 25 \\
BDENF & 4 & 0,4 & 4 & 12,9 & 2 & 10,5 & 2 & 16,6 \\
COCHRANE & 1 & 0,1 & 0 & 0 & 0 & 0 & 0 & 0 \\
LILACS & 197 & 20,4 & 15 & 48,3 & 10 & 52,6 & 5 & 41,6 \\
MEDLINE & 740 & 76,8 & 7 & 22,5 & 5 & 26,3 & 2 & 16,6 \\
\hline Total & 963 & 100 & 31 & 100 & 19 & 100 & 12 & 100 \\
\hline
\end{tabular}

Figura 1. Quantitativo de artigos encontrados, pré-selecionados, excluídos e incluídos segundo busca nas bases de dados. Brasília-DF, 2012.

A Figura 1 expõe na coluna denominada Artigos Encontrados $\circ$ resultado dos cruzamentos entre o descritor Aborto Legal com os que se seguem: 1) Bioética: foram localizados três artigos, apenas na base Scielo; 2) Pessoal de Saúde: localizaram-se 544 textos, sendo 532 na Medline, 11 na Lilacs, e um na Scielo; 3) Conhecimentos,
Atitudes e Práticas em Saúde: sem achados; 4) Estupro: foram encontrados 155 artigos, sendo 117 na Medline, 32 na Lilacs, cinco na Scielo, e um na BDEnf; 5) Violência Sexual: obteve-se 54 textos, sendo 10 na Medline, três na Scielo, 40 na Lilacs, e um na BDENF; 6) Ética: encontraram-se 165 artigos, sendo 81 na Medline, seis na Scielo, 76 na Lilacs, e um na 
BDEnf; 7) Equipe de Enfermagem: totalizou 34 artigos, sendo 33 na Lilacs e um na BDEnf. Para o descritor não controlado Objeção de Consciência obteve-se um total de oito artigos, sendo três na Scielo e cinco na Lilacs.

$\mathrm{Na}$ coluna Pré-selecionados constam os artigos que contemplavam os critérios de inclusão, os quais foram lidos integralmente a fim de se encontrar alguma inferência sobre Objeção de Consciência ou seu conceito e utilização no Brasil. A coluna denominada Incluídos retrata a adequação do estudo a todos os critérios de inclusão desta pesquisa. Durante o levantamento nas bases de dados, observou-se a necessidade da inclusão de outros descritores, com o objetivo de garantir a maior abrangência, incluindo-se maior número de estudos, como forma de garantir segurança e fidedignidade.
Alguns aspectos merecem menção especial: foram encontrados artigos que abordavam no título, resumo e descritores determinados temas não contemplados durante a leitura integral do texto, o que dificultou a avaliação e a seleção dos artigos nos critérios de inclusão desta pesquisa. No que diz respeito aos descritores, observou-se que sua delimitação por parte dos autores nem sempre correspondia à terminologia adotada nos Descritores em Ciências da Saúde (DeCS) da Biblioteca Virtual em Saúde ou no Medical Subject Headings (MeSH) e, tampouco, a indicação de descritores não controlados. Os artigos encontrados em mais de uma base de dados foram descartados, mantendo-se apenas uma de suas vinculações.

\begin{tabular}{|c|c|c|c|c|}
\hline $\begin{array}{l}\text { Autor } \\
\text { Formação } \\
\text { Acadêmica }\end{array}$ & Título & Periódico & $\begin{array}{l}\text { Método (tipo de } \\
\text { pesquisa } \\
\text { instrumento de coleta } \\
\text { de dados) }\end{array}$ & Ano \\
\hline $\begin{array}{l}\text { Lunardi } V L \text {, } \\
\text { Simões } A R^{25} \\
\text { Enfermagem }\end{array}$ & $\begin{array}{l}\text { (Re) Ações da equipe de enfermagem } \\
\text { frente à possibilidade de participação em } \\
\text { um aborto legal. }\end{array}$ & $\begin{array}{lc}R & \text { Enferm } \\
2004 ; 12: 173-8 .\end{array}$ & $\begin{array}{ll}\text { Qualitativa. } & \\
\text { Entrevista } & \text { semi- } \\
\text { estruturadas. } & \end{array}$ & 2004 \\
\hline $\begin{array}{l}\text { Higa R, Reis MJ, } \\
\text { Lopes } M^{2} M^{28} \\
\text { Enfermagem }\end{array}$ & $\begin{array}{l}\text { Interrupção legal da gestação decorrente } \\
\text { de estupro: assistência de enfermagem às } \\
\text { mulheres atendidas num serviço público } \\
\text { da cidade de Campinas-SP. }\end{array}$ & $\begin{array}{l}\text { Cienc Cuid Saude 2007; } \\
6(3): 372-6 \text {. }\end{array}$ & Não descrito no artigo & 2007 \\
\hline $\begin{array}{l}\text { Bedone AJ, } \\
\text { Faundes } \mathrm{A}^{26} \\
\text { Medicina }\end{array}$ & $\begin{array}{l}\text { Atendimento integral às mulheres vitimas } \\
\text { de violência sexual: Centro de Assistência } \\
\text { Integral à Saúde da Mulher, Universidade } \\
\text { Estadual de Campinas-SP. }\end{array}$ & $\begin{array}{l}\text { Cad. Saúde Pública, } \\
\text { 2007;23(2):465-9 }\end{array}$ & Não descrito no artigo & 2007 \\
\hline $\begin{array}{l}\text { Diniz } D^{12} \\
\text { Ciências Sociais }\end{array}$ & $\begin{array}{l}\text { Objeção de consciência e aborto: direitos } \\
\text { e deveres dos médicos na saúde pública. }\end{array}$ & $\begin{array}{l}\text { Rev Saúde Pública, } \\
\text { 2011; 45(5):981-5. }\end{array}$ & Não descrito no artigo & 2011 \\
\hline $\begin{array}{l}\text { Farias RS, } \\
\text { Cavalcanti LF } \\
\text { Serviço Social e } \\
\text { Direito. }\end{array}$ & $\begin{array}{l}\text { Atuação diante das situações de aborto } \\
\text { legal na perspectiva dos profissionais de } \\
\text { saúde do Hospital Municipal Fernando } \\
\text { Magalhães. }\end{array}$ & $\begin{array}{l}\text { Ciência \& Saúde } \\
\text { Coletiva, } \\
\text { 2012;17(7):1755- } \\
63,2012 \text {. }\end{array}$ & $\begin{array}{l}\text { Métodos mistos: } \\
\text { quantitativa } \\
\text { qualitativa. } \\
\text { Análise documental } \\
\text { institucional, } \\
\text { entrevistas semi- } \\
\text { estruturadas. }\end{array}$ & 2012 \\
\hline
\end{tabular}

Figura 2. Apresentação sintética dos itens que constavam no instrumento de coleta dos dados. Brasilia-DF, 2012.

A formação dos profissionais indicados na figura 2 foi pesquisada na Plataforma Lattes do Conselho Nacional de Desenvolvimento Científico e Tecnológico (CNPq). Quanto ao desenho metodológico, ressalta-se a necessidade de maior nitidez ou mesmo descrição do método adotado pelo estudo, assim como melhor aderência aos requisitos exigidos pelos periódicos.

Esses aspectos foram alvo de muitos debates entre os juizes que avaliaram os artigos, inclusive conjecturando sobre possíveis métodos aplicados, onde dois deles apresentavam características de relato de experiência e o terceiro como comentário ou editorial, não explicitados pelos autores, entre os artigos analisados. 
Figura 3. Apresentação da análise crítica dos estudos incluídos determinando o CASP, Nivel de Evidência e Fator de

\begin{tabular}{|c|c|c|c|c|}
\hline Título do artigo & Objetivo Geral & $\begin{array}{c}\text { Nivel de } \\
\text { Evidência }\end{array}$ & $\begin{array}{l}\text { Fator de } \\
\text { Impacto }\end{array}$ & CASP \\
\hline $\begin{array}{l}(\mathrm{Re}) \text { Ações da equipe de enfermagem } \\
\text { frente à possibilidade de participação } \\
\text { em um aborto legal }\end{array}$ & $\begin{array}{l}\text { Compreender como a equipe de } \\
\text { enfermagem (re) age frente à possibilidade } \\
\text { de participar da realização de um aborto } \\
\text { legal. }\end{array}$ & 6 & $\begin{array}{c}\text { Não } \\
\text { encontrado }\end{array}$ & A \\
\hline $\begin{array}{l}\text { Interrupção legal da gestação } \\
\text { decorrente de estupro: assistência de } \\
\text { enfermagem às mulheres atendidas } \\
\text { num serviço público da cidade de } \\
\text { Campinas-SP }\end{array}$ & $\begin{array}{l}\text { Descrever a assistência de Enfermagem, no } \\
\text { CAISM/Unicamp, à mulher que sofreu } \\
\text { violência sexual e optou pela interrupção } \\
\text { legal da gestação decorrente de estupro. }\end{array}$ & - & $\begin{array}{c}\text { Não } \\
\text { encontrado }\end{array}$ & B \\
\hline $\begin{array}{l}\text { Atendimento integral às mulheres } \\
\text { vitimas de violência sexual: Centro de } \\
\text { Assistência Integral à Saúde da } \\
\text { Mulher, Universidade Estadual de } \\
\text { Campinas }\end{array}$ & Não há & 7 & 0,7510 & A \\
\hline $\begin{array}{l}\text { Objeção de consciência e aborto: } \\
\text { direitos e deveres dos médicos na } \\
\text { saúde pública }\end{array}$ & $\begin{array}{l}\text { Discutir o dispositivo da objeção de } \\
\text { consciência por médicos, tendo por } \\
\text { situação concreta os serviços de aborto } \\
\text { legal. }\end{array}$ & 7 & 1,0540 & $B$ \\
\hline $\begin{array}{l}\text { Atuação diante das situações de } \\
\text { aborto legal na perspectiva dos } \\
\text { profissionais de saúde do Hospital } \\
\text { Municipal Fernando Magalhães. }\end{array}$ & $\begin{array}{l}\text { Analisar as percepções dos profissionais de } \\
\text { saúde do Hospital Municipal Fernando } \\
\text { Magalhães (HMFM) sobre a atuação diante } \\
\text { das situações de aborto legal. }\end{array}$ & 6 & 0,5220 & B \\
\hline
\end{tabular}

Impacto, Brasilia-DF, 2012.

Quanto ao Fator de Impacto, em dois periódicos com Qualis B1 essa informação não estava disponível, o que limitou a avaliação crítica do processo utilizado. Dois dos artigos restantes foram publicados em periódicos pertencentes ao estrato $A 2$ e um ao B1. Nesses casos o fator de impacto foi coletado considerando-se o período de três anos, tomando-se 2012 como ano-base.

A análise para a determinação do nível de evidência - que é fundamentada na abordagem metodológica adotada para o desenvolvimento do estudo -, e o CASP - que tem como objeto avaliativo a adequação da estrutura do texto - encontrou barreiras para sua definição quando o artigo apresentava pouca consistência no que se relacionava ao desenho metodológico. Outros aspectos dificultadores foram a indeterminação dos objetivos, aspectos éticos não descritos, ausência na elucidação sobre a seleção. Observou-se, ainda, alta incidência de inconsistências na apresentação dos objetivos, resultados e considerações finais. Além disso, ficaram evidenciadas lacunas na descrição sobre a relevância da pesquisa e a necessidade de aprimoramento no campo do estudo.

0 vínculo entre objeção de consciência e aborto legal no Brasil é abordado de forma escassa pelos autores e quando o fazem, estabelecem apenas sua conexão com os códigos de ética dos profissionais, mais especificamente nas áreas da enfermagem e da medicina. O termo objeção de consciência, propriamente dito, foi abordado em dois artigos, nos quais os autores eram provenientes do campo das Ciências Sociais, do Serviço Social e do Direito.
Os outros três artigos apresentaram o posicionamento dos profissionais de saúde para o enfrentamento do aborto legal, que deveria ser 0 de aceitação da realidade vivenciada como expresso nas seguintes verbalizações:

Eu não tenho que resolver nada, eu tenho que acatar as decisóes para o procedimento (E1b). Não tem como se negar, vem com tudo para fazer aborto é o médico que faz tudo, nós só fazemos o que está prescrito (AEf). ${ }^{25}$

Existe dificuldade de posicionar-se, devido à submissão história e a falta de autonomia profissional vivenciada pelos enfermeiros. No entanto, está explícito no Código de Ética dos Profissionais de Enfermagem que a equipe pode optar por participar ou não dos procedimentos requeridos para a realização do aborto legal.

Há referências contraditórias relacionadas à conscientização dos profissionais para aceitar a prática do aborto legal, mas que devem estar submetidas aos ditames da consciência pessoal. ${ }^{26}$ Um dos principais conflitos que impulsionam à negativa para participação no aborto previsto em lei diz respeito à influência que a religião imprime na concepção daquilo que seria certo ou errado para delimitar as atitudes das pessoas. ${ }^{27-8} 0$ profissional considera errada a conduta das pessoas que se submetem ao aborto legal, independente da sua presença no serviço.

Um dos artigos analisados "Objeção de consciência e aborto: direitos e deveres dos médicos na saúde pública"12 propõe a construção e utilização de uma terceira tese denominada justificação, formulada à luz de duas outras: tese da incompatibilidade e tese 
da integridade, onde a autora infere que o direito à objeção de consciência por parte da classe médica não é absoluto para o fim de trazer menos danos à saúde da mulher.

CONSIDERAÇÕES FINAIS

Os achados mostraram que os profissionais da saúde possuem poucos conhecimentos sobre a utilização da Objeção de Consciência no contexto de realização do aborto legal no Brasil. A reflexão sobre as atitudes e práticas diárias não thes permite transpor os limites impostos pela necessidade do cumprimento de seus deveres e obrigações, preferem ir de encontro à sua consciência e resolver logo a questão, ○ que afastaria $\circ$ problema até $\circ$ próximo evento.

No que se refere à equipe de enfermagem, persiste um questionamento: existe déficit na compreensão do código de ética ou ausência de empoderamento para atuar como enfermeiro assumindo prerrogativas inerentes ao exercício da profissão? É de fundamental importância o conhecimento aprofundado do código de ética, instrumento essencial para subsidiar atitudes profissionais no contexto das práticas cotidianas dos serviços de saúde.

Para a medicina aparece, também, um déficit na compreensão do Código Penal, ocasionando sofrimento que se reflete na necessidade de participar de procedimentos considerados ilegais pelos profissionais, mas que são realizados por temor de que possam acarretar demandas judiciais.

Uma das principais dificuldades encontrada por autoras e juizes para efetuar a avaliação dos artigos foi a fragilidade no estabelecimento da necessária coerência que deve existir entre os distintos elementos que compõem um artigo: título, descritores, resumo e objetivo, metodologia e resultados, discussão e conclusão. Esse fato nos permite tecer considerações sobre a importância da estrutura textual, o que contribuirá para composições harmônicas e fiéis ao escopo proposto nos periódicos.

O tema da objeção de consciência necessita de aprofundamento, discussão e pesquisas que contribuam para $o$ aumento no número de artigos publicados e da inserção de novos autores provenientes da área da saúde que possam cooperar para a ampliação do debate entre os profissionais de diferentes campos de atuação e nos serviços de saúde. Além disso, a sociedade em geral deve aproximar-se desse tema tanto para respeitar a postura adotada pelos profissionais (objetor de consciência), quanto garantir o direito de atenção qualificada e digna para mulheres e adolescentes que precisam se submeter ao aborto previsto em lei.

Por fim, propõe-se a inserção do termo objeção de consciência como um descritor controlado, fato que talvez incentive a ampliação de estudos sobre o tema por autores da saúde no Brasil.

\section{REFERÊNCIAS}

Hottois G, Missa JN. Nouvelle encyclopédie de bioéthique. Bruxelles: De Boeck; 2001.

Pellegrino E, Thomasma DC. For the patient's good: the restoration of beneficence in health care. New York: Oxford University Press; 1988.

Julie Cantor JD, Ken Baum MD. The limits of conscientious objection May Pharmacists Refuse to Fill Prescriptions for Emergency Contraception?. N engl $j$ med [Internet]. 2004 Nov [cited 2012 Dec 15];4:2008-12 Available from:

http: //www.andrew.cmu.edu/org/pugwash/rea dings/past/Cantor_Baum_pharmacists_refusal_o f_RX.pdf

Moller LL. Pluralismo e tolerância: valores para a bioética. Rev HCPA. 2008;28(2):101-9.

Porto R. Objeção de consciência, aborto e religiosidade: práticas e comportamentos dos profissionais de saúde em Lisboa. Estud Fem [Internet]. 2008 [cited $2012 \mathrm{dez}$ 10];16(2):661-6. Available from: http: / /www.seer.ufros.br/hcpa/article/downlo ad/5744/3517

Kane R. Conscientious objection to termination of pregnancy: the competing rights of patients and nurses. J Nurs Manag [Internet]. 2009 [cited 2012 Dec 11];17:907-12. Available from: http://www.ncbi.nlm.nih.gov/pubmed/1979324 8

Savulescu J. Conscientious objection in medicine. BMJ [Internet]. 2006 [cited 2012 Dec 10];332:294-7. Available from: http: //www.bmj.com/content/332/7536/294

National Secular Society. Secular Medical Forum. GMC consultation: personal beliefs and medical practice. United Kindon: NSS [Internet]. 2011. [cited 2012 Dec 15]. Available from: http: //www.secularmedicalforum.org.uk/wpcontent/uploads/2012/06/SMF-and-NSS-jointresponse-to-GMC-consultation-on-personalbeliefs-and-medical-practice-11-June-2012.pdf. College of Registered Nurses of British Columbia. Duty to provide care: practice standard for registered nurses and nurse practitioners. Nurs BC [Internet]. 2012. [cited 2012 Dec 15]. Available

from:https: //www.crnbc.ca/Standards/Lists/St andardResources/128ProfessionalStandards.pdf. McHale JV. Conscientious objection and the nurse: $\mathrm{A}$ right or a privilege? $\mathrm{Br} \mathrm{J}$ Nurs [Internet]. 2009 [cited 2012 Dec 
Camargo MG, Guilhem DB, Lago DMSK et al.

14];18(20):1262-3. Available from: www.ncbi.nlm.nih.gov/pubmed/20081664

Magelssen $M$. When should conscientious objection be accepted? J Med Ethics [Internet]. 2012 [cited 2012 Dec 08];38(1):18-21. Available from:

http://ce.rsmjournals.com/content/7/3/107.ful l

Diniz D. Objeção de consciência e aborto: direitos e deveres dos médicos na saúde pública. Rev saúde pública [Internet]. 2011 [cited 2012 Dec 18];45(5):981-5. Available from: http://www.scielo.br/pdf/rsp/v45n5/2721.pdf

Brasil. Ministério da Saúde. Secretaria de Atenção à Saúde. Prevencão e tratamento dos agravos resultantes da violência sexual contra mulheres e adolescentes: Norma Técnica. $3^{\mathrm{a}}$ ed. atualizada e ampliada. Brasília: Ministério da Saúde; 2012.

Rodrigues SG, Constâncio TB, Camargo MG. Rede contra Violência Sexual no DF: uma representatividade da saúde e da educação na adolescência. Comun ciênc saúde [Internet]. 2011 [cited 2012 Dec 19];22(4):343-52. Available from:

http://bvsms.saude.gov.br/bvs/artigos/rede_co ntra_violencia_sexual_df.pdf

Tomás CMS, Benedicto IC, Furlan KV, Avanci BS, Andrés KM, Paula GS. A atuação do enfermeiro no atendimento a criança vítima de violência sexual. J Nurs UFPE on line [Internet]. 2012 June;6(6):1403-12. Available from: http://www.revista.ufpe.br/revistaenfermagem /index.php/revista/article/view/2499 DOI: 10.5205/reuol.2365-18138-1-LE.0606201218

Conselho Federal de Enfermagem (COFEn). Código de ética dos profissionais de enfermagem. Brasilia: COFEn; 2007.

Conselho Federal de Medicina (CFM). Código de ética médica. Brasília: CFM; 2010.

Estado de São Paulo. Ministra Eleonora Menicucci critica médico que não faz aborto legal. Estadão [Internet]. 2012 [cited 2012 Dec 15]. Available from: http://www.estadao.com.br/noticias/vidae, min istra-eleonora-menicucci-critica-medico-quenao-faz-aborto-legal,849014,0.html.

Souza MT, Silva MD, Carvalho R. Revisão integrativa: o que é e como fazer. Einstein (Sao Paulo) [Internet]. 2010 [cited 2012 Dec 14];8(1):102-6. Available from: http://apps.einstein.br/revista/arquivos/PDF/1 134-Einsteinv8n1_p102-106_port.pdf

Madigan EA. Evidence-based practice in home healthcare. A springboard for discussion. Home Healthc Nurse [Internet]. 1998 [cited 2012 Nov 22];16(6):411-5. Available from: http://www.ncbi.nlm.nih.gov/pubmed/1982065 $\underline{5}$

Whittemore R, Knafl K. The integrative review: update methodology. J Adv Nurs [Internet]. 2005 [cited 2012 Nov 22];52(5):546-53. Available from:

http://www.ncbi.nlm.nih.gov/pubmed/1626886 1

Borba AKOT, Marques APO, Leal MCC, Ramos RSPS. Práticas educativas em diabetes mellitus: revisão integrativa da literatura. Rev Gaucha Enferm [Internet]. 2012 [cited 2012 Nov 22];33(1):169-76. Available from: http://www.scielo.br/pdf/rgenf/v33n1/a22v33n 1.pdf

Galvão MC. Níveis de evidência. Acta paul enferm [Internet]. 2006 [cited 2012 nov 21];19(2):v-vii. Available from: http://www.scielo.br/pdf/ape/v19n2/a01v19n2 .pdf

Bireme. Biblioteca Virtual em Saúde. Fator de impacto. São Paulo: BIREME [Internet]. 2012 [cited 2012 dez 15]. Available from: http://bc.bireme.br/f_impacto.htm.

Lunardi VL, Simões AR. (Re) ações da equipe de enfermagem frente à possibilidade de participacão em um aborto legal. Rev Enfermagem UFRJ [Internet]. 2004 [cited 2012 Nov 23];12(2):173-8. Available from: http://www.facenf.uerj.br/v12n2/v12n2a08.pdf Bedone AJ, Faúndes A. Atendimento integral às mulheres vítimas de violência sexual: Centro de Assistência Integral à Saúde da Mulher. Cad Saúde Pública [Internet]. 2007 [cited 2012 nov 21]; 23(2):465-9. Available from: http: //www.scielo.br/pdf/csp/v23n2/24.pdf

Farias RS, Cavalcanti LF. Atuação diante das situações de aborto legal na perspectiva dos profissionais de saúde do Hospital Municipal Fernando Magalhães. Ciênc saúde coletiva [Internet]. 2012 [cited 2012 Nov 21];17(7):175563. Available from: http: //www.scielo.br/pdf/csc/v17n7/14.pdf Higa R, Reis MJ, Lopes MHBM. Interrupção legal da gestação decorrente de estupro: assistência de enfermagem às mulheres atendidas num serviço público da cidade de campinas - SP. Ciênc Cuid saúde [Internet]. 2007 [cited 2012 Nov 20];6(3):372-6. Available from: http://periodicos.uem.br/ojs/index.php/CiencC uidSaude/article/view/1747/pdf

Submissão: 19/12/2012

Aceito: 16/04/2014

Publicado: 01/06/2014

\section{Correspondência}

Maria da Graça Camargo

SMPW Quadra 28 / Conjunto 5 / Lote 2

Casa 3

Park Way

CEP 71745-805 - Brasília (DF), Brasil 
4.2 ARTIGO 2: PERFIL DE MULHERES SUBMETIDAS AO ABORTO PREVISTO EM LEI: ESTUDO DESCRITIVO EXPLORATÓRIO.

Perfil de mulheres submetidas ao aborto previsto em lei: estudo descritivo exploratório. CAMARGO NEVES MC, GUILHEM D, RODRIGUES SG. Online brazilian journal of nursing, V. 14, N.1, P. 16-24, 2015.

Este artigo está de acordo com o segundo objetivo especifico deste estudo: Caracterizar o perfil de adolescentes e mulheres que buscam o Serviço de Aborto Previsto em Lei. 

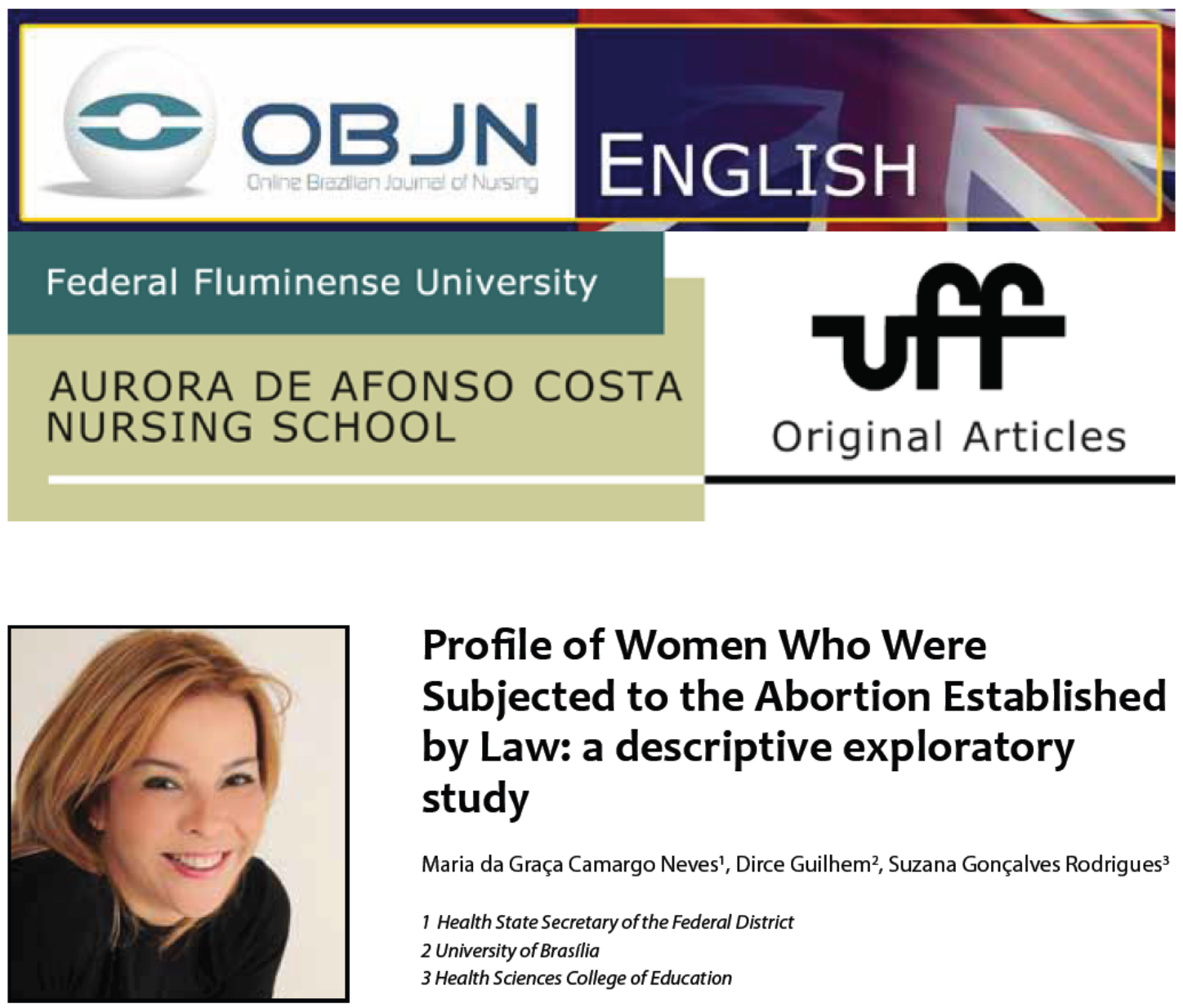

\title{
Profile of Women Who Were Subjected to the Abortion Established by Law: a descriptive exploratory study
}

Maria da Graça Camargo Neves', Dirce Guilhem², Suzana Gonçalves Rodrigues ${ }^{3}$

1 Health State Secretary of the Federal District

2 University of Brasilia

3 Health Sciences College of Education

\begin{abstract}
Aim: To define the profile of women undergoing pregnancy termination in the Legal Abortion program, in the Federal District. Method: A descriptive, exploratory and documental study that defines the profile of women and adolescents between 2007 and 2013. Results: Of the 81 women who interrupted pregnancy due to extra or intra-familial sexual violence, the majority were adolescents and young adult women with gestational age up to 12 weeks. Discussion: There are few publications on this topic in Brazil. The survey reveals that $7.4 \%$ of gestational interruptions diverge from the prescribed protocol in the Technical Standard. When compared to another research project in Brazil, we highlight differences between religion, color and gestational age at the time of interruption. Conclusions: To foster communication to stimulate information of individuals and self-care; to invest in the humanization of the professionals who monitor the process of women; to reformulate public policies and promote research in this area.
\end{abstract}

Descriptors: Abortion, Legal; Health Profile; Public Policies; Women's Health; Adolescent.

Neves MGC, Guilhem D, Rodrigues SG. Profile of Women Who Were Subjected to the Abortion Established by Law: a descriptive exploratory study. Online braz j nurs [internet] 2015 Mar [cited year month day]; 14 (1):16-24. Available from: http://www.objnursing.uff.br/index.php/nursing/article/view/4629 


\section{INTRODUCTION}

Public debates, which are fruits of the feminist movement in the 1960s and the American Convention of 1995, proposed that the State should bring together certain demands claimed to be public policies. The priority was gender violence with a view to prevention, punishment and eradication, determined as a crime that is responsibility of the society as a whole and causes physical, psychological and sexual suffering as well as death ${ }^{(1-2)}$. Sexual abuse, one of the oldest and most frequent forms of violence in our society, reflects bitter expressions of gender aggression and it is characterized by its increase in the unequal power relations and it represents a brutal violation of human, sexual and reproductive rights ${ }^{(3)}$.

Each year approximately 12 million people experience different situations of sexual violence. In Brazil, data show an average of 8.7 rapes per 100,000 inhabitants; in the United States of America (USA) one case occurs every 6.4 minutes and it is considered the fastest growing violent crime in the country ${ }^{(2,4,5)}$.

As a result of sexual violence, a complexity of psychological, social and biological reactions that are considered intolerable for many women emerges. We highlight depression, bulimia, anorexia, sexual affective disorders, emotional and relationship difficulties, suicide, sexually transmitted diseases and physical injuries. The unwanted and unintended pregnancy is seen as a revictimization and it exacerbates the reactional conditions described above, concomitantly to the immediate need of coping as in the case of gestational interruption that takes time, frequency and cost to the public service ${ }^{(3,4,6)}$.

The termination of pregnancy, linked or not to sexual violence, occupies a prominent place in contemporary societies which are characterized by a moral pluralism and the defense of a secular state, including a wide range of moral diversities $^{(7)}$.

Countries are confronted with regard to the legislation to be adopted in cases of pregnancy termination, as a referendum in Europe in 2007 found. Among the countries with restrictive laws, we may highlight Ireland and Malta ${ }^{(2.8)}$. Debates between legal, religious and feminist bodies and scientific societies lead to reflections on the decriminalization of abortion, thus reflecting the reform of the current legislation in abortion cases provided for in the Penal Code ${ }^{(4,5,6,9)}$.

Twelve European countries, including Germany, France, Spain and Portugal, allow abortion during the first 12 weeks of pregnancy in case there is risk of death for the woman or if there is a threat to their physical or mental health, as well as in cases of rape, incest or fetal malformation $^{(2,3,8)}$. In Latin and Central America, countries such as Chile, El Salvador, Nicaragua and the Dominican Republic do not interrupt the pregnancy under any circumstances. However, Argentina, Venezuela, Costa Rica, Peru and Paraguay, among others, permit abortion in some cases $^{(8)}$.

In Brazil, in cases of pregnancy resulting from sexual violence, women and adolescents, as well as their legal representatives, have the right to be informed of the possibility of terminating pregnancy, as stated in the 1940 Criminal Code as well as their right to keep it until the end. In case they decide to keep it they can choose to donate the newborn or not and prenatal care is ensured to them. However, only in the 1980s was care officially carried out in the Brazilian healthcare public service ${ }^{(4)}$.

In Brazil there are 441 childcare services aimed at women who are victims of sexual violence. Of these, sixty three (63) carry out the abortion provided for by the law ${ }^{(6)}$. The service depicted in this study, consisting of a multi-professional team, is supposed to welcome,

Neves MGC, Guilhem D, Rodrigues SG. Profile of Women Who Were Subjected to the Abortion Established by Law: a descriptive exploratory study. Online braz j nurs [internet] 2015 Mar [cited year month day]; 14 (1):16-24. Available from: http://www.objnursing.uff.br/index.php/nursing/article/view/4629 
protect and care biologically, psychologically and socially for women and adolescent girls who are victims of sexual violence when there is risk of maternal death and when they opt for the legal interruption of pregnancy.

The year 2007 tallied a total of seven records of pregnancy interruptions due to sexual violence. After four years, in 2011, the records already reached 16 interruptions, referring to an upward line in terms of the amount of procedures. From the year 2007 until the second half of 2013 the number of legal interruptions reached 81.

\section{METHOD}

This is a descriptive, exploratory, documentary and retrospective study ${ }^{(10-11)}$, which shows the profile of a public service that performs the legal interruption of pregnancy in teenagers and women victims of sexual violence in cases of risk of maternal death and since April 2012, in cases of anencephaly ${ }^{(12)}$.

The activities of the program on which this work was based began in 1996. However, the information was collected from primary sources - official records of the Abortion Program Predicted In Law (APL), of the Mother and Child Hospital of Brasilia - as from 2007 due to lack of interest, in relation to the records of information, to indicate the profile of women and adolescent victims of sexual violence who sought legal abortion.

The number of teenage girls and women who have been accepted by the APL program as from 2007 up to the second half of 2013 was 147. Of these women, eighty-one (81) performed the legal interruption of pregnancy.

As inclusion criteria, the following characteristics should be included in the official records of the program: age, gestational age, place of residence, religion, color (self-determined), the procedure adopted for gestational interruption, reason for pregnancy termination, perpetrator bond in cases of family violence, record of the police report and opinion of the Public Ministry.

The police report records the violence to the knowledge of the police authority, which may determine the opening of the inquiry and investigation. The report of the Forensic Medicine Institute (FMI) is the document drawn up to make the criminal evidence. The opinion of the Public Prosecutor portrays situations where the multidisciplinary team was faced with dislocations between the information narrated by the victim and the data related to the analysis of the Ultrasound exam. For questions regarding the realization of interruption, the request of the opinion and conduct is referred to this institution.

The characterization of the profile found and its analysis considered the following aspects: age according to adopted standardization ${ }^{(13-14)}$; gestational age (older or younger than 12 weeks) when searching for the interruption of the gestational program; method used for pregnancy termination; color (self-determined); religion; place of residence (Federal District or the surroundings of the Federal District); record of the police report; forwarding of the Public Prosecutor; reason for interruption and type of violence - extra or intra-family, and in the latter case stating aggressor's tie with the victim of violence.

The standards adopted for the age groups $^{(13-14)}$ involved the following subdivisions:

- Adolescence: 10 to 19 years;

- Initial young adulthood (IYA): age 20-25 years;

- Complete young adulthood (CYA): between 25-35 years;

- Final young adulthood (FYA): between 35-40 years;

- Initial average adulthood (IAA): it refers to the age group of $40-50$ years. 
As for the place of residence, a geographical split was used to better delineate the profile, adopting the Federal District (FD) and the surroundings of the Federal District as locals, and it grows at a faster rate than the Federal District itself. According to Census data in 2010, conducted by the Brazilian Institute of Geography and Statistics (IBGE), the 22 cities in the state of Goiás and Minas Gerais that border the Federal District suffered a population increase of $27.2 \%$ between 2000 and 2010. Before there were 906,275 residents, but last year $1,152,725$ residents were recorded. In the FD, population growth was $24.9 \%$ in 10 years (the national average is $12.3 \%$ ).

The Federal District consists of 31 administrative regions: Águas Claras, Brasilia, Brazlândia, Candangolândia, Ceilândia, Cruzeiro, Fercal, Gama, Guará, Itapoä, Jardim Botanico, Norte Lago, Sul Lago, Núcleo Bandeirante, Paranoá, Park Way, Planaltina, Recanto das Emas, Riacho Fundo, Riacho Fundo Il, Samambaia, Santa Maria, São Sebastião, SCIA/Estrutural, SIA, Sobradinho, Sobradinholl, Sudoeste/Octagonal, Taguatinga, Varjấo and Vicente Pires ${ }^{(15)}$. On the other hand, the surrounding areas encompass the cities of Abadiânia, Água Fria de Goiás, Águas Lindas de Goiás, Alexânia, Cabeceiras, Cidade Ocidental, Cocalzinho de Goiás, Corumbá de Goiás, Cristalina, Formosa, Luziânia, Mimoso de Goiás, Novo Gama, Padre Bernardo, Pirenópolis, Planaltina, Santo Antônio do Descoberto, Valparaíso de Goiás and Vila Boa (in Goiás), also including Unaí, Buritis and Grande Cabeceira (Minas Gerais) ${ }^{(15)}$.

The research protocol was submitted for review by the Ethics Committee in Research of the Health State Department of the Federal District, which includes the abortion program provided by law, and obtained its approval by the $0475 / 2011$ protocol. This study aimed to define the profile of adolescents and women who underwent pregnancy termination in an
Abortion Program Established by Law in a public hospital in the FD.

As for the ethical aspects, the Resolution No. 466/2012 of the National Health Council features research involving human subjects and points out that it is necessary to establish procedures to ensure the confidentiality and privacy, protection of the image and nonstigmatization $^{(16)}$.

\section{RESULTS}

The results are presented in tables for easy viewing of the data found and are discussed below.

Table 1. Characterization of women and adolescents treated at an abortion program established by law for a public hospital in the Federal District according to age, residence, religion and color (self-determined) from 2007 to the second half of 2013.

\begin{tabular}{|c|c|c|c|}
\hline $\begin{array}{l}\text { Characte- } \\
\text { ristics }\end{array}$ & Category & n. & $\%$ \\
\hline \multicolumn{4}{|l|}{ Faixa etária } \\
\hline & $\begin{array}{l}\text { Adolescents: } 10 \text { to } 19 \\
\text { years }\end{array}$ & 30 & 37 \\
\hline & AJl: 2 to 25 years & 14 & 17,2 \\
\hline & AJP: 26 to 35 years & 25 & 30,8 \\
\hline & AJF: 36 to 40 years & 8 & 9,8 \\
\hline & AMI: 41 to 50 years & 3 & 3,7 \\
\hline & Not specified & 1 & 1,2 \\
\hline & Total & 81 & 100 \\
\hline \multicolumn{4}{|c|}{ House location } \\
\hline & Federal District & 60 & 74 \\
\hline & $\begin{array}{l}\text { Surroundings of the Fede- } \\
\text { ral District }\end{array}$ & 20 & 24,6 \\
\hline & Not specified & 1 & 1,2 \\
\hline & Total & 81 & 100 \\
\hline \multicolumn{4}{|l|}{ Religion } \\
\hline & Catholic & 32 & 39,5 \\
\hline & Gospel & 43 & 53 \\
\hline & Spiritist & 1 & 1,2 \\
\hline & Others & 1 & 1,2 \\
\hline & No religion & 4 & 4,9 \\
\hline & Total & 81 & 100 \\
\hline
\end{tabular}




\begin{tabular}{ccc} 
Color (self-determined) & & \\
\hline Brown & 44 & 54,3 \\
White & 28 & 34,5 \\
Black & 7 & 8,6 \\
Not identified & 2 & 2,4 \\
Total & 81 & 100 \\
\hline
\end{tabular}

Source: Data generated by the authors, 2013.

Table 2. Characterization in terms of the gestational age at the time of interruption, the reason for the right for discontinuing it and the type of procedure used in pregnancy interruption in women and adolescents treated at an abortion program established by law of a Federal District public hospital between 2007 and the second half of 2013.

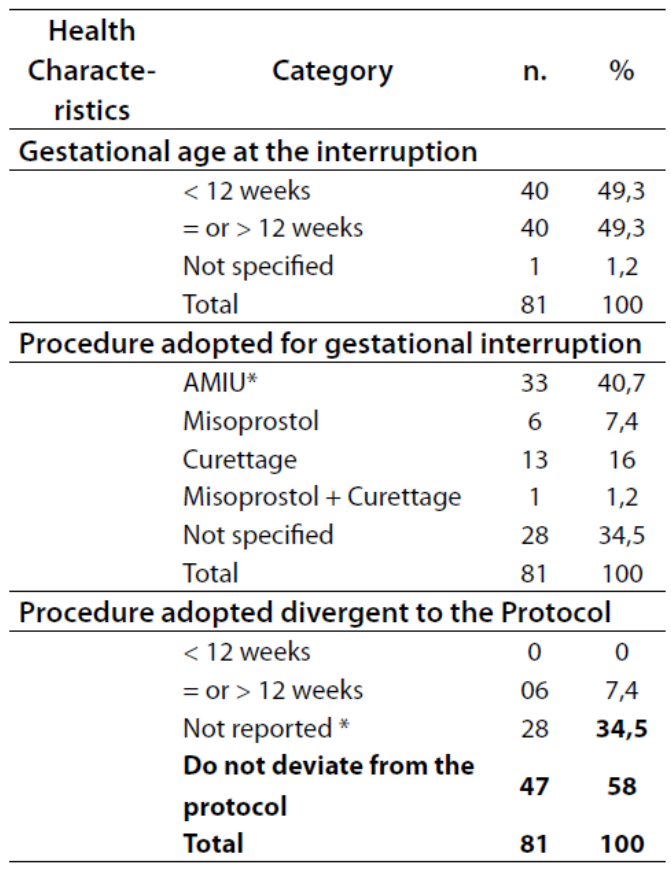

Source: Survey conducted in the Federal District from 2007 to the second half of 2013.

Source: Data generated by the authors, 2013.

* MVA: intrauterine manual vacuum aspiration.

* Lack of description in the records of gestational age and/ or procedure adopted for gestational interruption, which prevents the analysis of the Protocol fulfillment(3).
Table 3. Characterization of women and adolescents treated at an abortion program established by law for a public hospital in DF, regarding the police report registration of sexual violence, the opinion of the prosecuting authority in terms of gestational interruption and the type of link with the aggressor in inter-family cases from 2007 to the second half of 2013.

\begin{tabular}{|c|c|c|c|}
\hline $\begin{array}{c}\text { Other } \\
\text { Characteristics }\end{array}$ & Category & $\mathrm{n}$. & $\%$ \\
\hline \multicolumn{4}{|c|}{ Record of the police report } \\
\hline & Yes & 34 & 41,9 \\
\hline & No & 47 & 58 \\
\hline & Total & 81 & 100 \\
\hline \multicolumn{4}{|c|}{ Opinion of the Public Ministry } \\
\hline & Yes & 11 & 13,5 \\
\hline & No & 70 & 86,4 \\
\hline & Total & 81 & 100 \\
\hline
\end{tabular}

Source: Survey conducted in the Federal District from 2007 to the second half of 2013.

Table 4. Characterization of women and adolescents treated at an abortion program established by law for a public hospital in DF, regarding the reason for the termination of pregnancy and the perpetrator relationship, from 2007 to the second half of 2013.

\begin{tabular}{|c|c|c|c|}
\hline $\begin{array}{c}\text { Health } \\
\text { Characte- } \\
\text { ristics }\end{array}$ & Category & n. & $\%$ \\
\hline \multicolumn{4}{|c|}{ Aggressor (domestic violence) } \\
\hline & Stepfather & 3 & 23 \\
\hline & Father & 2 & 15,3 \\
\hline & Brother & 2 & 15,3 \\
\hline & Brother In Law & 1 & 7,6 \\
\hline & Uncle & 3 & 23 \\
\hline & Uncle and godfather & 1 & 7,6 \\
\hline & Father and brother & 1 & 7,6 \\
\hline & Total & 13 & 100 \\
\hline \multicolumn{4}{|c|}{ Right for the termination of pregnancy } \\
\hline & $\begin{array}{l}\text { Intrafamily Sexual vio- } \\
\text { lence }\end{array}$ & 13 & 16,1 \\
\hline & $\begin{array}{l}\text { Sexual violence outside } \\
\text { the family }\end{array}$ & 44 & 54,3 \\
\hline & Maternal death risk & 9 & 11,1 \\
\hline
\end{tabular}

Neves MGC, Guilhem D, Rodrigues SG. Profile of Women Who Were Subjected to the Abortion Established by Law: a descriptive exploratory study. Online braz j nurs [internet] 2015 Mar [cited year month day]; 14 (1):16-24. Available from: http://www.objnursing.uff.br/index.php/nursing/article/view/4629 


\begin{tabular}{lll} 
Birth defects & 1 & 1,2 \\
Not specified & 14 & 17,2 \\
Total & 81 & 100 \\
\hline
\end{tabular}

Source: Survey conducted in the Federal District from 2007 to the second half of 2013.

\section{DISCUSSION}

Studies on this type of profile are scarce in Brazil. The lack of information is still the greatest weapon against the consolidation of the collective health of Brazilian women, of the realization of self-care and the search for rights under the Unified Health System (UHS).

The data presented in this study are in line with research conducted in a Reference Center in 2008 regarding extra-familial sexual violence. Both studies reflect this predominance in more than $50 \%$ of the cases ${ }^{(2)}$.

As for the gestational age at the time of the interruption, 40 (49.3\%) women/teenagers assisted by the Program in the FD had pregnancy interrupted up to 12 weeks and the same percentage after 12 weeks. These results are similar to those found in a São Paulo referral center and the percentage of women (55\%) who underwent the termination beyond 12 weeks of gestation is slightly higher ${ }^{(2)}$. This is a finding that deserves attention from the departments involved in the APL programs, considering the risks (physical and/or psychological) arising from the performance of the procedure after 12 weeks.

There are differences with regard to religion: most women/teens of the FD (43), which correspond to $53.0 \%$, belonged to the Protestant religion, while in São Paulo 45\% were Catholic. As for the color, among women who have had gestational interruption resulting from sexual violence, 44 (54.3\%) identified themselves as brown and in São Paulo, $60 \%$ of them regard themselves as white in the present study.
Most women/teenagers who had the legal termination of pregnancy were in the age group of adolescence and young adulthood, aged between 10 and 44 years, with an average of 21.5 years. The sample features a low average age when compared to other studies ${ }^{(2)}$.

The interruption authorization according to the established law is limited to 22 weeks of gestation and the methods set out to perform it are provided in the technical standard, which regulates actions related to this issue ${ }^{(3)}$. The classification based on the gestational age of women/ teenagers when looking for the service is set as smaller or greater than 12 weeks. The appropriate method to perform the interruption is related to gestational age, so the intrauterine vacuuming is the recommended method for up to 12 weeks. Uterine curettage and medical abortion with misoprostol, which are considered valid and safe options for pregnancy termination, can also be used particularly in the first quarter ${ }^{(3,16,17)}$. For pregnancies after 12 weeks, abortion through a pharmacological process is the chosen method $(3,16,17)$.

Table 2 shows that six of the procedures performed (7.4\%) differed from the Technical Standard by using methods that did not follow the protocol for the legal interruption of pregnancy. This situation needs to be reviewed by the health team so that the established protocols are followed ${ }^{(3)}$.

The right to the termination of pregnancy resulting from sexual violence is established by ${ }^{l a w} w^{(4)}$. The requirement for presentation of the police report or the IML Report for care in health services is incorrect and illegal ${ }^{(3)}$. It is noteworthy that the record of the police report is based on the procedure of the IML report, which provides the criminal evidence. However, health professionals accept and give credit to the reports of women without making value judgments or any inference to an investigation: "Our goal is not to say if it is true or false"(12).

Neves MGC, Guilhem D, Rodrigues SG. Profile of Women Who Were Subjected to the Abortion Established by Law: a descriptive exploratory study. Online braz j nurs [internet] 2015 Mar [cited year month day]; 14 (1):16-24. Available from: http://www.objnursing.uff.br/index.php/nursing/article/view/4629 
The highest number of police reports was made by teenagers. This fact is not consistent with the protocols provided for the performance of abortion established by law; however, it makes it easier to carry out criminal investigation through the use of DNA in the fetus ${ }^{(18)}$.

Table 4 presents data related to the aggressor. In 13 cases (16.1\%) the perpetrator belonged to the family circle and 44 (54.3\%) women/teenagers have mentioned that the offender was not known. Regardless of the individual who originated the violation, it is guaranteed to women/ adolescents, or their legal representatives, the right to decide on carrying out the abortion established by law or not. Ignorance in terms of the author of violence is also prevalent in other published studies in which the perpetrator was not known for more than $50 \%$ of women/adolescents $^{(2,4)}$. In 14 cases (17.2\%) it was not possible to obtain this information.

Based on the profile outlined in this study, it is imperative that there are developments through other research on the subject. Data point to the need to redirect the management of this service for review of public policies aimed at modifying the flow chart that allows the screening of women and adolescent girls assisted by the service.

\section{CONCLUSION}

In the period from 2007 to 2013, ninetysix (96) women were treated in the service. Of these women, eighty-one (81) carried out the interruption management, and among these, 57 (70\% approximately) were proven to be victims of sexual violence. However, the exact number of women/teenagers who suffer sexual violence is difficult to estimate, since many of them do not report it to health services or public security for fear or shame and for this reason they become vulnerable in terms of unwanted pregnancy, sexually transmitted diseases and the acquired human immunodeficiency virus (AIDS). These situations are preventable through emergency contraception and prophylaxis against STD and AIDS available in most public hospitals in the Federal District.

After pregnancy interruption, women/ teenagers remain resistant to the monitoring by the multidisciplinary team, even in the presence of signs of depression and suicidal ideation that arise with some frequency. When there is an active search for these patients by the multidisciplinary team, they claim religious issues for Follow-up interruption by opting for silence and denial. This is an important vulnerability on the part of the service that deserves attention in order to be modified.

The humanization of the service still shows important deficits with regard to the relations between professionals and users, often creating asymmetrical relationships resulting from inter-professional and gender inequalities. Professionals are considered as technically holders of knowledge and they expect that women, who are conceived as an application object of this knowledge, act in a passive and inert form, alienated and without the power to choose. In this context, it is important to review the management process.

Performing other studies relating to the profile of women and adolescents who use the legal interruption of pregnancy services is necessary. The development of standard operating procedures (SOP) ${ }^{(19)}$ is an important element to achieve greater uniformity in terms of the actions taken, greater diligence and qualification as the biopsychosocial care of women victims of the violence so prevalent today. However, these strategies must be accompanied by reformulation of public policies for effective prevention of sexual violence.

Neves MGC, Guilhem D, Rodrigues SG. Profile of Women Who Were Subjected to the Abortion Established by Law: a descriptive exploratory study. Online braz j nurs [internet] 2015 Mar [cited year month day]; 14 (1):16-24. Available from: http://www.objnursing.uff.br/index.php/nursing/article/view/4629 
Research related to the effectiveness and availability of emergency contraception is needed in the public services, since the number of pregnancies has increased, even amongst those women who used the chemical treatment in time for its action. Other aspects that need to be investigated are those related to the control of STDs and HIV serology for these women, as provided for in the protocols. In this context, there is a long way to go.

\section{REFERENCES}

1. Rocha MIB, Barbosa R (Org.). Aborto no Brasil e países do Cone Sul: panorama da situação e dos estudos acadêmicos. Campinas: Núcleo de Estudos de População - Nepo. Unicamp; 2009.

2. Ministério da Saúde (Brasil). Secretaria de Atenção à Saúde. Magnitude do Aborto no Brasil. Aspectos Epidemiológicos e Sócio-Culturais. Abortamento Previsto em lei em situações de violência sexual. Brasília: Ministério da Saúse; 2008.

3. Ministério da Saúde (Brasil). Secretaria de Atenção à Saúde. Prevenção e tratamento dos agravos resultantes da violência sexual contra mulheres e adolescentes: Norma Técnica. 3. ed. Brasília: Ministério da Saúde; 2012.

4. Souza CM, Adesse L (org.). Violência sexual no Brasil: perspectivas e desafios. Brasília: Secretaria Especial de Políticas para as Mulheres. 2005; 188p.

5. Drezett J, Pedroso D. Aborto e violência sexual. Cienc. Cult. [Internet]. 2012 June [cited 2013 Dec 09]; 64(2): 35-38. Available from: http://cienciaecultura.bvs.br/ scielo.php?script=sci_arttext\&pid=S0009$-67252012000200015 \&$ Ing $=e n$.

6. Secretaria de Políticas para as Mulheres. Rede de Enfrentamento à Violência contra as Mulheres. Secretaria Nacional de Enfrentamento à Violência contra as Mulheres. Brasília: [s.e.] 2012.

7. Camargo MG, Guilhem DB. Abortion procedures provided by law - repercussions for the health service: an exploratory study. Online braz j nurs [periodic online]. 2012 Oct [cited 2013 Dec 09];
11 Suppl 1: 475-8. Available from: http://www. objnursing.uff.br/index.php/nursing/article/ view/3942

8. Rodrigues TJH. Aborto e legislação comparada. Cienc. Cult. [Internet]. 2012 June [cited 2013 Dec 09]; 64(2): 40-44. Available from: http://cienciaecultura.bvs.br/ scielo.php?script=sci_arttext\&pid=\$0009$-67252012000200017 \&$ Ing=en.

9. Aldana M, Winckler S. Direitos reprodutivos: debates e disputas sobre o direito ao aborto no contexto da redemocratização do Brasil. Revista Sequência [internet]. 2009 July [cited 2013 Dec 09]; 58: 167-183. Available from: https://www. journal.ufsc.br/index.php/sequencia/article/ view/2177-7055.2009v30n58p167/13611

10. Gil AC. Métodos e técnicas de pesquisa social. $6^{\text {a }}$ ed. São Paulo: Atlas, 2008.

11. Prodanov CC, Freitas EC. Metodologia do trabalho Científico: Métodos e Técnicas da Pesquisa e do Trabalho Acadêmico. 2. ed. Rio Grande do Sul: Universidade Feevale; 2013.

12. De Zordo S. Representations and experiences of obstetrician/gynecologists with legal and illegal abortion in two maternity-hospitals in Salvador da Bahia. Ciênc. saúde coletiva [Internet]. 2012 July [cited 2013 Dec 09]; 17(7):17451754. Available from: http://www.scielo.br/ scielo.php?script $=$ sci_arttext $\&$ pid $=$ S1413$-81232012000700013 \&$ Ing $=$ en.

13. Ministério da Saúde (Brasil). Secretaria de Atenção em Saúde. Diretrizes nacionais para atenção integral à saúde de adolescentes e jovens na promoção, proteção e recuperação da saúde. Brasília: Ministério da Saúde; 2010.

14. Santos BS, Antunes DD. Adult life, motivational processes and diversity. Educação [srial on the internet]; 2007 Jan/July [cited 2013 Dec 09]; 1(61), p. 149-164. Available from: http://revistaseletronicas.pucrs.br/ojs/index.php/faced/article/ view/544/380

15. Anuário do Distrito Federal. Regiões Administrativas. 2012. Available from: http://www.anuariododf.com.br/regioes-administrativas/

16. Ministério da Saúde (Brasil). Conselho Nacional de Saúde. Comissão Nacional de Ética em Pesquisa. Resolução 466/2012 de 13 de Junho de 2012. 


\subsection{ARTIGO 3: CONCEPÇÕES DOS PROFISSIONAIS DE SAÚDE QUE ATUAM NO ABORTO PREVISTO EM LEI POSSUEM SOBRE O CONCEITO DE OBJEÇÃO DE CONSCIÊNCIA}

Os resultados apresentados a seguir buscam responder o objetivo específico $\mathrm{n}^{\circ} 3$ proposto para esta tese: Conhecer as concepções que profissionais de saúde que atuam no aborto previsto em lei possuem sobre o conceito de Objeção de Consciência e como a sua apropriação interfere na prática cotidiana.

Para se alcançar este objetivo, foi realizada pesquisa qualitativa conforme descrito na sessão de métodos.

As mulheres que buscam o aborto previsto em lei, em particular devido a uma violência sexual, transitam pelo serviço em distintos espaços e momentos, nos quais realizam encontros diversos tanto com a equipe fixa como com a equipe flutuante. Essa última equipe é a que acompanhava as mulheres no momento da interrupção da gestação até o ano de 2014. O acompanhamento se estabelecia pela consonância entre a escala de trabalho dos profissionais de saúde com o dia em que a mulher se internava para a interrupção gestacional.

A seguir delinear-se-á o perfil de dez voluntários que aceitaram participar do estudo, dentre aqueles que compunham uma equipe composta por 125 profissionais da equipe flutuante.

\subsubsection{Perfil dos participantes do estudo}

Seguem-se os dados referentes à representação da equipe de saúde que compõe a equipe flutuante que atua no aborto previsto em lei.

Quadro 1 - Perfil dos participantes do estudo que pertenciam à equipe flutuante que atuava no aborto previsto em lei. Brasília, 2014.

\begin{tabular}{|l|l|l|l|l|l|}
\hline & Idade & Sexo & Estado Civil & Religião & Tempo de atuação \\
\hline E1 & 26 & F & Solteira & Espirita & 1 ano e 4 meses \\
\hline E2 & 48 & F & Casada & Não tem & 25 anos \\
\hline E3 & 38 & F & Solteira & Adventista & 12 anos \\
\hline
\end{tabular}




\begin{tabular}{|l|l|l|l|l|l|}
\hline E4 & 27 & F & Solteira & Não tem & 4 anos \\
\hline E5 & 24 & F & Solteira & Católica & Menos de 1 ano \\
\hline E6 & 56 & M & Solteiro & Católica & 12 anos \\
\hline E7 & 40 & F & Solteira & Não tem & 8 anos \\
\hline E8 & 39 & F & Casada & Espirita & 17 anos \\
\hline E9 & 25 & F & Solteira & Católica & Menos de 1 ano \\
\hline E10 & 41 & F & Casada & Católica & 1 ano e 2 meses \\
\hline
\end{tabular}

Fonte: Dados produzidos pela pesquisadora.

Compunham o conjunto de participantes do estudo profissionais de saúde provenientes das áreas de medicina, enfermagem, psicologia e serviço social. Esses profissionais foram entrevistados em momentos reservados para este fim e em local privativo, garantindo-se privacidade e confidencialidade.

Entre os entrevistados, nove eram mulheres, duas eram casadas e sete eram solteiras e em período reprodutivo. Três respondentes não possuíam religião declarada e os demais mencionaram serem adeptos de religiões distintas: católica, adventista do sétimo dia e espírita. O tempo de atuação no setor de trabalho variou de menos de um ano a 25 anos.

Os profissionais dessa equipe de saúde que aceitaram participar do estudo atuam em distintas esferas da atenção em saúde: programa de interrupção de gestação; assistência à saúde de forma ampla e contextualizada; trabalho em regime de demanda aberta (pronto atendimento) em um serviço de referência para alto risco gestacional e acolhimento emergencial às vitimas de violência sexual feminina e violência doméstica.

As concepções religiosas podem ter influência em suas decisões e atitudes profissionais, especialmente no que se relaciona ao atendimento de mulheres e adolescentes vítimas de violência sexual e no aborto previsto em lei. Valores pessoais e religiosos que têm influência direta em determinados momentos da assistência em saúde e que podem incidir nos direitos das pessoas que procuram serviços e programas podem representar condicionantes para requerer o estatuto de objetor de consciência (ROCHA, 2015).

A formação religiosa de cada profissional se traduz em comportamentos que podem provocar conflitos no processo de atenção às mulheres que procuram o programa de aborto previsto em lei. Essa situação pode revelar uma perspectiva estereotipada que se possui sobre o tema em pauta, confrontando o posicionamento do Estado brasileiro. De acordo com a 
Constituição Federal, o país se configura como Estado Laico, que abriga e respeita todas as concepções religiosas e a decisão das pessoas sobre o que consideram melhor para sua vida e saúde. Nessa mesma linha de pensamento, emerge o cenário propício para o uso da ferramenta de objeção de consciência para profissionais - como enfermeiras e médicos - que são amparados por seus referentes códigos de ética (PIROTTA, 2001; COREn 2007; CRM 2010).

Ramminger (2006) e Ferrer (2007) concordam com a ideia de que percepções e vivências profissionais provenientes de várias origens, ideologias e princípios religiosos podem influenciar nas atitudes dos profissionais da equipe de saúde, no que se relaciona ao atendimento das mulheres que utilizam o serviço do aborto previsto em lei. A forma como o cuidado é prestado e as relações entre mulheres e profissionais de saúde podem ser influenciadas por este background (GLANZNER, 2008).

A complexidade de conflitos que emergem nesse contexto, especialmente quando se considera a ótica dos profissionais em contraposição à visão das mulheres que recebem atendimento, torna evidentes os confrontos que surgem, as dificuldades existentes para colocar em prática princípios da Bioética, e de se preservar o respeito à autonomia das mulheres.

A mulher que busca o aborto previsto em lei e se depara com alguns componentes da equipe que possuem conflitos bioéticos, religiosos e de outra ordem - mas que não têm conhecimento sobre o tema da objeção de consciência ou não podem ser objetores de consciência por questões laborais - pode ter o direito de acesso aos princípios bioéticos violados. É preciso ter em mente que os princípios bioéticos devem ser respeitados pela equipe de assistência ao paciente, independente de seu posicionamento pessoal, considerandose que uma vez rompidos, levam a distorções e possíveis sofrimentos da parte de quem necessita de cuidado.

Este trabalho mostrou que quando a autonomia da mulher é desrespeitada, a paciente não é informada sobre seu direito de decidir na condução do processo interrupção ou manutenção da gravidez decorrente de violência sexual, cristaliza-se o impedimento da beneficência. Quando essa mulher não é tratada de forma digna, com equidade, possibilitando-se a existência de violência moral/institucional, se estabelece a não maleficência, ou seja, permite-se que sejam forjadas situações que agravam seu sofrimento físico ou psíquico. A ausência de justiça, representada pelo acesso ao serviço e a escolhas pessoais fundamentadas, torna essa mulher duplamente vulnerável e contribui para sua revitimização (ECO; MARTINI, 2009). 


\subsubsection{Categorias-síntese que emergiram a partir das verbalizações dos entrevistados}

A avaliação sistemática das entrevistas, de acordo com o método proposto por Bardin (2011), denotou a percepção de cada entrevistado a respeito do significado, das percepções e dos conflitos vivenciados pela equipe flutuante no aborto previsto em lei. São denominadas categorias-síntese aquelas que foram identificadas em mais de $60 \%$ das entrevistas. Será apresentada a definição de cada uma das categorias que emergiram após a análise das entrevistas, bem como temas e verbalizações que mais as representavam. Algumas verbalizações estão destacadas entre aspas na definição da categoria, pois foram de suma importância para sua construção e estão em acordo com o sentido das mesmas.

A partir do tratamento dos discursos provenientes das entrevistas, emergiram três

categorias, denominadas Categorias-Síntese: "Eu abandono"; "Eu fico triste"; "Humanização, neste serviço?".

A seguir, apresentam-se os dados categorizados.

\subsubsection{1 "Eu abandono"}

Essa categoria descreve as formas de enfrentamentos e atitudes que a equipe flutuante vivencia a partir de sua inserção no procedimento do aborto previsto em lei. Indica, ainda, as dificuldades intrínsecas de assumir a participação em determinadas práticas, como a interrupção da gravidez.

\section{Temas:}
1) Abandono
2) Troca de escala
3) Desconhecimento
4) Julgamento 


\section{Verbalizações:}

Eu abandono... e outros que são totalmente contra não entram, não atendem, nem aparecem. (E1)

...eu quase entrei em depressão, não sabia que era aborto legal... (E1)

...aqui o conflito maior que eu já tinha vivido são nos casos de aborto legal, né, mas eu sempre procuro não pensar. (E2)

...não vou avaliar, é o último lugar que eu vou avaliar, pra me preservar..., talvez do preconceito, da dor, o parto é sempre mais importante. (E8)

...vou pedir pra outro ficar no lugar e depois que terminar eu assumiria o cuidado. (E8)

...mas assim, pelos meus valores mesmo, eu sou contra. (E9)

...eu fiquei muito assustada (E9)

...se você quiser julgar as pessoas você tá no curso errado, vai fazer Direito. (E10)

É possível verificar que os participantes que forneceram dados para esta categoria revelaram suas atitudes para o enfrentamento da interrupção da gravidez de mulheres provenientes do programa do aborto previsto em lei no momento dos seus plantões. Alguns trechos das verbalizações podem representar certo grau de intencionalidade para ser um objetor de consciência. Porém, a ausência de conhecimento sobre esta possibilidade contribui para que a apresentem de forma empírica e não organizada. Apenas refutam atuar no momento do procedimento ou se concentram em cuidados, devidos a outras pacientes, que consideram ser mais importantes para a atuação profissional (CAMARGO et al., 2014).

O sofrimento proveniente dessa experiência parece condicionar a equipe para a fuga do plantão ou a troca na escala de procedimentos, o que seguramente representa estratégias de enfrentamento para situações estressantes ou com as quais não concordam.

Diversos autores defendem que o profissional de saúde lida na prática cotidiana com situações de sofrimento e dor constantes. Devido a isso, apresentam dificuldades para lidar com problemas durante a convivência diária junto a pacientes, familiares e colegas, fato que tem contribuído para gerar situações de estresse de difícil resolução (CAVALCANTI, 2003; GUTIERREZ, 2003; KÓVICS, 2010).

Profissionais de saúde que convivem com o sofrimento em suas diversas dimensões vivenciam conflitos internos sobre como deveriam se posicionar. No que se refere mais especificamente à equipe de enfermagem, há um fator suplementar que merece 
consideração. Esses profissionais estão em contato mais direto e contínuo com o paciente e, por vezes, sem autonomia para tomar uma série de decisões, o que pode gerar um estresse adicional (CAVALCANTI, 2003; GUTIERREZ, 2003).

A equipe de saúde entrevistada aponta que as estratégias de enfrentamento adotadas são: troca da escala e plantão, ignorar a existência de pacientes admitidas para a interrupção da gravidez, abandono do tipo de assistência a ser prestada. Como essa é uma situação que lhes ocasiona sofrimento, preferem assumir condutas algumas vezes questionáveis a exercerem seus direitos, fato que está respaldado nos códigos de ética da Enfermagem e da Medicina (COFEN, 2007; CRM, 2010). No entanto, esse documento fundante do trabalho em saúde sequer foi referido. A estratégia adotada foi o abandono daquilo que lhe causa dificuldades, como é o caso do aborto previsto em lei.

Este estudo demonstrou que o enfrentamento desses conflitos por parte da equipe se resume a se adaptar à situação e buscar recursos internos para o dia a dia, o que gera, muitas vezes, violência moral ou institucional. Uma fonte adicional de sofrimento para a equipe pode ser a dificuldade de ser continente para o sofrimento do outro, repercutindo de forma negativa no cuidado em saúde (GLANZNER; OLSCHOWSKY; KANTORSKI; 2011).

\subsubsection{2 "Eu fico triste"}

Esta categoria descreve os sentimentos revelados pela equipe flutuante durante sua atuação no procedimento de interrupção da gestação no programa de aborto previsto em lei.

\section{Temas:}

1) Complicado

2) Abalada

3) Tristeza

4) Assassinato 


\section{Verbalizações}

É complicado porque nós não temos tempo... (E3)

... já aconteceu, eu pude conversar mais com a paciente, pude ouvir mais. (E3)

... a gente não vai ficar chorando com elas. (E7)

... Sim, porque eu saio muito abalada quando eu vejo. (E1)

...Eu fico triste, porque eu acho que ninguém tem o direito de tirar a vida de ninguém. Acho que é um assassinato. (E7)

A equipe entrevistada exerce suas funções em um ambiente propício ao atendimento de adolescentes e mulheres que buscam o serviço para o nascimento de seus filhos, ao mesmo tempo em que realiza o aborto previsto em lei, a depender das demandas diárias e de sua escala de trabalho. As entrevistas revelaram que os sentimentos mencionados pelos participantes são difíceis de serem enfrentados e eles sentem dificuldade para continuar suportando a situação da interrupção legal da gestação.

Beauchamp e Childress (2009) defendem que o mesmo trabalho que é fonte de prazer e de desenvolvimento humano do profissional de saúde pode também ocasionar ao trabalhador sofrimento e adoecimento. Dessa forma, fica evidente que o trabalho e as relações que nele se originam nunca deveriam ser tomados como espaço de neutralidade subjetiva ou social.

A sobrecarga natural de trabalho, em funções discrepantes no cotidiano, reforçada por sentimentos negativos, favorece o adoecimento do trabalhador. A possibilidade de acompanhamento psicológico para a equipe poderia ajudar em momentos conflitivos de difícil mediação moral. A organização do trabalho é caracterizada pelo conteúdo da tarefa e pelas relações profissionais, aspectos que exercem impacto no funcionamento psíquico do trabalhador, gerando prazer/sofrimento, a depender do quanto a tarefa é significativa para ele (GLANZNER; OLSCHOWSKY; KANTORSKI, 2011).

A necessidade que trabalhadores em sofrimento têm de um espaço para falar sobre seus sentimentos, além da necessidade de uma escuta profissional qualificada, são elementos imprescindíveis para o fortalecimento da saúde mental dos profissionais de saúde (MONTEIRO, 2012). Esse movimento conduzirá à assistência mais bem qualificada, fortalecendo a consolidação dos princípios bioéticos para a mulher que busca o aborto 
previsto em lei, contribuindo para minimizar a possibilidade de violência moral/institucional no processo de atenção à saúde.

A Politica Nacional de Humanização - PNH (2013) aborda a questão Cuidando do Cuidador, que prevê apoio a trabalhadores que sofrem com determinadas situações cotidianas e que podem acarretar sofrimentos mais profundos, como depressões ou síndrome de Burnout. A política de humanização é preconizada para todo o âmbito do SUS. Uma vez que o local onde os dados foram coletados é um serviço de referência para o aborto previsto em lei e que os profissionais que atuam nesse serviço enfrentam situações impactantes, seria de fundamental importância receberem acompanhamento para subsidiar o desenvolvimento de suas atividades.

A PNH estimula a comunicação entre gestores, trabalhadores e usuários, para construir processos coletivos de enfrentamento nas relações de poder, trabalho e afeto. Relações que muitas vezes produzem atitudes e práticas desumanizadoras que inibem a autonomia e a corresponsabilidade dos profissionais de saúde em seu trabalho e dos usuários no cuidado de si (BRASIL, 2013).

4.3.2.3 "Humanização, neste serviço?"

Esta categoria traz a perspectiva da equipe flutuante sobre o processo de humanização durante o procedimento de interrupção legal da gestação.

\section{Temas:}

1) Sem condições

2) Prática nenhuma

3) Não julgar

4) Chamar psicólogo 


\section{Verbalizações}

... a gente chama também a psicóloga. (E1)

... Nem acredito que a gente tenha condições de fazer. (E2)

... primeiro não julgar, também não criticar. (E7)

... eu acho que não temos humanização. Deixamos muito a desejar. (E5)

... Na prática nenhuma. Aliás, pelo contrário, né... (E8)

As falas dos participantes revelaram que as práticas da humanização são pouco efetivas durante o procedimento da interrupção legal da gestação. Embora percebam que é importante, consideram-se sem condições de realizá-las, por déficit de recursos humanos e materiais. Alguns buscam efetuá-las da maneira como as entendem: chamar a psicóloga ou não julgar a paciente pela realização do procedimento. Contudo, a grande maioria desses entrevistados acreditava que não eram capazes de realizar a humanização no cuidado às mulheres do aborto previsto em lei.

Esta categoria requer o estabelecimento de escuta qualificada para o profissional de saúde que está em sofrimento, a fim de fortalecê-lo nas atividades cotidianas, o que contribuirá para melhorar o cuidado dispensado às mulheres (MONTEIRO, 2012). Dessa forma, estará capacitado para instituir escuta qualificada no que se relaciona às necessidades das mulheres que buscam o serviço do aborto previsto em lei. Isso permitirá garantir o acesso oportuno desses usuários a tecnologias adequadas, ampliando a efetividade das práticas de saúde. Assegura, por exemplo, que todas sejam atendidas em suas prioridades a partir da avaliação de vulnerabilidade, gravidade e risco da situação em que se encontram (PNH, 2013).

De forma geral, as categorias-síntese permitiram perceber a dificuldade que alguns componentes da equipe possuem para lidar com o aborto previsto em lei. Lançam mão de estratégias de enfrentamento, sublimam sentimentos ou emoções quando devem cumprir escalas que requerem o fornecimento de cuidados às mulheres e adolescentes que realizam esse procedimento.

Por parte dos profissionais de enfermagem, persistem dificuldades reais em manifestar seu posicionamento, em emitir opinião de forma contrária ao assunto, devido à submissão histórica e à falta de autonomia profissional por eles vivenciada (CAMARGO et $a l .$, 2014). No entanto, essa é uma possibilidade que se encontra explicitada no Código de 
Ética dos Profissionais de Enfermagem (CEPE): que a equipe poderá optar por participar ou não de procedimentos requeridos para a realização do aborto legal sempre que houver outro membro da equipe que possa substituí-los (COFEn, 2007).

Bedone e Faúndes (2007) apontam que há referências contraditórias relacionadas à sensibilização dos profissionais para aceitar a prática do aborto legal. Uma vez que esse processo está submetido aos ditames da consciência pessoal, não significa que ter sido sensibilizado para atuar no aborto previsto em lei resulte em tornar-se apto para atuar de forma humanizada. É preciso considerar também questões de consciência pessoal e sua relação com conflitos e ideologias nos quais a objeção de consciência está firmada. Portanto, aqueles profissionais dispostos a serem sensibilizados para atuar de forma mais humanizada devem se autodeclarar não objetores de consciência para essa questão.

$\mathrm{O}$ direito à Objeção de Consciência por parte da classe médica não é absoluto. $\mathrm{O}$ Serviço Público de Saúde está inserido na estrutura de um país laico, que deverá garantir os direitos das mulheres que buscam o aborto legal. A alegação de objeção de consciência não pode ocasionar danos à saúde da mulher (DINIZ, 2011). Os profissionais de saúde possuem pouco conhecimento sobre a utilização dessa prerrogativa no contexto de realização do aborto legal no Brasil. A reflexão sobre as atitudes e práticas diárias não lhes permite transpor os limites impostos pela necessidade do cumprimento de seus deveres e obrigações e preferem ir ao encontro de suas convicções e crenças (CAMARGO et al., 2014).

O desconhecimento sobre direitos profissionais, conforme expresso nos códigos de ética da enfermagem e medicina, para o enfrentamento de situações que lhe são difíceis como o aborto previsto em lei - se reflete em condutas constrangedoras. Submeter-se, obedecer e seguir a decisão de outros profissionais e regras do serviço é decorrente da ausência de embasamento científico e ético alicerçado para justificar suas ações em saúde (CAMARGO et al., 2014).

De fato, a realização de um cuidado por obrigação pode contribuir para que o profissional desenvolva práticas desagradáveis para consigo e para com aquela que está sob seus cuidados. Uma situação que poderá traduzir-se em violência psicológica e institucional para com as mulheres que buscam o aborto previsto em lei (GESTEIRA, 2008).

Como membro da equipe de saúde que dispensa cuidados para mulheres e adolescentes no programa de aborto legal, o enfermeiro deverá receber capacitação acadêmica prevista nas Diretrizes Curriculares Nacionais - DCN (2001): 
qualificações: assistir ao usuário de forma humanista, intelectualmente embasado e pautado em princípios éticos. Deverá ser capaz de conhecer e intervir sobre problemas/situações de saúde-doença mais prevalentes no perfil epidemiológico nacional, com ênfase na sua região de atuação, identificando as dimensões biopsicossociais dos seus determinantes. Capacitado a atuar, com senso de responsabilidade social e compromisso com a cidadania, como promotor da saúde integral do ser humano.

Essa seria a base para a prática do cuidado em saúde que incorpora, ainda, a governança, definida como "a expertise desenvolvida pelos enfermeiros por meio do conhecimento processual adquirido ao longo da experiência profissional, visando superar os entraves organizacionais e relacionais para o domínio do ambiente de cuidado" (COPELLI, 2015).

A governança é o processo de dirigir, orientar e regular indivíduos, organizações ou nações em suas condutas ou atos em prol de um bem comum. Trata-se de um conceito cada vez mais frequente em estudos de diversas áreas acadêmicas, principalmente em discussões atreladas à administração, gestão organizacional e desenvolvimento, e implementação de políticas públicas. Está relacionada aos seguintes termos: normas, direção, ordem, controle, governança corporativa, autoridade, autonomia e tomada de decisão (HUGHES, 2010; ROBICHAU, 2011).

A mediação das tensões no contexto da equipe de trabalho é uma das competências esperadas do enfermeiro, visando proporcionar melhor cuidado ao paciente no ambiente hospitalar (SCHERB et al., 2010; SWIHART; HESS, 2013). Ainda que o cuidado no ambiente hospitalar esteja centrado em ações técnicas, destacando-se o saber fazer em detrimento da interação e relação de subjetividade entre os sujeitos, torna-se necessário incorporar ao conhecimento técnico-científico a integralidade do cuidado em saúde. A qualidade da assistência prestada pela equipe de enfermagem está diretamente relacionada ao atendimento de questões psíquicas e sociais de um cidadão integral que busca o serviço para receber cuidado integral e contextualizado (RODRIGUES, 2013).

Valores e crenças pessoais no tratamento das pacientes favorece o direcionamento das ações para as necessidades biológicas, que são mais fáceis de conduzir. A crise ética que pode se estabelecer no confronto entre valores pessoais e questões profissionais torna difícil o processo de atenção às mulheres e adolescentes, negligenciando-se o suporte emocional requerido (MONTEIRO, 2012).

A assistência integral à saúde da mulher, tal como proposta no SUS, aponta para a relevância fundamental do fato de que os profissionais estejam instrumentalizados tanto no que se refere a aspectos técnicos, éticos e jurídicos do aborto, quanto a seus aspectos 
subjetivos, evitando o julgamento e a consolidação de preconceitos. É preciso colocar em prática mais do que técnica, é preciso trazer ao cenário interação efetiva, escuta qualificada, afetividade e acolhimento (PNH, 2013).

A vivência de um aborto proporciona momentos de reflexão para a mulher. $O$ abortamento pode envolver o sentimento de tristeza pela perda do filho que ainda fazia parte do corpo da mulher, resultar em solidão por estar em um ambiente estranho, muitas vezes sem a presença de um familiar. Por fim, a dor emerge não apenas no aspecto físico decorrente dos procedimentos realizados. Trata-se de uma dor profunda, que engloba as circunstâncias e a história de vida de mulheres e adolescentes envolvidas nesse processo. Por isso, há necessidade de acompanhamento biopsicossocial durante todo o processo (MARQUES, 2009; BRASIL, 2012).

O aborto se traduz em diversas repercussões para a saúde da mulher e para sua qualidade de vida. No processo de abortamento, a mulher procura o serviço de saúde, onde é essencial que os profissionais estejam sensibilizados para o atendimento dessa parcela da população feminina, com o processo de perda e a vivência do luto. Assim, é fundamental que a equipe multiprofissional preste cuidado de qualidade, despindo-se de preconceitos, respeitando e suprindo as necessidades das pacientes de forma humanizada (RIBEIRO, 2000). O serviço de saúde deve garantir à mulher acolhimento, informação, aconselhamento, competência profissional, tecnologia apropriada disponível e relacionamento interpessoal pautado em respeito à dignidade e aos direitos sexuais e reprodutivos (BRASIL, 2012; MARIUTTI, 2007).

O respeito à individualidade é fundamental, pois cada pessoa possui valores e necessidades próprias. $\mathrm{O}$ atendimento humanizado deve ser prestado olhando-se a mulher em sua totalidade, sem fragmentá-la em aspectos biológicos, psicológicos, sociais, culturais e econômicos. Esse processo fortalece os direitos reprodutivos das mulheres, contribuindo para sedimentar os direitos bioéticos na busca do serviço de saúde. O respeito à individualidade diz respeito à sua privacidade e incorpora o seu eu, sua história, o contexto em que vivenciou a violência que gerou a gestação e a repercussão que se instala em todas as dimensões pessoais, que merecem respeito e cuidados apropriados da equipe de saúde (PNH, 2013).

$\mathrm{Na}$ análise das verbalizações dos profissionais, observou-se que a humanização, para eles, pode muitas vezes ser traduzida no uso de medicação para o alivio da dor; no fato de chamar o psicólogo para o atendimento de necessidades emocionais; na indicação da ouvidoria para garantir direitos; na melhoria do espaço físico para o atendimento; na escuta qualificada que se resuma a ausência de julgamento; e na informação passo a passo sobre o 
procedimento. Dessa forma, a maior parte do processo de humanização se refere a aspectos de infraestrutura, muito mais do que ao cuidado propriamente dito. Atenção especial deve ser dada ao fato de que chamar o psicólogo para "humanizar" pode se transformar em uma forma de se eximir do processo de humanização, tornando-se rotineiro.

O acolhimento e a orientação são elementos importantes para atenção qualificada e humanizada às mulheres em situação de abortamento. Acolhimento é o tratamento digno e respeitoso, a escuta, o reconhecimento e a aceitação das diferenças, o respeito ao direito de decidir de mulheres e homens, assim como o acesso e a resolubilidade da assistência à saúde. A ação de orientar deverá promover a autodeterminação, segundo o principio ético da autonomia (BRASIL, 2012).

A capacidade de escuta sem pré-julgamento, a capacidade de lidar com conflitos, a valorização das queixas e a identificação das necessidades são pontos básicos do acolhimento que poderão incentivar mulheres e adolescentes a falarem de seus sentimentos e necessidades. Cabe ao profissional adotar atitude terapêutica, buscando desenvolver escuta ativa e relação de empatia, que é a capacidade de criar comunicação sintonizada a partir das demandas das mulheres, assim como a possibilidade de se colocar no lugar do outro. Esse posicionamento é ratificado pelo Conselho Nacional de Justiça, esclarecendo que o diálogo e a alteridade são ferramentas essenciais para o agir em saúde. A alteridade, que nos leva, por meio da educação e da ética, a uma vida mais humana no mundo contemporâneo. Dessa forma, torna-se possível perceber a influência que a ética da alteridade exerce sobre o homem contemporâneo, exigindo dele a responsabilidade para com o outro (BRASIL, 2012; SILVA; CAETANO, 2014; BRASIL, 2015).

É fundamental que o profissional de saúde adquira olhar holístico que facilite o desprendimento de seus pré-julgamentos, pré-concepções, para que não haja limitações na assistência prestada (MOTTA, 2005). Aqui existe representatividade do princípio da beneficência (fazer o bem) versus o da não maleficência (que pode levar a riscos). Merece destaque situações como a inadequação do controle da dor, pois provoca nas mulheres sofrimento desnecessário, além de aumentar suas ansiedades, e de exposição a mais complicações, provocando insatisfação quanto à qualidade da atenção prestada. É importante destacar que o controle da dor pode se dar pelo uso de medicação ou por meio de atitudes amigáveis e tranquilizadoras, uma vez que a situação emocional influencia na percepção de dor por parte das mulheres (BRASIL, 2012).

Persistem dificuldades, por parte dos profissionais de saúde, para lidar com problemas provenientes da esfera social e da subjetividade humana, sobretudo aqueles com 
formação estritamente baseada no modelo biomédico. Esses obstáculos não se limitam apenas à inabilidade quanto às ações práticas, mas ao fato de que muitas vezes não conseguem visualizar os aspectos sociais e culturais relacionados aos problemas de saúde e, ainda, aos aspectos emocionais. Essas diferentes nuances contribuem para a permanência de conflitos internos, pressões e dificuldades para lidar com o abortamento, especialmente no caso do aborto previsto em lei (SOARES; FARIAS, 2003; CAVALCANTI, 2012). 


\section{CONSIDERAÇÕES FINAIS E RECOMENDAÇÕES}

A realização deste estudo permitiu conhecer o cenário no qual estão inseridas as adolescentes e mulheres que buscam o aborto previsto em lei. O Programa do Aborto Previsto em Lei suscita reflexões profundas para refinamento da condução do trabalho que circunda o oferecimento desse procedimento, que está baseado em políticas públicas ofertadas por um Estado de Direito.

Como se verificou na sessão de resultados, os objetivos propostos para a pesquisa foram plenamente alcançados. As limitações deste estudo consistiram na recondução de alguns objetivos específicos em virtude de versar em suas contemplações, nos resultados, o excesso de exposição das mulheres que buscam o aborto previsto em lei, possibilitando algumas formas de revitimização. Essa situação foi explicitada, em entrevista aberta, nas falas das mulheres que buscam o aborto previsto em lei na instituição em questão. Outro fator relevante, que preponderou nas falas dessas mesmas mulheres que utilizaram o programa, demonstrou a possibilidade de haver fragilidade institucional em protegê-las de outras formas de violência, como a moral/institucional.

O tema da Objeção de Consciência é, ainda, muito incipiente na concepção da maioria dos membros da equipe de saúde da instituição na qual foram coletados os dados. Os profissionais de saúde necessitam obter maior conhecimento e compreensão sobre o assunto como forma de contribuir para o estabelecimento do debate institucional, o que trará benefícios inequívocos. O direito de se declarar objetor de consciência - direito que emergiu das diretrizes de um Estado laico - não pode ir de encontro ao direito que mulheres e adolescentes possuem de receberem tratamento justo para suas necessidades de saúde. A incorporação de princípios às práticas cotidianas, especialmente no Programa de Aborto Previsto em Lei, assegurará proteção às usuárias do serviço, evitando novos tipos de violência moral e institucional, bem como sua revitimização.

Essa lacuna poderá ser preenchida por meio do fomento de pesquisas com diferentes delineamentos, direcionadas tanto para profissionais de saúde como para as usuárias do serviço. Terão como objetivo captar diferentes olhares dos distintos atores que vivenciam o processo de abortamento, de forma direta ou indireta.

Vale salientar que a norma técnica para o aborto previsto em lei pode ser considerada uma política de estado que incorpora princípios da Bioética para subsidiar o processo de acolhimento, encaminhamento e realização do aborto legal. Por outro lado, os 
profissionais de saúde são, em última instância, representantes legais do Estado, sendo as pessoas que implementam políticas e práticas em saúde. Devem pautar suas condutas tanto no reconhecimento dos direitos das pessoas atendidas, proporcionando assistência integral e cuidadosa para as mulheres e adolescentes que buscam o serviço, baseadas no humanismo e na eticidade das ações de atenção à saúde.

No que se refere à gestão do cuidado direcionado às mulheres e adolescentes persiste a necessidade de reestruturação e capacitação das equipes, respeitando-se os limites pessoais e profissionais. A infraestrutura física carece de reorganização para fornecer maior privacidade nas distintas etapas de realização do procedimento. Além disso, é de fundamental importância definir o fluxograma de atendimento para que a qualidade e a humanização do cuidado prestado sejam prioridade no serviço.

As equipes que acompanham as mulheres e adolescentes que realizam o aborto previsto em lei necessitam de suporte gerencial para capacitação, educação permanente e apoio psicológico a fim de estender o mesmo tipo de cuidado ofertado às mulheres atendidas no serviço para aquelas pacientes em caso de aborto.

Estabeleceu-se um rapport entre a pesquisadora e os participantes da pesquisa. $\mathrm{O}$ envolvimento e a disponibilidade foram cruciais para que os objetivos propostos nesta pesquisa fossem alcançados. Algumas demandas emergiram a partir da realização do estudo:

- Fomentar debates sobre o tema da Objeção de Consciência nos serviços de saúde que realizam o aborto legal;

- Identificar e acompanhar vítimas de violência sexual no que se refere às infecções por DST e HIV, especialmente no que se refere à adesão ao tratamento;

- Identificar as causas de as mulheres vítimas de violência sexual buscarem, com rara frequência, o serviço de saúde imediatamente após a vivência da violência;

- Identificar os motivos de baixa adesão, pelas mulheres e adolescentes, ao acompanhamento proporcionado pelos CAPS;

Persistem indagações que, respondidas por meio de estudos científicos, poderiam promover reflexões para o delineamento de novas políticas para mulheres, tais como:

- O fato de as mulheres não necessitarem de Boletim de Ocorrência (BO) para acessar o programa de aborto legal pode levar ao aumento da frequência de buscas, por violência sexual forjada? 
- A utilização da mídia para orientação dos fluxos nos serviços de saúde para atendimento imediato às mulheres e adolescentes vítimas de violência sexual reduziria a gestação pós-violência?

- O denominado "produto do aborto previsto em lei", ou seja, o feto, quando liberado, recebe o apoio dos direitos humanos?

- O lócus privilegiado da violência sexual contra mulheres é maior no âmbito extrafamiliar ou esta é uma forma de proteção dos envolvidos encontrada pelas mulheres?

- Se as mulheres que procuram as delegacias para efetuar a denúncia recebessem acolhimento adequado e respeitoso, aumentaria o número de boletins de ocorrência?

- As teorias filosóficas que embasam o aborto previsto em lei fundamentam também a descriminalização do aborto?

Verifica-se que maior número de estudos sobre a temática da Objeção de Consciência e seu vínculo com o aborto legal são essenciais no Brasil. Uma visão ampliada sobre este cenário poderia gerar reflexões mais aprofundadas com o objetivo de ocasionar possíveis mudanças de atitudes e melhor preparo das equipes que cuidam das mulheres e adolescentes vítimas de violência sexual que buscam o aborto previsto em lei ou aborto legal. 


\section{REFERÊNCIAS}

BALZANO, Angela. Medicina riproduttiva e obiezione di coscienza - The Italian case: reproductive medicine and conscientious objection. Bioética y Derecho, v. 29, p. 11-23, set. 2013.

BARDIN, Laurence. Análise de conteúdo. Rio de Janeiro: Edições 70, 2001.

BAUER, Martin W.; GASKELL, George. Pesquisa qualitativa com texto, imagem e som: um manual prático. 2. ed. Rio de Janeiro: Vozes, 2002.

BEAUCHAMP Tom L.; CHILDRESS, James F. Principles of Biomedical Ethics. 6. ed. New York: Oxford, 2009.

BEAUCHAMP Tom L.; CHILDRESS, James F. Principles of Biomedical Ethics. 4. ed. New York: Oxford, 1994. p. 100-103.

BEAUCHAMP, Tom L. "The origins, goals, and core commitments of the Belmont Report and principles of biomedical". In: WALTER, Jennifer Kay; KLEIN, Eran Patrick. The Story of Bioethics: from seminal works to contemporary explorations. Washington, D.C.:

Georgetown University Press, 2003.

BEAUCHAMP, Tom L. "Why our conceptions of research and practice may not serve the best interest of patients and subjects". Journal of Internal Medicine, abr. 2011, p.383-7.

BEDONE, Aloísio José; FAÚNDES, Aníbal. Atendimento integral às mulheres vítimas de violência sexual: Centro de Assistência Integral à Saúde da Mulher, Universidade Estadual de Campinas. Cadernos da Saúde Pública, v. 23, n. 2, p. 465-9, 2007. Disponível em: <http://www.scielo.br/pdf/csp/v23n2/24.pdf>. Acesso em: 26 set. 2015.

BRASIL. Código Penal. Decreto-lei no 2.848, de 7 de dezembro de 1940. Disponível em: <http://www.jusbrasil.com.br/legislacao/91614/cp-decreto-lei-n-2-848-de-07-de-dezembrode-1940\#art-128>. Acesso em: 23 set. 2015.

BRASIL. Conselho Nacional de Justiça. Disponível em: <http://www.cnj.jus.br/files/ conteudo/destaques/arquivo/2015/06/6781486daef02bc6ec8c1e491a565006.pdf 2015>. Acesso em: 26 set. 2015.

BRASIL. Conselho Nacional de Saúde. Resolução n. 466, de 12 de dezembro de 2012. Disponível em: <http://conselho.saude.gov.br/resolucoes/2012/Reso466.pdf>. Acesso em: 12 jul. 2015.

BRASIL. Constituição da República Federativa do Brasil de 1988. Diário Oficial [da República Federativa o Brasil], Brasília, DF. Disponível em:

<http://www.planalto.gov.br/ccivil_03/constituicao/constituicaocompilado.htm>. Acesso em: 26 abr. 2015.

BRASIL. Decreto-Lei n ${ }^{\circ}$ 2.848, de 7 de dezembro de 1940, art. 128, inciso II. Diário Oficial da União, Seção I: 23.911, 31 dez. 1940. 
BRASIL. Ministério da Saúde. Secretaria de Atenção à Saúde. Área de Saúde do Adolescente e do Jovem. Marco legal: saúde, um direito de adolescentes. Brasília: Ministério da Saúde, 2005. (Série A. Normas e Manuais Técnicos). Disponível em:

<http://www.saude.sp.gov.br/resources/ses/perfil/profissional-da-saude/grupo-tecnico-deacoes-estrategicas-gtae/saude-das-populacoes-privadas-de-liberdade/saude-dos-adolescentesem-conflito-com-a-lei/seminario-ministerio-da-saude-fundacao-casa-eses/marco_legal_saude_um_direito_de_adolescentes.pdf 2005>. Acesso em: 26 set. 2015.

BRASIL. Ministério da Saúde. Secretaria de Atenção à Saúde. Departamento de Ações Programáticas Estratégicas. Área Técnica de Saúde da Mulher. Atenção humanizada ao abortamento: norma técnica. 2. ed. Brasília: Ministério da Saúde, 2012.

BRASIL. Ministério da Saúde. Secretaria de Atenção à Saúde. Prevenção e tratamento dos agravos resultantes da violência sexual contra mulheres e adolescentes: Norma Técnica. 3. ed. Brasília: Ministério da Saúde, 2012.

BRASIL. Ministério da Saúde. Secretaria de Políticas para Mulheres, 2010. Disponível em: <http://www.sepm.gov.br/>. Acesso em: 11 abr. 2015.

BRASIL. Ministério Público de Sergipe. Coordenadoria Geral. Disponível em: <http://www.mpse.mp.br/CoordenadoriaGeral/>. Acesso em: 23 set. 2015.

BRASIL. Ministério Público e Estado do Rio Grande do Sul. Doutrina. Disponível em: <https://www.mprs.mp.br/infancia/doutrina/id617.htm.2009>. Acesso em: 20 set. 2015.

BRASIL. Portaria $n^{\circ} 1.508$, de $1^{\circ}$ de setembro de 2005. Dispõe sobre o Procedimento de Justificação e Autorização da Interrupção da Gravidez nos casos previstos em lei, no âmbito do Sistema Único de Saúde - SUS. Disponível em:

<http://bvsms.saude.gov.br/bvs/saudelegis/gm/2005/prt1508_01_09_2005.html>. Acesso em: 28 jun. 2013.

Brasil. Presidência da República. Casa Civil. Subchefia para Assuntos Jurídicos. Lei 8069 de 13 de julho de 1990. Dispõe sobre o Estatuto da Criança e do Adolescente e dá outras providências. Disponível em: http://www.planalto.gov.br/ccivil_03/Leis/L8069.htm>. Acesso em 22 set. 2015.

BRASIL. Presidência da República. Casa Civil. Subchefia para Assuntos Jurídicos. Constituição Federativa do Brasil - 1988. Brasília: Presidência da República, 2012.

Disponível em: <http://www.planalto.gov.br/ccivil_03/constituicao/ConstituicaoCompilado. htm>. Acesso em: 03 jun. 2014.

BRASIL. Secretaria de Políticas para as Mulheres. Rede de Enfrentamento à Violência contra as Mulheres. Brasília: Secretaria Nacional de Enfrentamento à Violência contra as Mulheres, 2011.

CABRAL TAVARES, João Manuel. Da atribuição do Estatuto de Objetor de Consciência. Revista do Ministério Público, ano 10, n. 40, 1989.

CAMARGO, Maria da Graça; GUILHEM, Dirce Bellezi; LAGO, Diane Maria Scherer Kuhn; RODRIGUES, Suzana Gonçalves. Objeção de consciência e aborto legal sob a perspectiva da saúde: revisão integrativa. Revista de Enfermagem da UFPE, v. 8, n. 6, p. 1774-81, 2014. Disponível em: <http://www.google.com.br/url?sa=t\&rct=j\&q=\&esrc=s\&frm=1\&source= 
web $\&$ cd $=2 \&$ ved $=0 \mathrm{CCUQFjAB} \& u r l=\mathrm{http} \% 3 \mathrm{~A} \% 2 \mathrm{~F} \% 2 \mathrm{Fwww} \cdot$ revista.ufpe.br $\% 2$ Frevistaenfer magem\%2Findex.php\%2Frevista\%2Farticle\%2Fdownload\%2F4231\%2F9392\&ei=2bUWVf DaH4jHsQTCiYHwCw\&usg=AFQjCNHQzprGhhkxnpvWyzkwzd8tMuKBiQ\&sig2=rGKf6n xi1eSe-DWJBNm4OA>. Acesso em: 05 abr. 2015.

CASANOVA-RÍSPOLI, Eduardo. Patria y bien común: objeción de conciencia y desobediencia civil. Persona y Bioética, v. 14, n. 2, p. 163-166, 2010.

CAVALCANTE, Maria de Belém Gomes. Humanização no processo de formação de profissionais de saúde: experiências de alunos do curso de graduação em enfermagem. 2003. Tese (Doutorado) - Universidade de São Paulo. São Paulo: Escola de Enfermagem da USP, 2003.

COLLEGE OF REGISTERED NURSES OF BRITISH COLUMBIA - CRNBC. Duty to Provide Care: Practice Standard for Registered Nurses and Nurse Practitioners. Canada: CRNBC, 2007. Disponível em: <https://crnbc-old.crnbc.ca/Standards/PracticeStandards/Lists/ GeneralResources/398DutytoProvideCarePracStd.pdf>. Acesso em: 05 abr. 2015.

COLLEGE OF REGISTERED NURSES OF BRITISH COLUMBIA. Duty to provide care: practice standard for registered nurses and nurse practitioners. 2012. Disponível em: <https://www.crnbc.ca/Standards/Lists/StandardResources/128ProfessionalStandards.pdf >. Acesso em: 05 abr. 2015.

CONSELHO FEDERAL DE ENFERMAGEM (COFEN). Código de Ética dos Profissionais de Enfermagem. Disponível em:

$<$ http://www.portalcofen.gov.br/2007/materias.asp?ArticleID=7323\&sectionID=37>. Acesso em: 05 abr. 2015.

CONSELHO FEDERAL DE MEDICINA (CFM). Código de Ética Médica. 2010. Disponível em: 〈http://www.portalmedico.org.br/novocodigo/index.asp>. Acesso em: 05 abr. 2015.

COPELLI, Fernanda Hannah da Silva; OLIVEIRA, Roberta Juliane Tono de; ERDMANN, Alacoque Lorenzini et al. Compreendendo a governança da prática de enfermagem em um centro obstétrico. Escola Anna Nery Revista de Enfermagem, 2015, v. 19, n. 2. Disponível em: <http://www.scielo.br/pdf/ean/v19n2/1414-8145-ean-19-02-0239.pdf>. Acesso em: 05 abr. 2015.

CRESWELL, John W.; PLANO CLARK, Vicki L. Designing and conducting mixed methods research. 4. ed. Thousand Oaks, CA: Sage, 2014.

CRESWELL, John W.; PLANO CLARK, Vicki L. Designing and conducting mixed methods research. 2. ed. Thousand Oaks, CA: Sage, 2011.

CRESWELL, John W.; PLANO CLARK, Vicki L. Designing and conducting mixed methods research. Thousand Oaks, CA: Sage, 2007.

DALL'AGNOL, Darlei. Bioética. Rio de Janeiro: Jorge Zahar, 2005.

DALMAU LLISO, Juan Carlos. La objeción fiscal a los gastos militares. Madrid: Tecnos, 1996. 
DAMASCENO CORREIA, António. O direito à Objeção de Consciência. Lisboa: Vega, 1993.

DELEUZE, Gilles; GUATTARI, Félix. Micropolítica e segmentaridade. In: .Mil platôs: capitalismo e esquizofrenia. Rio de Janeiro: Editora 34, 1996. p. 83-115. (Coleção Trans).

DEMO, Pedro. Pesquisa e informação qualitativa. 2. ed. Campinas: Papirus, 2001.

DINIZ, Débora. Objeção de consciência e aborto: direitos e deveres dos médicos na saúde pública. Revista de Saúde Pública, v. 45, n. 5, p. 981-985, 2011. Disponível em: <http://www.scielo.br/pdf/rsp/v45n5/2721.pdf>. Acesso em: 05 out. 2014.

DINIZ, Débora; DIOS, Vanessa C; MASTRELLA, Myriam; MADEIRO, Alberto P. Objeção de consciência, barreiras, e o aborto em caso de estupro: um estudo entre os médicos no Brasil. Revista Bioética, v. 22, n. 2, p. 291-298, 2014.

DWORKIN, Ronald. Life's dominion: an argument about abortion, euthanasia and individual freedom. New York: Vintage Books, 1994.

FARIAS, Rejane Santos; CAVALCANTI, Ludmila Fontenele. Atuação diante das situações de aborto legal na perspectiva dos profissionais de saúde do Hospital Municipal Fernando Magalhães. Ciências e Saúde Coletiva, Rio de Janeiro, v. 17, n. 7, jul. 2012. Disponível em: <http://www.scielo.br/scielo.php?script=sci_arttext\&pid=S1413-81232012000700014>. Acesso em: 05 out. 2014.

FAÚNDES, Aníbal; BARZELATTO, José. O drama do aborto: em busca de um consenso. Campinas: Komedi, 2004.

FERRER, Ana Luíza. Sofrimento psíquico dos trabalhadores inseridos nos Centros de Atenção Psicossocial: entre o prazer e a dor de lidar com a loucura. 2007. 136 f. 2007. Dissertação (Mestrado em Saúde Coletiva) - Faculdade de Ciências Médicas, Universidade Estadual de Campinas, Campinas, 2007.

FERRER, Jorge José; Álvarez, Juan Carlos. Capítulo 1: Ética, moral y bioética. In: Para fundamentar la bioética: teorías y paradigmas teóricos en la bioética contemporánea Madrid, Universidad Pontificia de Comillas, 2003. p. 21-82.

GESTEIRA, Solange Maria dos Anjos; DINIZ, Normélia Maria Freire; OLIVEIRA, Eleonora Menicucci de. Healthcare for women in process of induced abortion: statements of nursing professionals. Acta Paulista de Enfermagem, São Paulo, v. 21, n. 3, p. 449-53, 2008. Disponível em: <http://www.scielo.br/scielo.php?script=sci_arttext\&pid=S010321002008000300011\&lng=en\&nrm=iso>. Acesso em: 25 set. 2015.

GIL, Antônio Carlos. Métodos e técnicas de pesquisa social. 2. ed. São Paulo: Atlas, 1987.

GLANZNER, Cecília Helena. Avaliação dos fatores de sofrimento e prazer no trabalho em um centro de atenção psicossocial. 2008. Dissertação [Mestrado] - Escola de Enfermagem, Universidade Federal do Rio Grande, Porto Alegre, 2008. 
GLANZNER, Cecília Helena; OLSCHOWSKY, Agnes; KANTORSKI, Luciane Prado. O trabalho como fonte de prazer: avaliação da equipe de um Centro de Atenção Psicossocial. Revista de Escola de Enfermagem da USP, v. 45, n. 3, p. 716-21, 2011.

GOFFIN, Tom. The physician's right to conscientious objection: an evolving recognition in Europe. Medicine and Law, v. 29, n. 2, p. 227-37, jun. 2010.

GOLDIM, José Roberto. Princípios Éticos. Bioética. Núcleo Interinstitucional de Bioética. (Base de dados dos Grupos de Pesquisa). Disponível em:

<http://dgp.cnpq.br/buscaoperacional/ detalhegrupo.jsp?grupo=0384401DE1TO1K>. Acesso em 19 set. 2015.

GOMES CANOTILHO, José Joaquim. Anotação ao Acórdão do Tribunal Constitucional n. ${ }^{\text {o }}$ 5/96, de 16 de janeiro. Revista de Legislação e Jurisprudência, Coimbra, ano 129, n. 3865, 1996-1997.

GOMES CANOTILHO, José Joaquim. Anotação ao Acórdão n. ${ }^{\circ}$ 363/91, de 13 de julho, do Tribunal Constitucional. Revista de Legislação e Jurisprudência, Coimbra, ano 129, n. 3807, 1991.

GOMES CANOTILHO, José Joaquim; MOREIRA, V. Constituição da República Portuguesa anotada. 3. ed. Coimbra: Coimbra Editora, 1993.

GRACIA, Diego et al. Medicina clínica, v. 117, n. 1, p. 18-23, 2001.

GRACIA, Diego. Fundamentos de Bioética. Madrid: Eudema, 1989.

GRACIA, Diego. La deliberación moral: el método de la ética clínica. In: GRACIA, Diego; JÚDEZ, Javier (ed.). Ética en la práctica clínica. Madrid: Fundación de Ciencias de la Salud, Editorial Triacastela; 2004. p. 21-32.

GRACIA, Diego. Planteamiento de la bioética. In: GARCÍA, Marciano Vidal (Ed.). Conceptos fundamentales de ética teológica. Madrid: Trotta, 1992. p. 421-38.

GUTIERREZ, Beatriz Aparecida Ozello. O processo de morrer no cotidiano do trabalho dos profissionais de enfermagem de Unidades de Terapia Intensiva. 2003. Tese (Doutorado) Universidade de São Paulo. Escola de Enfermagem, São Paulo, 2003.

HARRIES, Jane; COOPER, Diana; STREBEL, Anne; COLVIN, Christopher J. Conscientious objection and its impact on abortion service provision in South Africa: a qualitative study. Reproductive Health, v. 11, n. 1, p. 16, 2014. Disponível em: <http://www.reproductivehealth-journal.com/content/11/1/16>. Acesso em: 11 abr. 2015.

HESS, Robert G.; SWIHART, Diana. Shared governance: What it can mean for nurses. Nursing Spectrum, v. 25, n. 1, p. 38-43, jan. 2013.

HIGA, Rosangela; REIS, Maria José dos; LOPES, Maria Helena Baena de Moraes. Interrupção legal da gestação decorrente de estupro: assistência de enfermagem às mulheres atendidas num serviço público da cidade de Campinas-SP. Ciência, Cuidado e Saúde, v. 6, n. 3, p. 372-6, 2008. Disponível em: <http://periodicos.uem.br/ojs/index.php/CiencCuidSaude/article/view/1747/pdf>. Acesso em: 11 abr. 2015. 
HOTTOIS, Gilbert; MISSA, Jean-Noël. Nouvelle encyclopédie de bioéthique. Bruxelas: De Boeck, 2001.

http://dx.doi.org/10.1590/S1413-81232012000700014 Acesso em 26 de SET de 2015

HUGHES, Owen. Does Governance Exist?. In: OSBORNE, S. P. (Ed.). The New Public Governance? Emerging Perspectives on the Theory and Practice of Public Governance. London: Routledge, 2010. p. 87-104.

JONAS, Hans. Técnica, Medicina y Ética: la práctica del principio de responsabilidad. Barcelona: Paidós, 1997.

JONSEN, Albert R. The Birth of Bioethics. Oxford: Oxford University Press, 2003.

JOURNAL OF NURSING MANAGEMENT. 2009, v. 17. Disponível em:

<http://onlinelibrary. wiley.com/journal/10.1111/(ISSN)1365-2834/issues>. Acesso em: 05 abr. 2015.

KANE, Roslyn. Conscientious objection to termination of pregnancy: the competing rights of patients and nurses. Journal of Nursing Management, n. 17, p. 907-12, 2009. Disponível em: <http://www.ncbi.nlm.nih.gov/pubmed/19793248>. Acesso em: 05 abr. 2015.

KOVÁCS, Maria Julia. Sofrimento da equipe de saúde no contexto hospitalar: cuidando do cuidador profissional. O Mundo da Saúde, São Paulo, 2010, v. 34, n. 4, p. 420-9. Disponível em: <http://www.saocamilo-sp.br/pdf/mundo_saude/79/420.pdf >. Acesso em: 26 set. 2015.

KUHN, Thomas. A estrutura das revoluções científicas. São Paulo: Perspectiva, 1975.

KULCZYCKI, Andrzej; POTTS, Malcolm; ROSENFIELD, Allan. Abortion and Fertility Regulation, v. 347, jun. 1996, p. 1663-8.

LAMACKOVÁ, Adriana. Conscientious objection in reproductive health care: analysis of Pichon and Sajous v. France. European Journal of Health Law, v. 15, n. 1, p. 7-43, maio 2008.

LAMEGO, José. "Sociedade Aberta" e liberdade de consciência: o direito fundamental de liberdade de consciência. Lisboa: AAFDL, 1985.

LANCMAN, Selma; SZNELWAR, Laerte (Org.). Christophe Dejours: da psicopatologia à psicodinâmica do trabalho. 2. ed. Rio de Janeiro: Fiocruz, 2008.

MARIUTTI, Mariana Gondim; ALMEIDA, Ana Maria; PANOBIANCO, Marislei Sanches. O cuidado de enfermagem na visão de mulheres em situação de aborto. Revista LatinoAmericana de Enfermagem. Ribeirão Preto, v. 15, n. 1, p. 20-26, 2007.

MARQUES, Girlene de Oliveira; MASCHERPE, Greta; SOUZA, Kelly Brígida Gomes de. Mulheres em situação de abortamento: percepção sobre a assistência da equipe de enfermagem. São Paulo, 2009.

MARTINEZ-TORRON, Javier. La Objeción de conciencia en la jurisprudencia del Tribunal Supremo norteamericano. Anuario de derecho eclesiástico del Estado, v. I, Madrid, 1985. 
MARTINI, Carlo Maria; ECO, Humberto. Em que creem os que não creem?12. ed. Rio de Janeiro: Record, 2009.

MARTINS, Isabel Otília Parreiral Pinheiro de et al. A operacionalização dos princípios da Bioética no principialismo de Beauchamp e Childress. Dissertação (Mestrado em Filosofia) Faculdade de Ciências Sociais e Humanas. Universidade Nova Lisboa, 2013.

McHALE, Jean V. Conscientious objection and the nurse: a right or a privilege? British Journal of Nursing, v. 18, n. 20, p. 1262-1263, set. 2009.

MENDES, Ana Magnólia; TAMAYO, Álvaro. Valores organizacionais e prazer-sofrimento no trabalho. Psico-USF, v. 6, n. 1, p. 39-46, 2001.

MENESES CORDEIRO, ANTÓNIO. Contrato de trabalho e objecção de consciência. Estudos de Homenagem ao Prof. Doutor Raúl Ventura, v. II, Faculdade de Direito da Universidade de Lisboa, Coimbra Editora, 2003.

MINAYO, Maria Cecilia de Souza. O desafio do conhecimento: pesquisa qualitativa em saúde. São Paulo: Hucitec, 2004.

MINISTÉRIO DA SAUDE. Área Temática da Humanização. Biblioteca Virtual em Saúde Ministério da Saúde. Secretaria de Atenção à Saúde. 2013. Disponível em:

<http://www.saude.gov.br/bvs/humanizacao>. Acesso em: 26 set. 2015.

MIRANDA, Jorge. A Constituição Portuguesa de 1822 no texto actual da Constituição. 3. ed. Lisboa: Petrony, 1992.

MIRANDA, Jorge. Manual de Direito Constitucional. Tomo II. 3. ed. Coimbra: Coimbra Editora, 2000.

MÖLLER, Letícia Ludwig. Pluralismo e tolerância: valores para a bioética. Revista do Hospital de Clínicas de Porto Alegre, v. 28, n. 2, p. 101-9, 2008.

MONTEIRO, Janine Kieling. Sofrimento psíquico de trabalhadores de unidade de terapia intensiva. Revista Psicologia: Organizações e Trabalho, v. 12, n. 2, p. 245-50, 2012. Disponível em: <http://pepsic.bvsalud.org/scielo.php?script=sci_arttext\&pid=S1984$66572012000200009 \& \operatorname{lng}=$ pt\&nrm=iso>. Acesso em: 26 set. 2015.

MOTTA, Ilse Sodré da. A relação interpessoal entre profissionais de saúde e a mulher em abortamento incompleto: "o olhar da mulher". Revista Brasileira de Saúde Materno-Infantil, 2005, v. 5, n. 2, p. 219-27.

NATIONAL SECULAR SOCIETY. GMC Consultation: Personal beliefs and medical practice. 21 set. 2007. Disponível em: <https://www.secularism.org.uk/uploads/

NORDBERG, Eva MK; SKIRBEKK, Helge; MAGELSSEN, Morten. Conscientious objection to referrals for abortion: pragmatic solution or threat to women's rights? BMC medical ethics, v. 15, n. 1, p. 15, 2014. Disponível em: <http://www.biomedcentral.com/ 1472-6939/15/15>. Acesso em: 28 fev. 2014.

PELLEGRINO, Edmund; THOMASMA, David C. For the patient's good: the restoration of beneficence in health care. New York: Oxford University Press, 1988. 
PESSINI, Leocir; DE BARCHIFONTAINE, Christian de Paul. Problemas atuais de bioética. 10. ed. São Paulo: Loyola. 2012

PIOVESAN, Flávia; PIROTTA, Wilson R. Buquetti. Direitos reprodutivos e o poder Judiciário no Brasil. In: OLIVEIRA, Maria Coleta Albino; ROCHA, Maria Isabel Baltar da. Saúde reprodutiva na esfera pública e política na América Latina. Campinas: Editora da Unicamp; NEPO; 2001. p.155-86.

PORTO, Rozeli Maria. Objeção de Consciência, aborto e religiosidade: práticas e comportamentos dos profissionais de saúde em Lisboa. Revista de Estudos Feministas, v. 16, n. 2, p. 661-666, 2008. Disponível em: <http://www.seer.ufrgs.br/hcpa/article/download/ 5744/3517>. Acesso em: 05 abr. 2015.

POST, Stefhen Garrard. Encyclopedia of Bioethics. 3. ed. United States: Macmillan; 2003.

POTTER, Van Rensselaer. Bioethics, the science of survival. Perspectives in biology and medicine, n. 14, p. 127-53, 1970.

POTTER, Van Rensselaer. Bioethics: a bridge to the future. New Jersey: Prentice-Hall, 1971.

POTTER, Van Rensselaer. Global Bioethics: building on the Leopold Legacy. Michigan, USA: Michigan State Press; 1998.

QUAGHEBEUR, Toon; DE CASTERLÉ, Bernadette Dierckx; GASTMANS, Chris. Nursing and euthanasia: a review of argument-based ethics literature. Nursing Ethics, v. 16, n. 4, p. 466-86, 2009.

RAMMINGER, Tatiana. Trabalhadores de saúde mental: reforma psiquiátrica, saúde do trabalhador e modos de subjetivação nos serviços de saúde mental. Santa Cruz do Sul: Ed. UNISC; 2006.

REICH, Warren Thomas (Ed.). Encyclopedia of Bioethics, New York: Free Press, 1982.

REICH, Warren Thomas (Ed.). Encyclopedia of Bioethics. 2. ed. New York: Free Press, 1995.

RIBEIRO NETO, J. J. A. Profissional de saúde e o abortamento: É preciso humanizar o atendimento. Jornal da Rede Nacional Feminista de Saúde e Direitos Reprodutivos, v. 21, p. 6-8, 2000.

ROBICHAU, Robbie Waters. The mosaic of governance: Creating a picture with definitions, theories, and debates. Policy Studies Journal, v. 39, n. s1, p. 113-31, 2011.

ROCHA, Wesley Braga da et al. Percepção de profissionais da saúde sobre abortamento legal. Revista de Bioética, Brasília, v. 23, n. 2, p. 387-399, ago. 2015. Disponível em: <http://www.scielo.br/scielo.php?script=sci_arttext\&pid=S198380422015000200387\&lng=en\&nrm=iso>. Acesso em: 20 set. 2015.

RODRIGUES, Polianna Formiga; AMADOR, Daniela Doulavince; SILVA, Kenya de Lima et al. Interação entre equipe de enfermagem e família na percepção dos familiares de crianças com doenças crônicas. Escola de Enfermagem Anna Nery, v. 17, n. 4, p. 781-7, 2013. 
ROTHMAN, David J. Strangers at the Bedside: a history of how law and bioethics transformed medical decision making. New York: Basic Books, 2003.

RUDIO, Franz Victor. Introdução ao projeto de pesquisa científica. 3. ed. Petrópolis: Vozes, 1986.

SCHERB, Cindy A. et al. Decisional involvement: staff nurse and nurse manager perceptions. Western Journal of Nursing Research, v. 33, n. 2, p. 161-79, 2011.

SCHRAIBER, Lilia B.; D'OLIVEIRA, A. F. P. L. Violência contra mulheres: interfaces com a saúde. Interface - Comunicação, Saúde e Educação, n. 5, p. 11-28, 1999.

SCHRAMM, Fermin Roland. Uma breve genealogia da bioética em companhia de Van Rensselaer Potter. Revista Bioethikós, v. 5, n. 3, p. 302-8, 2011.

SELLTIZ, Claire; WRIGHTSMAN, Lawrence S.; COOK, Stuart Welldford. Métodos de pesquisa nas relações sociais. 2. ed. São Paulo: Herder, 1987.

SHIMIZU, Helena Eri. As representações sociais dos trabalhadores de enfermagem não enfermeiros (técnicos e auxiliares de enfermagem) sobre o trabalho em Unidades de Terapia Intensiva em um hospital-escola. Tese (Doutorado) - Universidade de São Paulo. São Paulo: Escola de Enfermagem da USP, 2000.

SILVA, Juliano Xavier da Costa; CAETANO, Renato Fernandes. A concepção de alteridade em Lévinas: caminhos para uma formação mais humana no mundo contemporâneo. Revista Eletrônica Igarapé, n. 3, 2014. Disponível em:

<http://www.periodicos.unir.br/index.php/igarape>. Acesso em: 26 set. 2015.

SMITH, George P. Refractory pain, existential suffering, and palliative care: releasing an unbearable lightness of being. Cornell Journal of Law and Public Policy, v. 20, n. 3, p. 469$532,2011$.

SOARES, Gilberta Santos. Profissionais de saúde frente ao aborto legal no Brasil: desafios, conflitos e significados. Cadernos de Saúde Pública, Rio de Janeiro, v. 19, supl. 2, p. S399S406, jan. 2003. Disponível em: <http://www.scielosp.org/scielo.php?script=sci_arttext \&pid=S0102-311X2003000800021\&lng=en\&nrm=iso>. Acesso em: 26 set. 2015.

SORIANO, Ramón. La Objeción de Conciencia: significado, fundamentos jurídicos y positivación en el ordenamiento jurídico español. Revista de Estudios Políticos, n. 58. Madrid: Nueva Época, 1987.

TORRES, José Henrique Rodrigues. Aborto e legislação comparada. Ciência e Cultura, v. 64, n. 2, p. 40-4, 2012.

TRIALS OF WAR CRIMINAL BEFORE THE NUREMBERG MILITARY TRIBUNALS. The Nuremberg Code. Control Council Law, n. 10, p. 181-182. US Government Printing Office, Washington DC, 1949.

TUDOMÁNYEGYETEM, Szegedi; SZENTHÁROMSÁG, Szeged. Euthanasia outside Europe. Orvosi Hetilap, Hungria, v. 155, n. 32, p. 1259-64, ago. 2014. 
VELÁSQUEZ-CÓRDOBA, Luís Fernando; CÓRDOBA-PALACIO, Ramón. Objeción de consciencia y la antropología filosófica. Persona y Bioética, v. 14, n. 2, p. 167-75, 2010.

VENDITTI, Rodolfo. Le Recenti Novita Giurisprudenziali. Dovere costituzionale di difesa e servizio civile dell'obiettore di coscienza (Sent. 164/1985 della Corte Costituzionale). In:

Obiezione di Coscienza al Servizio Militare: profili giuridici e prospective legislative, Padova: CEDAM, 1989.

WASHINGTON. The Belmont Report: Ethical Guidelines for the Protection of Human Subjects. Washington: DHEW Publications (OS) 78-0012, 1978.

WMA. The World Medical Association Declaration of Helsinki. 1964. 


\title{
APÊNDICE A - TERMO DE CONSENTIMENTO LIVRE E ESCLARECIDO (TCLE) PARA A PARTICIPAÇÃO NA PESQUISA QUE TEM COMO TÍTULO: ABORTO PREVISTO EM LEI E SUAS REPERCUSSÕES: VIVÊNCIAS EM UM SERVIÇO PÚBLICO
}

\author{
PESQUISADORA RESPONSÁ VEL: Maria da Graça Camargo Neves \\ TELEFONE: 95550593 \\ COMITÊ DE ÉTICA EM PESQUISA DA SEC. DE SAÚDE: 3325-4955
}

1. OBJETIVOS DO ESTUDO: Conhecer e descrever o trabalho desenvolvido no serviço do aborto previsto em lei em um serviço público de saúde.

2. JUSTIFICATIVA: Este estudo se justifica pela sua transcendência da magnitude de um problema biológico, social e psicológico que afeta adolescentes, mulheres e profissionais de saúde e suas vivências descritas e comparadas com realidades internacionais. Busca-se, assim, o aprimoramento para gestão/organização de um hospital publico, fortalecendo-o como referência não somente no centro oeste, como no Brasil; o fomento de debates em políticas de saúde para mudanças nas estratégias das gestão/clínicas dos serviços (CARLIRI; MARZIALI 2000); e a promoção de parcerias entre formuladores de políticas e pesquisadores (SOUZA; CONTANDRIOPOULOS, 2004).

\section{PROCEDIMENTOS UTILIZADOS:}

3.1. A pessoa que participar do estudo vai responder a entrevista realizada pela pesquisadora, a qual, em parte, será registrada em papel; e a outra parte será gravada. As fitas serão preservadas com a pesquisadora e, posteriormente, destruídas após cinco anos do término da pesquisa, cujos resultados serão divulgados em uma tese de doutorado da Universidade de Brasília e no âmbito do serviço de saúde, com data prevista para 2015.

3.2. Essa entrevista buscará evidenciar como as concepções culturais interferem no processo do aborto previsto em lei na perspectiva da equipe e de mulheres violentadas. Caso queiram e em razão da durabilidade da entrevista, os entrevistados receberão lanches.

3.3. Serão retirados do prontuário das adolescentes e mulheres dados sobre o seu acompanhamento.

3.4. O participante terá direito de recusar-se a responder perguntas que lhe ocasionem 
constrangimentos de alguma natureza.

3.5. A adolescente/mulher que não quiser participar do estudo será acompanhada normalmente no serviço público de saúde.

3.6. O profissional da equipe multidisciplinar poderá optar por não participar da pesquisa.

\section{CONFIDENCIALIDADE:}

4.1. Nenhum participante será identificado. Será garantido sigilo absoluto a todos os participantes.

4.2. O Termo de Consentimento possuirá duas cópias. Uma ficará com o participante e/ou responsável (caso seja adolescente), profissional e a outra será lacrada em um envelope na sua frente, permanecendo assim até o término da pesquisa, quando será destruída.

4.3. O Termo de Assentimento, que segue os mesmos critérios do TCLE, será oferecido a adolescente que aceite participar da pesquisa.

\section{DESCONFORTOS, RISCOS E BENEFÍCIOS:}

Para os adolescentes, mulheres e profissionais que participarem:

5.1. A entrevista tem como previsão de duração de uma hora a uma hora e meia.

5.2. Se a adolescente/mulher e profissional da equipe multidisciplinar não se sentirem bem durante ou depois da entrevista, será atendida por psicóloga ou médico de imediato.

5.3. O resultado do estudo irá contribuir para melhorar o atendimento às adolescentes e mulheres que buscam o aborto previsto em lei serviço de referência do Centro Oeste.

5.4. Ao final da entrevista, o participante poderá tirar dúvidas e receber informações que julgar necessárias.

\section{DÚVIDAS:}

Qualquer dúvida poderá ser sanada no momento da entrevista com a entrevistadora ou no seguinte endereço:

Maria da Graça Camargo Neves

SMPW QD 28 CONJ 05 LT 2 95550593. Brasília-DF

\section{CONSENTIMENTO:}

Li todas as informações e tirei todas as dúvidas a respeito do estudo. Sei que a minha participação é por vontade própria e que posso desistir mesmo depois de ter começado, sem que isso me traga qualquer problema. Sei também que participando ou não, posso contar com 
o atendimento nos serviços públicos de saúde.

Por isso, concordo em participar.

Eu li este Termo e recebi as instruções que após assiná-lo, deverei dobrá-lo, colocar em envelope, lacrar e receber uma segunda via deste documento.

Data:

Assinatura da (o) responsável:

Assinatura da (o) entrevistada (o):

Assinatura da pesquisadora: 


\section{APÊNDICE B - PESQUISA: ABORTO PREVISTO EM LEI E SUAS REPERCUSSÕES: VIVÊNCIAS EM UM SERVIÇO OFERECIDO POR HOSPITAL PÚBLICO}

As perguntas serão realizadas verbalmente pela pesquisadora.

\section{ENTREVISTA INDIVIDUAL}

Entrevistados* $\mathbf{n}^{\mathbf{0}}$

Data: Entrevistadora: Maria da Graça Camargo

\section{VARIÁVEIS SÓCIODEMOGRÁFICAS}

1. Qual a sua data de nascimento?

2. Onde você nasceu? Estado: Cidade:

3. Estado Civil?

4. Possui filhos? Quantos?

5. Idade e sexo dos filhos?

6. Qual a sua cor (autodeclarada)?

$$
\text { 1. ( ) Branca }
$$

2. ( ) Preta

3. ( ) Amarela

4. ( ) Parda

5. ( ) Indígena

7. Onde você mora atualmente? Estado: Cidade:

8. Qual a sua escolaridade?

1. ( ) Nunca estudou e não sabe ler

2. ( ) Nunca estudou mas sabe ler

3. ( ) Ensino fundamental completo

4. ( ) Ensino fundamental incompleto

5. ( ) Supletivo Fundamental

6. ( ) Ensino médio completo

7. ( ) Ensino médio incompleto

8. ( ) Supletivo

9. ( ) Nível superior

9. Qual a sua ocupação principal? 
10. Com quem você mora? (Pode marcar mais de uma alternativa)

1. ( ) Família nuclear (pai, mãe e irmãos).

2. ( ) Pais adotivos

3. ( ) Companheiro(a)

4. ( ) Amigos

5. ( ) Outro. Especificar

11. Tipo de moradia

1. ( ) Casa própria

2. ( ) Casa alugada

3. ( ) Casa cedida

4. ( ) Na casa do empregador

5. ( ) Pensão

6. ( ) Casa de apoio

7. ( ) Albergue

9. ( ) Outro. Especificar:

12. A renda familiar provém de:

1.( ) Aposentadoria, pensão

2.( ) Aluguel

3.( ) Pensão alimentícia, mesada, doação recebida de não morador

4.( ) Rendimentos provenientes de programas oficiais de auxílio (renda mínima, bolsa-escola etc.)

5.( ) Trabalho

6.( ) Outros

13. Religião: 


\section{APÊNDICE C - ROTEIRO PARA A ENTREVISTA ABERTA COM \\ PROFISSIONAIS DA EQUIPE MULTIDISCILPLINAR QUE ATUAM NO ABORTO PREVISTO EM LEI}

Data:

Entrevistada $\mathbf{n}^{0}$

1. Que concepções você tem sobre o aborto previsto em lei?

2. Quais as motivações que o leva a atuar neste serviço e no aborto previsto em lei?

3. Você recebeu capacitação para atuar no aborto previsto em lei?

4. Como a capacitação reflete no cuidado a mulher e adolescentes que buscam o aborto previsto em lei?

5. Você tem conhecimento sobre a Objeção de Consciência?

6. Há influência da Objeção de Consciência no processo de trabalho?

7. Já lançou mão da ferramenta Objeção de Consciência? Se sim, por quê?

8. Já presenciou outro profissional lançar mão da Objeção de Consciência? Se sim, por qual motivo da decisão?

9. Que tipos de situação você presenciou/participou/tomou conhecimento com relação à mulher/adolescente e/ou feto no processo do aborto previsto em lei e qual sua percepção sobre ela?

10. Qual sua percepção sobre reuniões multi e interprofissionais e sobre a prática do aborto previsto em lei?

11. Você tem alguma sugestão de condução do processo de trabalho do aborto previsto em lei? 
APÊNDICE D - MATRIZ: AÇÕES, VERBALIZAÇÕES, TEMAS, FREQUÊNCIA, CATEGORIA E DEFINIÇÃO DAS CATEGORIAS

Registro $n^{\circ}$.

\begin{tabular}{|c|c|c|}
\hline Verbalizações & Tema & Categoria \\
\hline 1. & \multirow[t]{5}{*}{1.} & \\
\hline 2. & & \\
\hline 3. & & \\
\hline 4. & & \\
\hline 5. & & \\
\hline 6. & \multirow[t]{8}{*}{2.} & \\
\hline 7. & & \\
\hline 8. & & \\
\hline 9. & & \\
\hline 10. & & \\
\hline 11. & & \\
\hline 12. & & \\
\hline 13. & & \\
\hline 14. & \multirow[t]{7}{*}{3.} & \\
\hline 15. & & \\
\hline 16. & & \\
\hline 17. & & \\
\hline 18. & & \\
\hline 19. & & \\
\hline 20. & & \\
\hline
\end{tabular}




\section{ANEXO 1 - CARTA DE APROVAÇÃO DO COMITÊ DE ÉTICA EM PESQUISA DA SECRETARIA DE ESTADO DE SAÚDE DO DISTRITO FEDERAL}

\section{GOVERNO DO DISTRITO FEDERAL SECRETARIA DE ESTADO DE SAÚDE COMITÊ DE ÉTICA EM PESQUISA}

EMENDA A PROJETO

\section{I - IDENTIFICAÇÃO}

Projeto $\mathrm{N}^{\circ}$. $356 / 11$

\section{GDF}

Título: - "Aborto previsto em lei e suas repercussões: vivencias em um serviço
oferecido por hospital público do Distrito Federal."

Pesquisador responsável:- Profissional de saúde

Data de Entrada no CEP: 01/11/2013

Data de Redistribuição ao relator: 04/11/2013

\section{II - INTRODUÇÃO: MOTIVO(S) DA EMENDA}

A solicitação de prorrogação do prazo, por mais dois anos é justificada devido haver, ainda, coleta de dados a serem efetivadas, tais como: 1) entrevistas aos das entrevistas às murama de interrupção legal da gestação; 2) complementação espontânea); 3) das entrevistas.

A aprovação irá doutorado.

\section{III - PARECER DO CEP FRENTE ÀS RESOLUÇÕES 196/96 CNS/MS E COMPLEMENTARES:}

A Emenda proposta está em conformidade com a Resolução CNS/MS 466/2012 (Projeto prorrogado, a sua validade até 11 novembro de 2015

$$
\text { IV - EMENDA }
$$

Emenda aprovada 